Florida International University

FIU Digital Commons

$5-23-2019$

\title{
Virtual Patient Simulation: Training Pre-Health Professionals in Suicide Risk Prevention
}

Francisco Javier Fajardo

Florida International University, ffaja001@fiu.edu

Follow this and additional works at: https://digitalcommons.fiu.edu/etd

Part of the Curriculum and Instruction Commons, and the Educational Technology Commons

\section{Recommended Citation}

Fajardo, Francisco Javier, "Virtual Patient Simulation: Training Pre-Health Professionals in Suicide Risk Prevention" (2019). FIU Electronic Theses and Dissertations. 4271.

https://digitalcommons.fiu.edu/etd/4271

This work is brought to you for free and open access by the University Graduate School at FIU Digital Commons. It has been accepted for inclusion in FIU Electronic Theses and Dissertations by an authorized administrator of FIU Digital Commons. For more information, please contact dcc@fiu.edu. 


\title{
FLORIDA INTERNATIONAL UNIVERSITY
}

Miami, Florida

\section{VIRTUAL PATIENT SIMULATION: TRAINING PRE-HEALTH PROFESSIONALS}

\author{
IN SUICIDE RISK PREVENTION
}

A dissertation submitted in partial fulfillment of the requirements for the degree of

DOCTOR OF PHILOSOPHY

in CURRICULUM AND INSTRUCTION

by

Francisco Javier Fajardo 
To: Dean Michael R. Heithaus

College of Arts, Sciences and Education

This dissertation, written by Francisco Javier Fajardo, and entitled Virtual Patient Simulation: Training Pre-Health Professionals in Suicide Risk Prevention, having been approved in respect to style and intellectual content, is referred to you for judgment.

We have read this dissertation and recommend that it be approved.

Adriana Foster

Maureen C. Kenny

Haiying Long

M.O. Thirunarayanan, Major Professor

Date of Defense: May 23, 2019

The dissertation of Francisco Javier Fajardo is approved.

Dean Michael R. Heithaus

College of Arts, Sciences and Education

Andrés G. Gil

Vice President for Research and Economic Development and Dean of the University Graduate School

Florida International University, 2019 
(C) Copyright 2019 by Francisco Javier Fajardo

All rights reserved. 


\section{DEDICATION}

This dissertation is dedicated to the memory of one my dearest friends, Felix R. Garcia a brother, best friend, and guardian angel. You inspired me to start this journey five years ago and I know that you will be watching from heaven as I cross that stage at commencement.

"If you can dream it, YOU CAN DO IT".

-Walt Disney 


\section{ACKNOWLEDGMENTS}

There are so many people to thank and who made all this possible. First, I have to thank my parents, Francisco Fernando Fajardo, Mercedes Fajardo, and step-father, Lawrence Massa, the most supportive and loving parents anyone could have. Mom, Dad, and Larry, you all have imparted great values, especially the value of hard work and that anything is possible when you put your mind to it. I love you so much and always hope I make you proud. My sister, Vanessa, thank you for the motivation and being the most supportive sister a brother could ask for. In addition, the rest of my family, my grandmothers, uncles, aunts, cousins, thank you for your prayers along the way. Los quiero todos!

Second, I must thank all the members of my committee, starting with Dr. M.O. Thirunarayanan, whose support and guidance made my doctoral studies an easier journey to the end. Thank you for your patience and being there every step of the way. Dr. Haiying Long, thank you for being an amazing teacher and mentor. I don't know where I would be without your endless support and making statistics fun. Dr. Adriana Foster, thank you for your inspiration and allowing me to use your research for my study; you have been so good to me. I hope to collaborate more with you in the future. Dr. Maureen Kenny, I cannot thank you enough for your guidance and for your help with data collection as well as your advice. You made this process so much easier.

I cannot forget to thank Dr. Melissa Ward Peterson for connecting me with Dr. Foster and introducing me to the world of virtual patient simulation. Also, I have to thank all of the program directors who made data collection a smooth process: Mr. Jimmy Santana, Dr. Mary Hayden, Dr. Kristin Nichols Lopez, and Dr. Maureen Kenny. 
Along with these directors, I have to thank the faculty who were so gracious and kind to allow me to come into their classrooms and recruit students. Therefore, a big thank you to Jennifer Abeloff, Shimon Cohen, Dr. Valerie Russell, Dr. Maureen Kenny, Dr. Lisa Arango, Yaimara Roman Gonzalez. Of course, I must thank Dr. Benjamin Lok and Stephanie "Stevie" Carnell for letting me use Virtual People Factory-I'm eternally grateful for your support.

A special thank you to the faculty at the School of Education, especially Dr. Linda Bliss, Dr. Joanne Sanders-Reio, Dr. Eric Dwyer, and Dr. Linda Spear-Bunton - thanks for all your help and pearls of wisdom. Also, I like to thank the amazing staff, especially Caprila Almeida and Linnette Sabater for helping me navigate through all the paperwork and processes at the University. A huge THANK YOU to all of you!

This journey would have not been possible without the support of friends, colleagues, and loved ones. In no particular order, I would like to thank the following special people for motivating me to the end so that I might complete this work: Cosette Gomez, Wesley Alvarez, Nelson Silberberg, Tony Siefe, Michelle Solomon, Kelly Bouchareune, Ruben Ilizarbe, Marilene Reyes, Maria Garcia, Carlos Martinez, Carlos Fernandez, Jorge E. Perez, Hector Perez-Gilbe, Zoila De Yurre, Luda Dolinksy, Ana Arteaga, Ileana Perdomo, Rebecca Roth, Yumi Yaguchi, Duke Ingram, Stefanie Moore, Stephanie Garcia, Dr. Samantha Lemus-Martinez, Peter Oelkers, Dr. Alan Wells, Dr. Marin Gilis, Erica Radcliffe, Gloria De Los Reyes, Gregg Stevens, Tony Nguyen, Nicole Covone, Frank Moya Lorenzo, Nache Atkins, and Max Anderson. I could not have done it without you all. Thank you for all your prayers, support and being there for me during those tough times. THANK YOU!! 


\title{
ABSTRACT OF THE DISSERTATION \\ VIRTUAL PATIENT SIMULATION: TRAINING PRE-HEALTH PROFESSIONALS IN SUICIDE RISK PREVENTION
}

by

\author{
Francisco Javier Fajardo
}

Florida International University, 2019

Miami, Florida

Professor M.O. Thirunarayanan, Major Professor

The use of simulators and simulation training has become standard practice for students in medical and pre-health programs, including but not limited to, clinical and counseling disciplines in pre-health education. Students train and sharpen their skills using this technology to prepare them for real-life encounters with future patients (Berman, Durning, Fischer, Huwendiek, \& Triola, 2016). One possible encounter, a suicidal patient, is a challenge that most counselors or therapists are not prepared for, causing stress and affecting their confidence. The literature describes how treating clients/patients with suicidal ideation and behavior is stressful for even the most experienced mental health professional (Farberow, 2005; Foster \& McAdams, 1999; Gulfi et al., 2010; Mirick et al., 2016; Osteen et al., 2014; Smith et al., 2015). This challenge has been addressed by education programs using standardized patients to recreate similar encounters, which can lead to an increase in confidence and self-efficacy (Fallucco, Hanson, \& Glowinski, 2010). However, the use of standardized patients is not feasible in all cases. One solution is virtual patient simulation as a complement to traditional face-to-face lectures and training. The purpose of this study is to understand 
the impact of virtual patient simulation on self-efficacy levels when students are faced with a suicide risk scenario. This quantitative study relied on the collection of data from pre-health professional students $(n=111)$ and involved the testing of hypotheses following published self-efficacy and education literature. The hypotheses were tested using a factorial analysis of variance (ANOVA), a factorial analysis of covariance (ANCOVA), and a bivariate correlation analysis among the different training methods. The results of the ANOVA and ANCOVA did not indicate a significant result for differences amongst the different training groups. However, results of the bivariate correlation analysis indicated a significant relationship $(p<.05)$ between previous mental health experience and self-efficacy. The information collected provides insight and direction on the development of future training. 
TABLE OF CONTENTS

CHAPTER

PAGE

I: INTRODUCTION

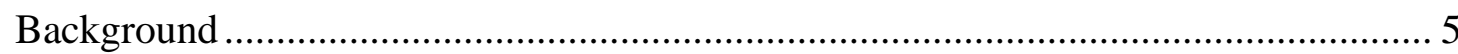

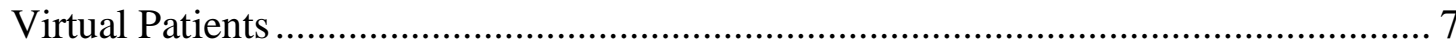

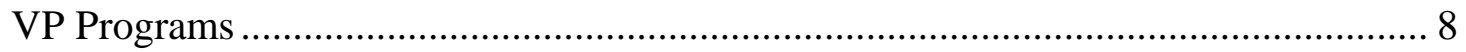

Theoretical Foundation ..................................................................................... 11

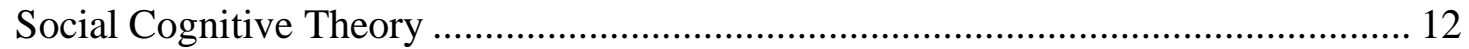

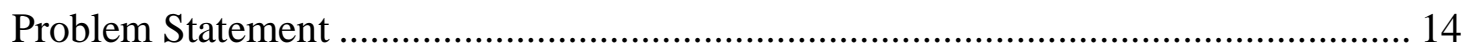

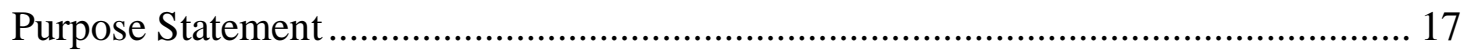

Research Questions .................................................................................... 18

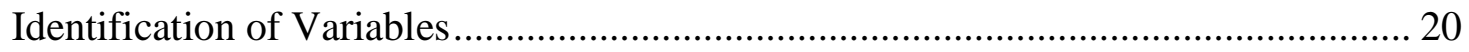

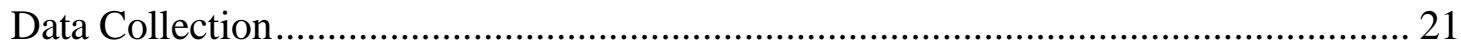

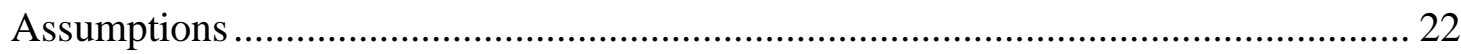

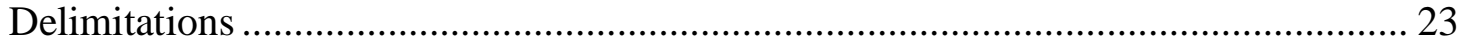

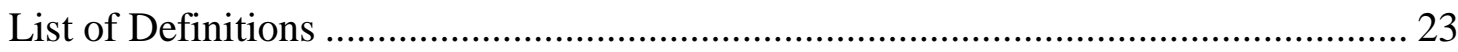

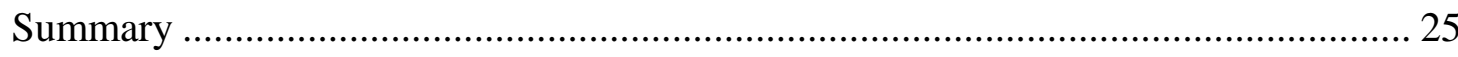

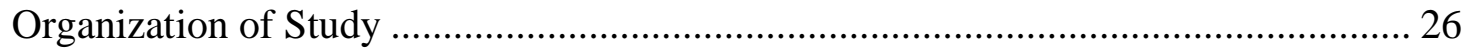

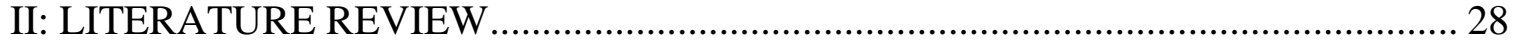

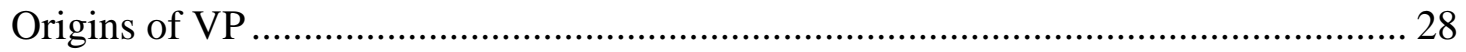

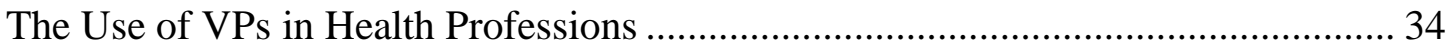

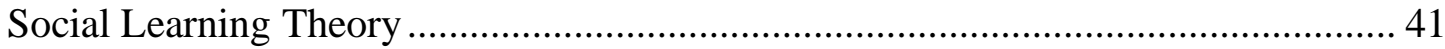

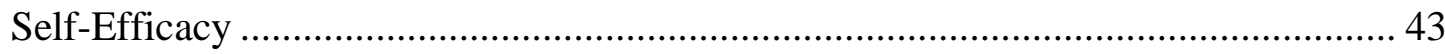

Self-Efficacy and Virtual Patient Simulation .......................................................... 45

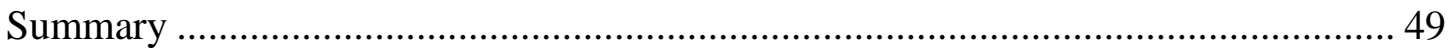

III: METHODS

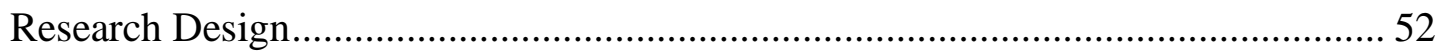

Sampling and Participants................................................................................ 54

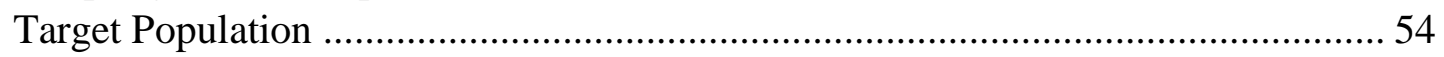

Sampling Frame

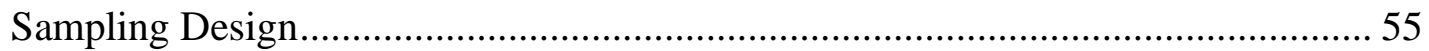

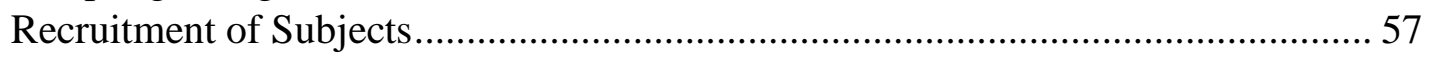

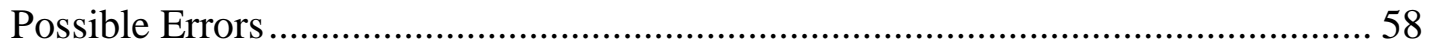

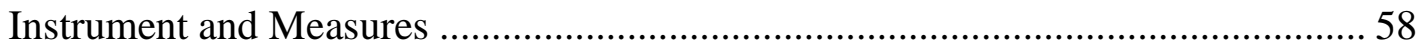

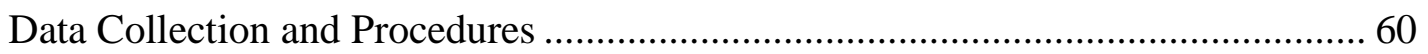

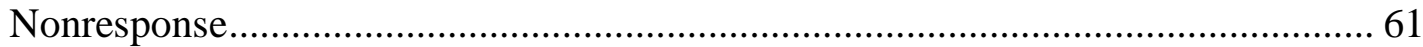

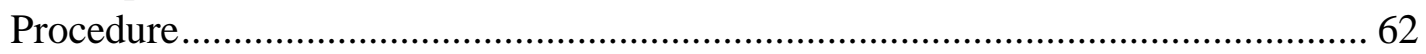

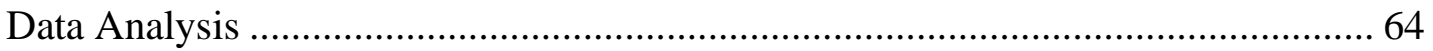


Summary

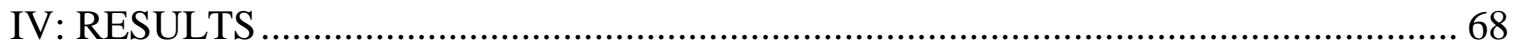

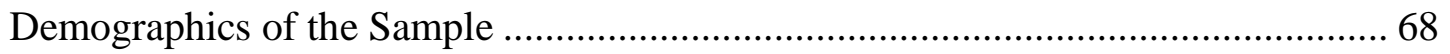

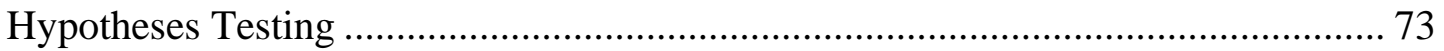

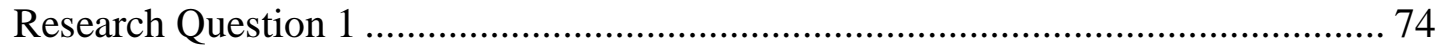

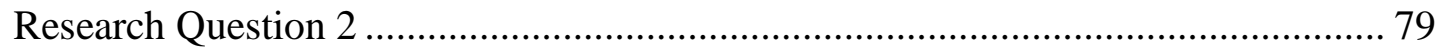

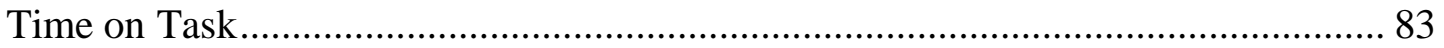

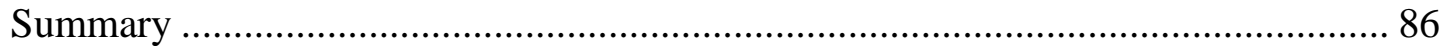

V: DISCUSSION

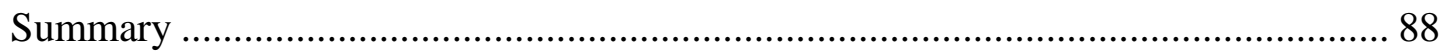

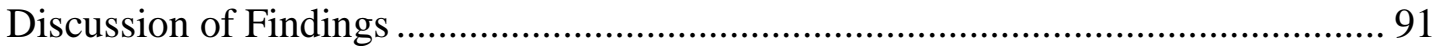

Summary and Discussion for Research Question \#1 ............................................... 92

Summary and Discussion for Research Question \#2 ............................................... 94

Summary and Discussion for Research Question \#3 ............................................. 95

Summary and Discussion of Time Spent on Task ………….................................... 96

Summary and Discussion of Social Learning Theory ……….................................. 97

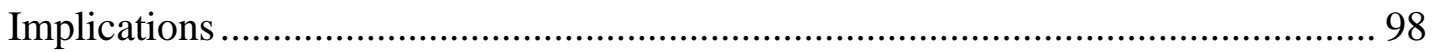

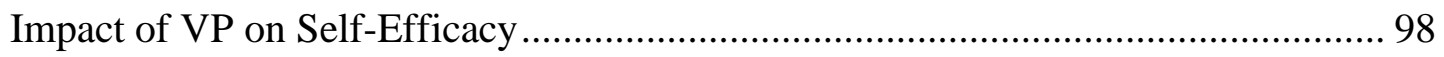

Traditional Pedagogical Methods vs. VP Simulation ............................................. 100

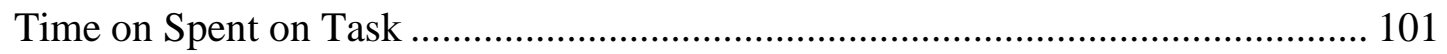

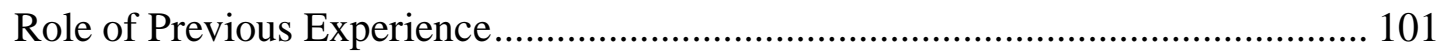

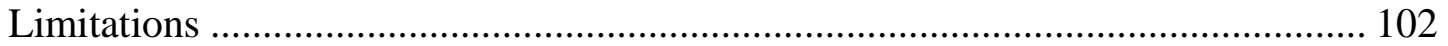

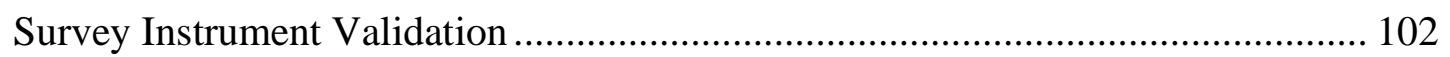

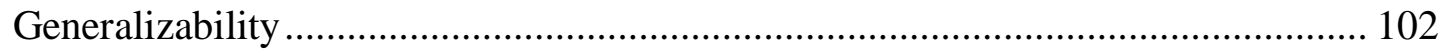

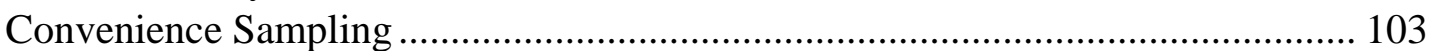

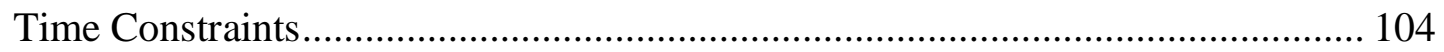

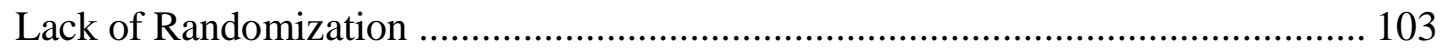

Follow-up and Mixed Methods Design ................................................................ 105

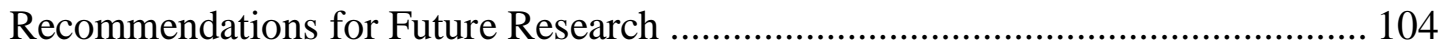

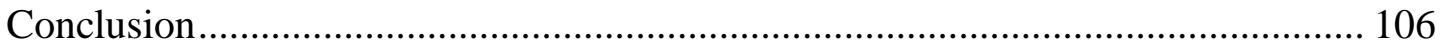

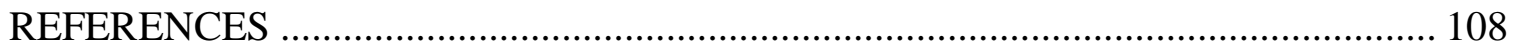

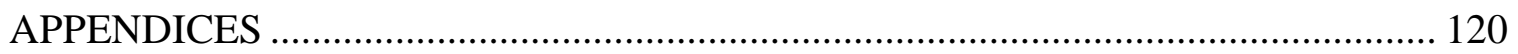

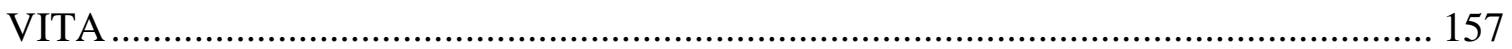




\section{LIST OF TABLES}

TABLE

PAGE

1. Race, Ethnicity, Frequencies, and Percentages of the Sample 69

2. Comparison Groups, Frequencies, and Percentages of the Sample ........................... 70

3. Age, Frequencies, and Percentages of the Sample …........................................... 71

4. Work experience, Frequencies, and Percentages of the Sample.............................. 71

5. Academic Program, Frequencies, and Percentages of the Sample ............................ 72

6. Descriptive Statistics of Pre and Post Self-Efficacy Aggregate Scores..................... 73

7. Hypothesis 1, ANOVA Table for Pre and Posttest ............................................... 75

8. Hypothesis 1-Pairwise Comparison of Groups Pre to Posttest .................................. 77

9. Hypothesis 1-Pairwise Comparisons of Time*Training Methods ............................ 78

10. Hypothesis 2 ANCOVA Table for Academic Program .......................................... 80

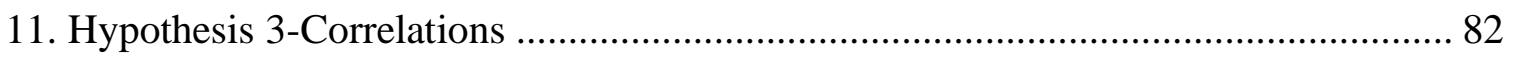

12. Correlations Table-Time on Task and Differences in Scores ................................. 84

13. Correlations Table-Time on Task \& Difference in Scores for Virtual Patient Group 85

14. Correlations Table-Time on Task \& Difference in Scores for Video Patient Group . 86

15. Hours (Direct or Indirect) of Training Received ................................................. 96 


\section{CHAPTER I: INTRODUCTION}

Educational technology has become increasingly prominent in the curriculum for most medical and pre-health programs around the world. Technology continues to change the traditional pedagogical tools and delivery of information in clinical settings (e.g., hospitals, physicians' practices, mental health facilities). Some examples of technology in health education programs include, but are not limited to, electronic medical records for patient information, tablet computers for clinical activities, instruction on mobile applications (commonly known as apps), and the use of simulation for clinical training. It has become common practice to have students train and sharpen their skills using simulators preparing them for a variety of possible real-life encounters with patients or clients (Berman, Durning, Fischer, Huwendiek, \& Triola, 2016). Moreover, the use of simulators in health sciences education has many applications that may use standardized patients (real-life human beings), virtual or computer-based models, and computer-controlled or high-fidelity mannequins.

These simulation types, or combinations of them, are used not just to train healthcare practitioners, but also to improve patient care and safety. Additionally, simulation is used to collect data for designing and implementing programs in health education (both in medical and mental health disciplines) as well as for reinforcing concepts learned in traditional lectures. Potentially, certain types of simulation training also save money by reducing the number of standardized patients (an individual paid to act like a real patient) and provide training safer environments safer for both students and patients (Albright, Adam, Serri, Bleeker, \& Goldman, 2016). Depending on the format, it is also portable, allowing students to practice skills online anywhere (both synchronously 
and asynchronously). Simulators and simulation-based (SB) training are quite common in medical education (Washburn, Bordnick, \& Rizzo, 2016). In addition, this technology is used in other mental health fields e.g., psychology, social work, school counseling, occupational therapy, physical therapy, and physician assistant programs. This underlines the use of SB training across the different levels of pre-health professions and inter-professional teams involved in treating patients with mental health issues.

Simulation-based training in medical education has allowed students to learn and practice procedures such as in surgery or emergency medicine, and to improve physicianpatient communication skills necessary in tasks such as in recording patient history or in diagnosis (Stevens et al., 2006). Optimally, students need to learn a patient-centered approach, where they must understand the needs of the patient, understand their feelings and concerns, and educate the patient about their choices in care (Levinson \& Pizzo, 2011). Simulation-based training gives students the opportunity for practice and learning interviewing skills to elicit information from their patients. Similarly, mental health education involves communication between the therapist/counselor and client to provide an optimal level of psychosocial functioning for the client (Hershenson \& Power, 1987). As such, SB training provides an opportunity for students in mental health programs to practice communication and interviewing skills in a multitude of settings and possible scenarios. There is evidence in the literature that the earlier one exposes students to possible scenarios, the greater their knowledge, intrinsic motivation, and self-efficacy become than not exposing them, makes them more proficient at health decision making in the real world (Makransky et al., 2016). 
Accordingly, SB training allows students to learn or acquire knowledge by way of simulating interactions or experiences and achieving desired patient outcomes. Therefore, simulations act like models through which students or trainees learn by observing and practicing desired behaviors. Learning through modeling, which is part of the social cognitive theory, provided the theoretical framework for my study. From social learning theory, specifically regarding self-efficacy, the higher the self-efficacy, the higher the chances for success in accomplishing goals (Bandura, 1977b). Therefore, when one exposes students to clinical scenarios by way of SB training one could potentially enhance performance and increase self-efficacy.

As discussed previously, using SB technology to train pre-health students for future encounters with vulnerable or at-risk patients could potentially save lives. Therefore, the present study focused on SB training and its impact on self-efficacy of students in four pre-health specialties involved with mental health: physician assistants (PAs), social work, psychology, and mental health counseling students in master's level programs were the focus of this study.

Physician assistants are trained, certified, and licensed to conduct history taking, physical examination, and diagnosis, and to treat commonly encountered medical problems as well as to demonstrate technical skills under the supervision of a licensed physician, who thereby extends the physician's capacity to provide medical care (Stedman \& Teton, 2006). Social workers are professionals involved with services or activities concerning the care, aid, treatment, or investigation of those economically, mentally, or socially disadvantaged (Doel, 2012). Mental health counselors are professionals who apply the knowledge and skills of counseling to assist individuals, 
groups, organizations, and communities to determine and attain their optimal level of psychosocial functioning (Hershenson \& Power, 1987).

Moreover, each program has different practicum and internship requirements, requiring students to complete a number of hours beyond their coursework to fulfill individual degree requirements. Despite the different requirements and curricula, students in each field could potentially encounter any number of mental health scenarios, which require additional training beyond what they learn in the classroom. One such scenario, which is difficult to simulate, is the recognition and assessment of a patient who might harm themselves or pose a risk for suicide. Simulation-based training potentially provides students a way to recognize and prevent such tragedies if they are exposed early on in their curriculum. Social cognitive theory and increasing self-efficacy suggests than using SB training students may become proficient in recognition of such a highly stigmatized and preventable tragedy. The theory indicates, if students believe they are confident that they can perform when faced with this situation in their practice, the more likely they can successfully assess such a threat.

The current study measures the impact of SB training on the self-efficacy and confidence of students from each of the four programs above after participating in a scenario involving a possible suicide risk. The focal scenario is difficult to simulate in real life but one they are likely to encounter in a clinical setting. The study, by using social learning theory, measured self-efficacy of these students as a way to predict success if faced with such a scenario in clinical practice. 


\section{Background}

Historically, SB training was used to complement didactic sessions with students and mimic a clinical scenario they would encounter in practice. Simulation-based training and learning using high fidelity (HF) mannequins are a common practice in nursing and medical education programs (Bauman, 2013). High-fidelity mannequins are also used in allied health education programs. Allied health or allied health professionals is an umbrella term that describes someone who is trained to perform services in the care of patients other than a physician or a registered nurse (Stedman et al., 2006). These mannequins are HF simulators that re-create a realistic clinical scenario, often either a procedure or trauma situation. High fidelity simulators are highly sophisticated, computer-controlled mannequins, which reproduce physiologic responses appropriate to the clinical scenario (Hicks, Coke, \& Li, 2009). Some of these physiologic responses include breathing, bleeding, having seizures, and even giving birth. These mannequins can simulate almost any common medical situation. Each of these HF simulator mannequins may cost hundreds of thousands of dollars, depending on how advanced the unit is. Despite the benefits of using this simulation technology in medical education, it does not replace real-life experience with patients. Over time, simulation training has allowed students to apply what they learned in the classroom and has become an effective teaching instrument.

As we design curricula, we will have more simulation choices to help students learn and practice skills and concepts with these advancements in technology. Moving forward, educators and those implementing curriculum must be cognizant of how SB training and education affect performance in clinical settings. Many studies in the 
medical and nursing education literature have covered how SB training has proven useful and effective, as well as how to improve it, creating a more realistic scenario for the student. Nevertheless, there is a need for additional analysis of the effects of this simulation technology on student performance in other areas, such as in mental health. Student performance is a concern for many involved in developing education programs in allied health disciplines. Those involved in pre-health education and in curriculum development are trying to improve the traditional proficiency-based training for students by gathering data from these simulations (Henriksen, Rodrick, Grace, \& Brady, 2018). Also, how can SB training be used to improve communication between physician and patient or between counselor/therapist and client? Questions arise such as how we can improve student performance; what we can do to enhance students' experience in the simulation; and when is the best time to implement these pedagogical tools during a program of study (Henriksen et al., 2018).

Simulation-based training and education has evolved to teaching students in virtual environments. The advances in technology and artificial intelligence can simulate real-life scenarios where students receive feedback from programs depending on their responses in real-time. Because they are interactive, involving more communication and assessment skills of the students, these virtual environments go beyond the HF mannequin training. These advancements provide an additional method for students and practitioners to minimize medical errors and notetaking when considering a patient's history (Berman et al., 2016). 


\section{Virtual Patients}

Beyond the traditional SB training and education programs or the use of HF mannequins in a clinical scenario, virtual patient simulation is currently used as a complement to traditional lectures and didactic sessions in health education. These virtual patients are used to meet educational goals but also to fill in gaps left by students' experience in fundamental clinical problems (depending on the specialty and the clinical scenario).

Virtual patients (VPs) are defined as:

Interactive, computer simulations of real-life clinical scenarios for the purpose of healthcare and medical training, education or assessment as well as a specific type of computer program that simulates real-life clinical scenarios through which learners emulate the roles of healthcare providers to obtain a history, conduct a physical exam, and make diagnostic and therapeutic decisions. (Berman et al., 2016, p.1217)

Other medical educators have defined VPs as multimedia and screen-based interactive clinical scenarios like a video game (Berman et al., 2016). Virtual patient computer technology generates simulated patients with whom the student can interact performing tasks imitating a healthcare provider. The student can interact by asking questions, interpreting, taking patient history, and finally, making decisions based on the interaction. While some are still skeptical about its applications, VPs can potentially be effective by integrating into a combination of traditional lectures, didactic sessions, and students' clinical experience. Virtual patient simulation is portable, adaptable, cost-effective, and interdisciplinary. For example, applications can be developed for not just medical but in the social sciences or communication disciplines. Virtual patients can also be deployed asynchronously and in a variety of formats (e.g., desktop computer or tablets). This 
asynchronous feature makes it easier for the instructor instead of having the challenge of scheduling students at a certain time and place. Students are able to participate anywhere they have access to the simulation program.

Berman et al. (2016) and other proponents support the potential of VP simulation to promote learning, capture intrinsic motivation, support development of clinical reasoning, assess competence to reduce medical errors and analyze data to develop a understanding of educational outcomes. However, challenges are present with its wide implementation or in the broader use of it. Berman et al. (2016) indicated the following barriers to the implementation of VPs:

There is a disconnect between available VP programs and the needs of the educators who might incorporate them into their teaching or courses. A lack of clarity among educators and learners regarding the educational role of VPs leads to difficulties in effectively integrating VPs in clinical education. A widely accepted system for ongoing financial and technical support of VPs does not yet exist, and significant efforts to support dissemination and adoption of VPs have not yet resulted in widespread sharing or repurposing. Finally, a lack of sufficient evidence for the features of VPs that create effective learning remains a significant barrier for those skeptical educators who may have seen educational fads come and go in the past. (p.1220)

The use of VP programs in in medicine and allied health programs is not widespread. Many educators are unaware of VPs', portability, and potential to capture useful data that may help shape curriculum.

\section{VP Programs}

Once more, technology has advanced offering a multitude of choices for SB training. Some are standalone, but most are web-based client programs where a user either synchronously or asynchronously logs into a VP program and interacts with the patient. The following programs are the most frequently used and present different 
features which can be customized to the users and instructor needs. Some of the programs described are commercial (e.g., vSim, Shadow Health, DxR Clinician, iHuman) and some are research-only tools (e.g., Virtual People Factory).

vSim. The VP program known as vSim was developed by Laerdal Medical and Wolters Kluwer Health designed for nursing students (Wolters Kluwer Health, 2017). Students can experience a variety of VP interactions dealing with medical to surgical scenarios with links to additional content (depending on the content). The vSim records all interactions with the VP and provides personalized feedback to the user such as in strengths and areas in need of improvement. Feedback also includes curriculum-based materials for additional support for reinforcing topics.

Shadow Health. Shadow Health is a web-based simulation program with customizable proprietary features or simulations on general health assessments to mental health scenarios (Shadow Health, Inc., 2017). Students engage with VPs in real time, interacting with open-ended conversations, examining and documenting their findings. Shadow Health provides assessments of the students' performance providing feedback on their strengths and weaknesses. One particular standout feature is the mental health product Shadow Health offers whereby students can interact with patients who present a multitude of mental health conditions. Shadow Health also features SB training products in pharmacology, gerontology, and general health assessments.

DxR Clinician. The DxR Clinician by the DxR Development Group is a patient simulation program originally developed at Southern Illinois University by Howard Barrows, M.D., Kevin Dorsey, M.D., Ph.D., and Hurley Meyers, Ph.D. with courseware 
in anatomy, physiology, and clinical medicine (DxR Development Group, 2017). The program features numerous VP scenarios ranging from adult to pediatric cases and interactions. Students receive detailed feedback on their performance after their interaction or simulation exercise. The DxR Clinician program is also available in multiple languages.

i-Human. The i-Human program is an interactive, cloud-based simulation software used to simulate patient encounters to enhance diagnostic reasoning and clinical decision making (i-Human Patients, 2018). The product is designed for medical, nursing, and physician assistant students featuring a multitude of possible clinical encounters and immediate feedback to students upon completion of the simulation exercise. The VPs in the i-Human program allow students to build and rank differential diagnoses, take a patient's history, as well as order and evaluate tests (i-Human Patients, 2018).

Virtual People Factory. Virtual People Factory (VPF) by Virtual Experiences Research Group at the University of Florida was developed by Dr. Benjamin Lok. Virtual People Factory uses crowdsourcing to develop VP experiences allowing for editing as well as testing of VP dialogue/animations in a web-based portal. The VPF keeps logs of all VP interactions in a cloud-based, HIPPA compliant server, alllowing for safe and secure training opportunities with health professionals in a variety of disciplines and clinical scenarios (Rossen, Cendan, \& Lok, 2010). Educators are able to create conversational content via these virtual humans as question-answering characters made possible by a database of questions and corresponding responses (Rossen, Lind, \& Lok, 2009). 
The web-based portal takes whatever input the learner says to the virtual human and is able to match it against the database of questions created by the content area expert. The feature allows VPF the portability and flexibility those involved in health education need when coordinating students and multiple schedules. Virtual People Factory will be the program used for this quasi-experimental investigation on a cohort of PA, mental health counseling, school counseling, and social work students.

\section{Theoretical Foundation}

Once more, as we continue to design curricula in health sciences education, we will have more simulation choices to help students learn and practice skills and concepts. Moving forward, educators and those implementing curriculum must be cognizant of how these simulations affect performance in clinical settings. Many studies in the health education literature have covered how simulator training has proven useful and effective, as well as how to improve it, creating a more realistic scenario for the student. Still, there is a need for additional analysis of the effects of this technology on student performance in scenarios involving mental health. Performance in these clinical scenarios is a concern for many involved in academic medicine and allied health education. Those involved and those responsible for curriculum development are trying to improve the traditional proficiency-based training for students by gathering data from these simulations. Questions arise such as how we can improve student performance; what we can do to enhance students' experience in the simulation; and when is the best time to implement these pedagogical tools during a course of study (Henriksen et al., 2018).

The theoretical foundation for the current quasi-experimental study used social cognitive theory, specifically self-efficacy, as the framework by which to examine how 
self-efficacy affects confidence and performance in clinical settings. Social cognitive theory considers observational learning and the acquisition of skills based on students' social environment.

\section{Social Cognitive Theory}

Social cognitive theory stresses that much learning occurs in the social environment (Schunk, 2012). Students observe others as well as their instructors and acquire knowledge on the basis of their observations. Medical schools, allied health programs, and other mental health professional programs have a unique social environment where learning occurs on both an individual and a group basis. Students are assessed on academic performance, professionalism, but also on how they apply that knowledge in a clinical setting. Many times, in these clinical settings, students must perform with minimal exposure in a clinical context.

Albert Bandura and fellow researchers examined the social environment in which students learned and other personal factors affecting learning (Schunk, 2012). One of those personal factors was self-efficacy, one's personal beliefs about one's capacity to learn or to perform actions at designated levels. His conceptual framework of selfefficacy looks at individuals' perceived capacity for performing certain actions and accomplishing goals. Bandura (1997) also studied outcome expectations of self-efficacy levels of student performance. Self-efficacy and outcome expectations may mean something completely different, but they are related. Students will perform well if they have confidence in their learning capabilities and expect positive outcomes from their efforts (Schunk, 2012). The same should apply to understanding the confidence levels of medical students in their learning capabilities and their outcome expectations. 
According to Bandura's (1977a) social learning theory, expectations of personal efficacy are derived from four major sources of information: performance accomplishments, vicarious experience, verbal persuasion, and physiological states. He believed that self-efficacy was one of the principal motivators for changes in behavior and was also an explanatory factor in the way it can predict behavioral changes through different methods of treatment. In his work, Bandura (1977a), explained that the way someone perceives their efficacy can influence the choice and behavior in the activities they choose. Furthermore, he explains, "efficacy expectations determine how much effort people will expend and how long they will persist in the face of obstacles and adverse experiences" (Bandura, 1977a, p. 80). Therefore, the more self-efficacy one has, the more actively one approaches activities or tasks assigned in any given situation.

Self-efficacy theory offers one of the principal predictors of performance and confidence in completing a task such as participating in a VP simulation. As indicated above, students in medical and health programs barely experience or are exposed to situations in traditional SB training. Hence, when students encounter these situations in a real-life clinical setting, if their anxiety is high, their confidence levels could be affected. When students are exposed to these possible clinical scenarios within VP environments that are complemented by traditional lectures followed up by deliberated practice, confidence and motivation can positively influence behaviors. Additionally, the VPs, as well as, the feedback obtained after the interaction with the VP, in addition to their instructors can serve as models, which Bandura (1977a, 1977b, 1997) also described as influential agents to one's self-efficacy. By observing the behavior of these so-called “models," subjects can acquire skills in dealing with a potentially stressful situation. 
Research on social cognitive theory and its applications in medicine and the allied health fields are substantial; however, much of it focuses on communication (Leigh, 2008). For example, topics range from taking a patient's history, inter-professional collaboration, patient interviewing, and disease-specific topics to the treatment of a patient (Giordano et al., 2013). Consequently, research on SB training and the impact on self-efficacy is another subject area that has substantial contributions from researchers in nursing and medical education. In conducting this quasi-experimental study, the intention was to build upon the existing literature by focusing on a largely overlooked area, which is mental health.

\section{Problem Statement}

According to the National Institutes of Mental Health and Centers for Disease Control, in 2015, suicide was the tenth leading cause of death in the United States, claiming over 44,000 lives (Centers for Disease Control and Prevention, 2016). If broken down by age and sex, among women, the suicide rate in 2014 was highest for ages 45 to 64, and for men, the suicide rate was highest for those ages 75 and over (Centers for Disease Control and Prevention, 2016).

The statistics presented in Figure 1, presents the suicide rates for males and females by age in the United States for the year 2014. Figure 1 provides a breakdown with a graphical representation of the problem. Within the Figure 1, suicide rates for those ages 45 to 64 as well as 25 to 44 make up a considerable number of suicides within the country. Therefore, the ages range from younger to older citizens alike, spanning generations and gender. 


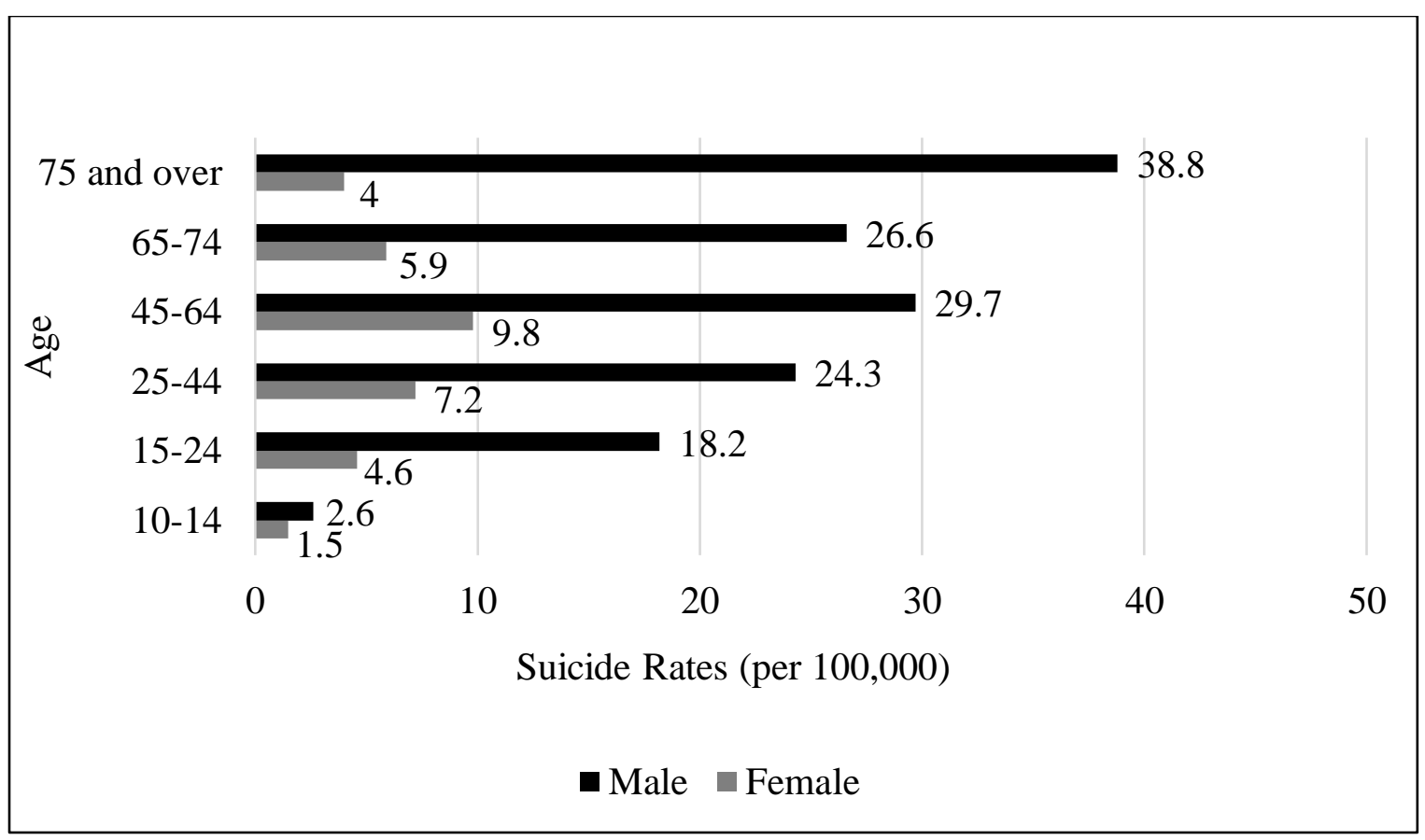

Figure 1. Suicide rates for males and females by age per 100,000 in the United States in 2014. Data taken from the Centers for Disease Control and Prevention (CDC), 2016.

The CDC also indicated that over the past 15 years (from 1999 to 2014) the suicide rate has increased 24\% (CDC, 2016). These alarming statistics point to the likely possibility that students in mental health disciplines (or those who work in the mental health field) might encounter a patient or client who is suicidal. Professionals, such as social workers and mental health counselors, will likely encounter clients at risk for suicide especially in community-based mental health services (Osteen, Jacobson, \& Sharpe, 2014). Encountering suicidal clients is a common component of their practice. While encountering suicide is common, many mental health professionals are not well trained in current best practices for suicidal assessment and crisis intervention (Mirick, McCauley, Bridger, \& Berkowitz, 2016). Suicide risk is also common in our schools. 
Mental health counselors in school settings often encounter students who face significant challenges and may not have acquired sufficient coping strategies to deal with their problems (Gallo, 2018). According to the CDC, suicide is the second leading cause of death within the 14 to 24-year-old age group (CDC, 2016). Considering the CDC data, teenagers and young adults are particularly vulnerable.

The public health issue even extends to other fields peripherally involved in mental health such as the case with physician assistants. In the summer of 2017, six national PA organizations met at a mental health conference to discuss the impact of the mental health crisis in the United States. At the 2017 conference, the chair of the National Commission on Certification of Physician Assistants Health Foundation, Ted Wendel, Ph.D., noted that one in five adults in the United States experiences mental illness every year (Rittle, 2017). Consequently, it is likely that future physician assistants might encounter patients who are suicidal or experiencing some suicidal ideation. Therefore, it is with this unique opportunity that with these pre-health profession trainees, we can explore training possibilities to prepare the next generation of students for the workforce. The next generation will encounter mental illness and related issues as our population continues to grow in the United States.

Given the public health issue and the increased number of graduates entering the workforce with varying degrees of training in suicide prevention or crisis intervention, additional training opportunities must be explored. The influx of graduates provokes the question: Are they ready to handle patients with a mental illness and/or diagnose them properly? The use of VP simulation is one viable solution to the growing dilemma in an already overwhelmed health care system. Using VPs for training students can prove 
effective for the growing demand for better mental health care. The healtcare system faces a shortage of mental health workers who are trained in the diagnosis and treatment of mental illness.

Existing studies on self-efficacy impacting confidence and performance do exist in the health science education literature, but there is a lack of empirical studies measuring the same for mental health profession trainees. Moreover, there is a need for more empirical studies using VPs and measuring the impact on self-efficacy and confidence in a mental health scenario. By doing so, the researcher intends to contribute to the academic medical and mental health literature, ultimately contributing to how we train our students in dealing with the mental health crisis plaguing our healthcare system.

\section{Purpose Statement}

The purpose of this quasi-experimental study was to compare three different approaches in suicide risk prevention and its impact of self-efficacy levels using master's degree level, mental health profession trainees. Trainees were general PA (i.e., not specialized in mental health), clinical mental health counseling, school counseling, and social work master's program students. The majority of the literature on self-efficacy and confidence in health education focuses on traditional SB training using high fidelity mannequins or standardized patients. Moreover, literature also focuses on health and medical students using scenarios that involve disease-specific, communication, or other basic clinical skills. The current study is unique in that it involved PA students from a newly accredited PA program, specifically the Master in Physician Assistant Studies (MPAS) program at Florida International University (FIU). In addition, it includes students from the Master of Social Work, Professional Counseling Psychology, and 
Master in Counselor Education (Clinical Mental Health Counseling) students.

Additionally, it is unique because it examined self-efficacy and confidence using a mental health scenario, which contributes to the body of research using VP simulation.

The quantitative study relied on the collection of numerical data from these students and involved the testing of hypotheses developed from the published literature on self-efficacy and health, as well as on mental health education. The study provides insight on current suicide assessment training in these programs as well as guidance for any future training of health and mental health care professionals. The empirical evidence will be used to support or refute any existing theories based on social learning theory. The information collected was used to describe as well as infer from these students' self-efficacy.

\section{Significance of the Study}

The study is of importance to educators in the field of medical, allied health and mental health education involved with clinical skills and mental health training. The research will contribute to existing research on how this VP technology can supplement traditional face-to-face lectures in health professional programs. As a result, educators, course directors, curriculum designers, students, and other stakeholders in mental health care education could benefit from this research.

\section{Research Questions}

The quasi-experimental study investigated the impact of VP simulation on selfefficacy and confidence levels on health profession students using a mental health scenario for training. On the basis of the literature review, research on self-efficacy and 
confidence levels using VP simulation training module as well as using a mental health issue as the scenario is lacking.

The research questions answered as a result of the present quasi-experimental study are the following:

1. To what extent are students interacting with a virtual patient different from those having a video simulation (of the same content) and those learning by traditional teaching in their self-efficacy in assessing suicidal risk between pre-and post-test?

a. To what extent are students' self-efficacy of three groups different across the pre-and post-tests (difference between the three groups across two time points)?

b. To what extent are these students' self-efficacy different before and after they experience three teaching approaches (difference between before and after across three groups)?

c. Is there a significant interaction between three groups and two time points (i.e., pre-post)?

2. After controlling for students' major, to what extent are they different in their self-efficacy between pre and posttest?

3. Is there a significant relationship between students' previous healthcare or mental illness experience and their self-efficacy in assessing suicidal risk? 


\section{Research Hypotheses}

The research hypotheses for this quasi-experimental study were:

1. There is a significant difference between the means of three groups of students' level of self-efficacy between pre- and posttest.

2. After controlling for students' major, there is a significant difference between posttest means of among the three groups concerning their self-efficacy.

3. There is a significant relationship between students' previous healthcare or mental illness experience and their self-efficacy in assessing suicidal risk.

\section{Identification of Variables}

As with all research studies and especially in the present quasiexperimental study, the importance of identifying the variables are crucial for analysis. The independent variable in the study is the training method the students were assigned. The dependent variable is their self-efficacy after participation in the assigned training method. Previous healthcare and/or mental health work experience and academic program served as the covariates. These covariate variables were adopted because the literature indicated that they might have a confounding effect on the outcome of the analysis (Hinkle, Wiersma, \& Jurs, 2003). It is important to consider such variables when analyzing the impact of different training methods when discussing the results of quasi-experimental studies. In the current study it was important to determine if prior experience or program might have a direct impact on the results. 
Students in the VP group completed a pre-simulation survey, then participated in a VP simulation immediately followed by a post-simuluation survey administered online. These pre-post surveys measured their self-efficacy and confidence levels along with demographic information for analysis. There was also a video module group (VM), which also took a pre-survey, participated in a video regarding the same content (suicide risk) and took the survey immediately after, as well. Finally, there was a lecture group, who participated in a tradtional face-to-face lecture about suicide risk and prevention. The lecture group also took a pre and post-lecture survey, measuring their self-efficacy before and after the lecture.

All surveys were deployed via Qualtrics, which is a web-based survey software program embedded in a content and curation management tool called Libguides. The LibGuides are a content management system used at many libraries across the globe (Springshare, 2018). Most librarians use it to curate knowledge and share information, organize class and subject-specific resources, and to create and manage websites. The content for the VP, VM, as well as the lecture group were curated in a Libguide as well. All groups had a Libguide with links to the individual modules and surveys.

\section{Data Collection}

Once these data were collected from the survey administration, it was downloaded into the statistical analysis program SPSS (Statistical Package for the Social Sciences). The survey instrument (see Appendices) is divided into four areas: VP simulation/video interaction, self-efficacy, previous experience, and 
demographics. Both the interaction and the self-efficacy items follow validated survey instruments previously published in other studies (Artino, Dong et al., 2012; Foster, Robb et al., 2015). The survey was designed to measure previous experience in mental health as well as self-efficacy after exposure to a patient who might pose a suicide risk.

The information collected from the students determined if there are any differences between the groups regarding the different training methods. In addtion, the researcher wanted to detemine if one of the training methods is more effective than the other. Testing the hypotheses associated with the current study led to results that provided answers to the research questions posed.

\section{Assumptions}

The underlying assumptions of this quasi-experimental study were:

1. Some of the students have (depending on their program) some or limited exposure to any mental illness scenario in a clinical setting prior to these virtual patient or video training modules.

2. None of the students have had any simulation training as part of their curriculum or in any of their courses.

3. Most of the students have limited prior medical or clinical skills training. 


\section{Delimitations}

The quasi-experimental study had the following delimitations:

1. The study only used FIU students. Therefore, the results are only generalizable to FIU students in these programs and not other mental health profession students.

2. The subjects were only composed of a limited number of students in social work, psychology, physician assistant studies, and education programs. Again, this limits the generalizability of the results to other students in similar programs and thereby limits the analysis in terms of the statistical power.

3. The different academic calendars of all the programs included in the study presented a challenge which affected scheduling of data collection.

4. The study only sampled students via convenience sampling from these programs at FIU therefore results are not generalizable to the population of pre-health professionals.

\section{List of Definitions}

Allied health. Allied health or allied health professionals is an umbrella term used to describe someone who is trained to perform services in the care of patients other than a physician or a registered nurse (Allied Health, 2015).

High-fidelity simulation. This type of simulation involves the use of computercontrolled mannequins also known as high-fidelity simulators that re-create a realistic 
clinical scenario, whether it involves a procedure or a trauma situation (Hicks et al., 2009).

Libguides. Libguides is a content management tool used to curate information, resources, and knowledge to organize information. The tool is used heavily in libraries across the world and provides an easy way to manage content and library asset for distribution to a variety of patrons (Springshare, 2018).

Master in Counseling Education. Refers to the FIU Masters in Counseling Education (specializing in clinical mental health counseling) at the School of Education and Human Development. This is a 60 credit program, which requires 1000 hours of supervised field experience to complete the requirements for the degree (School of Education, 2017).

Master in Professional Counseling Psychology. Refers to the FIU Masters of Science in Psychology (Professional Counseling Psychology) program. This is a 60 credit program, which includes a combination of theory, foundational, electives, and supervisory field experience courses designed for professional training and counseling. In addition to coursework, students are required to complete 1000 hours in a supervised clinical setting to be eligible to take the Florida state exam for a license in Mental Health Counseling (Department of Psychology, 2017).

Master in Physician Assistant Studies. Refers to the FIU Masters in Physician Assistant Studies program, which is a three-year program composed of two years of inclass curriculum with one year of clinical rotation. The PA program at FIU is a 93-credit program composed of a combination of basic sciences, anatomy, human behavior, and clinical skills training (Herbert Wertheim College of Medicine, 2017). 
Master of Social Work. Refers to the FIU Masters in Social Work program, which is a 60 credit program featuring a combination of coursework and field instruction in social work. Students enrolled in this program must complete three field practicum courses as requirements for graduation (Robert Stempel College of Public Health and Social Work, 2017).

Physician Assistant. Is a person who is trained, certified, and licensed to perform history taking, physical examination, diagnosis, and treatment of commonly encountered medical problems usually under the supervision of a licensed physician (Stedman et al., 2006).

Qualtrics. Is a web-based survey software program usually deployed via email or Internet sent to a distribution list (Snow \& Mann, 2013).

Social learning theory. A theory that postulates "expectations of personal efficacy are based on four major sources of information: performance accomplishments, vicarious experience, verbal persuasion, and physiological states" (Bandura, 1977b, p.193).

Virtual-Patient simulation. Is an interactive computer simulation of real-life clinical scenarios for the purpose of healthcare and medical training, as well as education where learners emulate the roles of healthcare providers (Berman et al., 2016).

\section{Summary}

The purpose of the present study was to understand the impact three different approaches of suicide risk prevention training and their impact on self-efficacy and confidence levels. The unique approach in this particular VP simulation involves a mental 
health scenario using health profession trainee students as research subjects. Given the paucity of literature on mental health simulation, especially VP simulation and mental health, the study contributes to the discipline and allied health education. Once more, VP simulation can have a positive impact on education, especially for allied health professionals. It could be used as stand-alone training or in combination with lectures and deliberate practice reinforcing principles in the classroom. In addition, VPs can potentially assist in alleviating some of the stress and anxiety that counselors or therapists experience when dealing with patients who are suicidal.

The three hypotheses were tested using a repeated measures analysis of covariance (ANOVA) mixed design to determine if (a) there is a significant difference among three groups of students' self-efficacy between pre-and posttest, (b) after controlling for students' academic program, if there is a significant difference amongst the three groups in relation to their self-efficacy. Then after using an analysis of covariance (ANCOVA) if (c) students with the previous healthcare or mental illness experience demonstrate higher self-efficacy and confidence levels versus other students without this previous clinical experience and exposure to mental illness (as a covariate). The next chapter will discuss the use of simulation in health education, theoretical framework, studies measuring self-efficacy in health education, virtual patient simulation, and virtual patient simulation using mental health scenarios.

\section{Organization of Study}

The quasi-experimental study is composed of five chapters. Chapter 1 provides an introduction to the problem and basis of the study. The second chapter provides a review 
of the pertinent literature. The third chapter presents the methodology used for data collection and analysis in order to test hypotheses and answer all research questions. The fourth chapter provides the analysis of the results and answers for the research questions. And finally, the fifth chapter provides a summary and a conclusion of the study. 


\section{CHAPTER II: LITERATURE REVIEW}

This chapter reviews the relevant literature and is divided into different sections to guide the reader, and explore the different areas within SB training leading into VP simulation. The first section explores the origins of VP with a history and evolution of virtual reality technology, which was the progenitor of SB training in medicine. The second section discusses the role of standardized patients in diagnosing/treating suicidal ideation. The third section explores the use of VPs in health professions. And finally, the fourth section discusses social learning theory and how the role of self-efficacy is a crucial part of the theorectical framework of the current study.

\section{Origins of VP}

The origins of VP simulation can be traced back to the origins of virtual reality and even the Internet. In the 1960s, military scientists, through years of research and development, were able to find a way to connect computers and large networks of machines over great distances. From these advances in technology, military scientists and those in the U.S. Air Force wanted to find a better and safer way to train our pilots preparing them for a variety of war scenarios. Consequently, the challenge was to develop a safe environment where these pilots could train and develop their aerial combat skills without getting hurt. The solution was to develop a computer that would generate sensory input where a jet pilot could experience an actual cockpit (Heim, 1993). For example, the pilot would feed input into a computer by turning the control knob and it would respond by providing sensations in the form of images and movement in front of a screen. Today, this technology sounds rudimentary, similar to a basic video game, but 
was used to train many pilots without ever leaving the ground. Moreover, it has become standard practice for pilots to log many hours in a flight simulator for training and maintaining their flight license.

Beyond video games and flight simulators, the technology has evolved since the 1960s into a revolution of interactive and immersive experiences for consumers and professionals. The developers of these flight simulators continued to experiment with different environments and scenarios unaware that it would later develop into what is known as "virtual reality." Heim (1993) posed the question, "what is virtual reality" and his definition includes seven concepts: "simulation, interaction, artificiality, immersion, telepresence, full-body immersion, and network communications” (pp. 109-117). In other words, virtual reality can be considered any electronic representation with which you can interact or it also can be a sensory immersion into a virtual environment (Heim, 1993). Moreover, according to Heim (1993), if you combine the Webster's dictionary definitions of "virtual" and "reality" you are able to define virtual reality "as an event or entity that is real in effect but not in fact" (p. 108). Similarly, Jerald (2016) defined "virtual reality as a computer-generated digital environment that can be experienced and interacted with as if that environment were real" (p. 9).

Eventually, virtual reality found its way to applications in the consumer entertainment industry by way of popular culture, theme park attractions, and even mobile phones. Researchers and engineers who developed the technology soon realized the limitless applications in education and medical training. Virtual reality worked for fighter pilots and it could also work for physicans and students training in the field of medicine. The advancements in virtual reality technology have allowed doctors and 
students to go beyond images and interact with computer systems providing real-time feedback to users, making the experience more realistic to learners. Continued advances along with the development of enhanced operating systems will pave the way for realistic virtual experiences and more training opportunities.

\section{Standardized Patients in Diagnosing /Treating Suicidal Ideation}

Diagnosing patients with depressive mood disorders is difficult for physicians. It is even more of a challenge to parcel out those patients who pose a suicide risk. Treating clients/patients with suicidal ideation and behavior is another major challenge which is stressful for even the most experienced mental health professional (Farberow, 2005;

Foster \& McAdams, 1999; Gulfi, Castelli Dransart, Heeb, \& Gutjahr, 2010; Mirick et al., 2016; Osteen et al., 2014; Smith et al., 2015). Since this is a reality that most physicians, residents, and allied health professionals face, more effective ways to manage this challenge have to be addressed.

Many professionals have experienced stress, anxiety, fear of legal ramifications, and even decreased self-efficacy and professional competence (Castelli Dransart, Heeb, Gulfi, \& Gutjahr, 2015; Farberow, 2005; Gallo, 2018; Hendin, Hass, Maltsberger, Szanto, \& Rabinowicz, 2004; Osteen et al., 2014) as result of this occupational hazard. Mental health professionals new to the field also express reluctance, feeling uncomfortable working with suicidal clients because of the difficulty of asking the right questions to elicit the client's level of risk, level of planning, and overall sense of planning(Gallo, 2017).

Brown (1987) and Foster and McAdams (1999) discussed the impact of suicidal clients on student trainees as having more of a lasting effect than on experienced 
professionals. Student therapists are more likely to feel that they have failed as people than are experienced professionals who are better able to separate personal failure from limitations of the therapeutic process (Foster \& McAdams, 1999). Furthermore, these personal failures are compounded by feelings of guilt, loss of self-esteem, and intrusive thoughts about the suicide for years after (Farberow, 2005). This challenge is an issue on an international scale due to the gap in knowledge and practice (Smith et al., 2015).

Consequently, this challenge has been addressed by most health education programs and hospitals in the form of SB training using standardized patients (SPs). These SPs are trained actors used to create a scenario similar to one that a clinician or health professional would encounter in their day-to-day interactions with patients. Using these SPs have met with some success in curbing the challenge of treating/diagnosing those patients that present these symptoms.

The literature reveals a mix of results with both physicians and mental health professionals that use SPs to assess suicide risk. Most have yielded positive results when combining SPs with traditional didactic sessions when training students or professionals working in the field. One major positive outcome is the increased self-confidence in screening patients for suicidal risk factors (Fallucco, Hanson, \& Glowinski, 2010). Moreover, the increase in self-confidence also leads to increased self-satisfaction, satisfaction, and perceptions learning styles (i.e., active learning, collaboration, and interdisciplinary practices; Luebbert \& Popkess, 2015). Physicians and students alike find this training useful when assessing performance in a clinical setting. In some instances, the use of SPs and using real-time video to break down the performance of participants have proved useful in these scenarios combining multiple methods to assess 
students (Lu, Lee, Hsu, \& Shu, 2016). The reason for taping these simulations is to capture what other factors contribute to lack of confidence or hesitation in working with patients who present these symptoms.

However, some similar studies using SPs in suicide risk scenarios were met with mixed results demonstrating the difficulty of executing training. Many physicians and healthcare professionals still fail or have trouble in assessing as well as managing suicide risk. The difficulty in working with suicide can be traced to the stigma behind suicide and the highly sensitive nature of the subject. Even highly trained professionals approach the issue with pause and concern when examining a patient. Therefore, researchers have tried to understand both the vocabulary and narrative context of inquiries about suicide with patients to understand how communication could be improved in a primary care setting (Vannoy et al., 2010). Moreover, beyond improving the dialogues between patients and physicians, researchers also have tried to identify the practices physicians have when they probe about suicidal ideation (Duberstein, Chapman, Epstein, McCollumn, \& Kravitz, 2008; Feldman et al., 2007). When investigating communication practices, researchers found that the language a physician uses could affect the level of disclosure of a possible suicide risk. Vannoy et al. (2010) found that scenarios must be designed to help healthcare professionals communicate with and have a more meaningful follow-up with patients. They found that most physicians unintentionally reinforce patients to deny any suicidal ideation (Feldman et al., 2007, p. 37).

Although these SPs are excellent ways to train healthcare professionals, the fact still remains that executing SB training related to mental health disorders, especially suicide, is a challenge. Simulation experts and SPs alike, are challenged by the amount 
of time and difficulty it takes to evaluate performance but over time improvements are possible in the evaluation of these patients (Amini et al., 2016). Future research must be conducted to understand the factors that contribute to a physician's intention to conduct a suicide risk assessment despite the difficulty in diagnosing (Hooper et al., 2012). Compiling these findings using SPs could lead to improved evaluation instruments in assessing risk and managing suicidal ideation (McNiel, Hung, Cramer, Hall, \& Binder, 2011). These tools could help develop better and improved simulations using SPs or other types of SB training.

Simulations involving suicide stimulus are difficult for certain SPs because of the stigmas associated with mental illness, possible depression, and emotion distress, and other discomfort brought on by participating in these portrayals. Even the most welltrained SPs are subject to some of these effects. Hanson et al. $(2002 ; 2007 ; 2008)$ discovered these effects after working with many adolescent standardized patients, specifically working in suicide-based scenarios using medical students and practicing physicians. Their work highlights the usefulness of SPs in this type of training but also some of the drawbacks associated with it. Some drawbacks include additional screening and recruitment of SPs, possible negative effects and depression, and SPs' discomfort with suicide and other mood disorders (Hanson et al., 2002, 2007, 2008). These challenges make it difficult to execute proper training along with difficulties in offering them frequently to a large number of students or physicians. Simulation-based training is important to the students' reinforcement of clinical and didactic materials, often improving the quality of care in multiple clinical scenarios while increasing motivation and confidence. However, with the challenges that SPs present, there needs to be a 
solution to how SB training is offered and executed. Current simulation traning must be improved if we are to meet the demands for more trained healthcare professionals in suicide risk prevention and diagnosis.

One possible solution is using VP simulation instead of SPs for suicide risk scenarios. The literature on VPs over the last 12 years is limited to interaction, patient history or assessment skills, and communication skills of students in various clinical scenarios (Berman et al., 2016; Deladisma et al.,2007; Fleming et al., 2009; Guise, Chambers, \& Valimaki, 2012; Stevens et al., 2006; Sunnqvist, Karlsson, Lindell, \& Fors, 2016; Washburn, Bordnick, \& Rizzo, 2016). Moreover, the literature is even more limited when discussing self-efficacy or confidence. The following is a review of the literature of the different and novel uses of VPs in healthcare settings. From medicine to social work, VPs training can potentially be used in many different disciplines to enhance what is learned in the classroom or gathered from textbooks.

\section{The Use of VPs in Health Professions}

Almost a decade ago, the majority of medical schools in the United States and in Canada were not even using VP training of any sort in their curriculum (Huang, Reynolds, \& Candler, 2007). In fact, the use of VPs has prompted the changes in healthcare, from the length of hospital stays to new opportunities to interact and learn from patients (Huang et al., 2007). Therefore, a quick solution to the lack of training interaction needed to be made to enhance the clinical decision-making process. Hence, technology and incorporating technological innovations in healthcare education was one way to address these challenges in clinical training. At the time, the technology was still in its infancy but had already shown improvement in cognitive and behavioral skills of 
students when used in combination with other traditional methods. Those schools that did have or used VP training encouraged its use in allowing trainees the opportunity to practice both in a realistic and safe learning environment (Huang et al., 2007). By 2008, the use of VPs played a larger role in medical education as a way to prevent medical error not from procedural or the technical side but focusing on the human side of the equation (McConnell \& Pardy, 2008). McConnell and Pardy used the example of the aviation industry, which uses simulation training to train pilots to minimize error while flying and compared it to how we train medical professionals in medicine. The use of SB training potentially could curb a number of medical errors which is a leading cause of medical malpractice on a global scale. To reduce these errors McConnell and Pardy (2008) encouraged SB training as a way to open communication and enhance critical reasoning for medical trainees in clinical settings, whether in private practice or in a hospital.

Within the last decade, VP programs have advanced using more sophisticated features, such as natural language processing, instead of predetermined responses to questions (Berman et al., 2016). The result is realistic feedback in real-time allowing the user to advance beyond static responses, and thus, allowing developers more versatility and creating more scenarios for learners. McCoy, Lewis, and Dalton (2016) have included VP simulation as part of the "gamification" of medical education whereby "game-thinking" and "game mechanics" are used to engage users and solve problems (p. 23). In other words, simulation is part of a game where the user is taken through an exercise and must solve a given problem. The advantage is having dynamic and mobile platforms that can be used for clinical decision-making, increased engagement, and realworld applications. McCoy et al. also note the advantage in offering a "blended" 
classroom experience, whereby you can combine field experiences with the traditional face-to-face lecture to reinforce concepts (p. 27). Moreover, these platforms can be integrated into a LMS to capture analytics such as scoring and statistics to provide to instructors. Such information is vital to the success in a classroom and enriches the educational experience for the learner.

Botezatu, Hult, and Fors (2010a) examined the pedagogical implications of using VPs in and out of the classroom. One implication of their research is the value of using VP simulation as a tool preparing students for future practice. Botezatu et al. described learners' experiences when using the program WebSP (a web-based simulation program) implemented in the curriculum across two countries. They identified these important themes when they interviewed students who participated in focus group after a simulation: learning, teaching, assessment, authenticity, and implementation (Botezatu et al., 2010). Students felt their learning was enhanced as the VP simulation helped with clinical reasoning development and allowed them to recognize their mistakes. The VP simulation covered areas readily missed in clinical rotations, especially content related to diseases "missed in short clinical rotations" or that it "increased motivation" and finally provided "feedback" about the patient making it a more realistic experience (Botezatu et al., 2010a, p.562).

Botezatu et al. (2010b) examined the differences in assessment results between VP simulation and regular course exams using medical students. They found that VPs can be used for assessment not just supplementing lectures and course material. They compared four cohorts of medical students in internal medicine: one cohort with VP simulation or lectures for learning; one with VP simulation and lectures or only lectures; 
and a pair-set up with both lectures and VP simulation. The results demonstrated that the examination results were significantly higher in the VP simulation group compared to the regular exam group (Botezatu et.al, 2010b). Similarly, Botezatu et al. (2010c) explored the variations in retention with VP simulation versus regular learning activities. The aim of their study was to understand the effect of learning of VP simulation and how it supports knowledge retention. Here the researchers conducted a randomized controlled study on early and analyzed assessment results of 49 medical students using VP simulation in an internal medicine course. They found better retention amongst students with VP simulation than with traditional learning methods, that is, lectures or other didactic activities (Botezatu et. al, 2010b). However, the use of VP simulation is contingent upon stakeholders at the institution. Stakeholders include administrators, students, faculty, curriculum directors, and university leaders, etc. Their buy-in and input on cases and scenarios for each VP simulation are crucial for the successful implementation of this technology in the curriculum (Botezatu, et. al, 2010a).

In recent years, the technology supporting VP simulation has advanced allowing users the ability to log in remotely and receive feedback and evaluation for their performance (Bediang, Raetzo, \& Geissbuhler, 2012). For example, VP programs are now available on the web, which allows the user to log into a site to work through a simulation. These advances have allowed VP programs to be used in a multitude of disciplines in the health professions. One such example is the training of future surgeons and using VP simulation for medical training in this area. Virtual patient simulation programs now allow surgical trainees tools to manipulate a series of computerized images and perform surgery in a virtual environment (Badash, Burtt, Solorzano, \& Carey, 2016). 
The simulated images feature detailed and almost lifelike realism as a consequence of the advances in graphics and three-dimensional imaging. Surgical trainees are able to practice without hurting a patient and learn techniques similar to traditional methods. These VP simulators allow surgical trainees to practice a procedure preoperatively in a virtual environment with accurate renditions of a patient's anatomical variations (Badash et al., 2016). The technology is used to train students in evaluating patients with possible cranial nerve damage; a very challenging lesson when teaching students about neurological abnormalities (Johnson et al., 2013). When medical students learn about this particular abnormality, students all to often learn diagnosis through lecture, textbook, and video-based materials which do not engage the critical thinking skills required for information synthesis or diagnosis formation (Johnson et al., 2013). Virtual patient simulation makes teaching such a lesson less laborious and easier for students to engage.

Virtual patient simulation and training continues to expand. Virtual patients offer versatility and flexibility in programming numerous applications and all sorts of scenarios to train healthcare staff. For example, nursing and emergency room staff using VPs in training for a disaster or emergency situation and practicing in safe environments (Dubovsky et al., 2017). Also, scenarios can include pharmacological or pharmaceutical educational applications, such as training pharmacy students in critical care therapeutics (Smith, Siemianowski, \& Benedict, 2016). The number of possible scenarios and VP simulation training is almost endless. However, the focus in most of the VP literature is in history taking, communication skills, and diagnosis offering limited information on other possible applications (Smith et al., 2016). Using VPs in other disciplines is the next step as well as is collaborating with other professionals. For example, one such 
collaboration is an interprofessional collaboration including medical, allied health, and mental health professionals to enhance learning objectives and patient care (Fleming et al., 2009; Shoemaker, de Voest, Booth, Meny, \& Victor, 2015; Shoemaker, Platko, Cleghorn, \& Booth, 2014).

Over the last ten years, VP technology has proven useful in and out of the classroom, especially in clinical settings. Virtual patient simulation is effective in teaching communication patient history skills as well as offering a unique way to practice different psychomotor functions, for example, surgery, or most patient examination techniques (Albright et al., 2016). Consequently, as VP technology has become more advanced and refined, it is becoming more commonplace and used in different mental health clinical settings. Virtual patient simulation offers a safe environment to practice and works with these applications via interactive and real-time feedback of a possible patient presenting a variety of mental health disorders. For example, in the area of mental health nursing, VP technology provides valuable training and critical thinking, communication, and decision-making (Guise et al., 2012). Virtual patients could potentially assist nurses to mitigate a situation with a distressed patient making ethically sound and therapeutically appropriate care decisions (Guise et al., 2012).

Virtual patient simulation can also help with mental health assessment skills. One recent study by Washburn et al. (2016) examined the use of VP simulation to "enhance social workers' mental health assessment skills as a way to curb misidentification of behavioral health issues" (p. 676). The reason for the misidentification of these issues is a result of limited "practice opportunities with live clients in field placements, and the use of unstandardized assessment measures to assess competence" (Washburn et al., 
2016,p.676). The lack of training and much-needed experience as well as the cost of using standardized patients limits these training. In particular, the use of standardized patients is taxing on any actor re-creating the scenarios. Virtual patients offers a creative solution to address these logistical problems. Hence, with more exposure the students have with the scenarios, the more improved their assessment skills should become.

Another similar study, Sunnqvist et al. (2016), examined the use of VP simulation as supporting collaborative learning in a psychiatric setting. Again, students or learners in mental health and psychiatric courses experience anxiety and fear before starting their clinical practice. Most learners have never met a mentally ill person before and they presume it is difficult to communicate with them (Sunnqvist et al., 2016). Their experience demonstrated VP simulation has the potential for training students in dealing with patients in psychiatric care. Learners felt positive about their experiences and believed it reinforced what they learned in their lectures (Sunnqvist et al., 2016).

Finally, another example of VP simulation in a psychiatric setting, Foster, Chaudhary et al. (2015) used VPs to train health profession trainees using suicide risk as the scenario. Their study measured the interaction with VPs as well as observation of a videotaped interview to enhance students'suicide risk assessment proficiency. Their study indicated greater knowledge acquisition with the VP simulation than the video; however, both tools helped students to improve their suicide risk assessment skills through the ability to capture student responses or discoveries and providing immediate feedback (Foster, Chaudhary et al., 2015).

Other applications of VP technology include alcohol screening/intervention and teaching students empathy (Deladisma et al., 2007; Fleming et al., 2009; Foster et al., 
2016). Previous studies highlight the endless possibilities and applications of VP technology. Virtual partients allow learners to train in a safe environment and have important dialogues regarding substance abuse, interpersonal violence, and even sexual practices (Fleming et al., 2009). However, regarding clinical skills, VP simulation can also enhance communication with patients and healthcare providers in teaching important nonverbal behaviors such as empathy (Deladisma et al., 2007). Therefore, VP simulation addresses many of the knowledge gaps and difficult concepts in the classroom supplementing the content for the learners. In addition, VP simulation has been shown to improve clinical performance and communication skills in tandem with deliberate practice (Liaw, Chan, Chen, Hooi, \& Siau, 2014; Stevens et al., 2006). As VP technology continues to advance, additional applications and expansion into other disciplines will be a possibility.

\section{Social Learning Theory}

As VP technology continues to change education, we need to design curriculum to support the use of technology, and as a supplement to traditional pedagogy. Moving forward, educators and those implementing curriculum must be cognizant of how these simulations affect performance in clinical settings. Many studies in the health education literature have covered how simulator training has been demonstrated to be useful and effective, as well as how to improve the VP technology, creating a more realistic scenario for the student. Still, there is a need for additional analysis of the effects of VP technology on student performance in scenarios involving mental health. Student performance in mental health scenarios is a concern for many involved in academic 
medicine and allied health education. Those involved and those responsible for curriculum development are trying to improve the traditional proficiency-based training for students by gathering data from these simulations. Questions arise such as: How can we improve student performance? What can we do to enhance students' experience in the simulation? And when is the best time to implement these pedagogical tools during a course of study?

The theoretical foundation for the present study used social learning theory, specifically using self-efficacy, as the lens by which to examine how self-efficacy affects confidence and performance in clinical settings. Bandura (1977b) explained

that most psychological procedures, whatever their form, alter expectations of personal efficacy. Within this analysis, efficacy and expectations are distinguished. An outcome expectancy is defined here as a person's estimate that a given behavior will lead to certain outcomes. An efficacy expectation is the conviction than one can successfully execute the behavior required to produce the outcomes. (p.79)

Social learning theory (derived from social cognitive theory developed by Neal E. Miller and John Dollard) looks at observational learning and the acquisition of skills depending on the students' social environment. Social learning theory stresses that much learning occurs in the social environment (Schunk, 2012). Students observe others as well as their instructors and acquire knowledge based on their observations. Medical schools, allied health programs, and other mental health professional programs have a unique social environment where learning occurs on both an individual and a group basis. Students are assessed on academic performance, professionalism, but also on how they apply that knowledge in a clinical setting. Many times, in these clinical settings, students 
must perform with minimal exposure in a clinical context. The clinical skills training mimics the dynamics of a hospital or group practice setting.

Albert Bandura and fellow researchers (1977a, 1977b) examined the social environment in which students learned and other personal factors affecting learning. One of those personal factors was self-efficacy, one's personal beliefs about one's capacity to learn or to perform actions at designated levels (Schunk, 2012). His conceptual framework of self-efficacy looks at students' perceived capacity for performing certain actions and accomplishing goals. Bandura also studied outcome expectations as a function of the self-efficacy levels of what a student can perform. Self-efficacy and outcome expectations may mean something completely different, but they are related. Students will perform well if they have confidence in their learning capabilities and expect positive outcomes from their efforts (Schunk, 2012). The same should apply to understanding the confidence levels of students in their learning capabilities and their outcome expectations.

\section{Self-Efficacy}

According to Bandura's (1977a) social learning theory, "expectations of personal efficacy are determined by four major sources of information: performance accomplishments, vicarious experience, verbal persuasion, and physiological states" (p.192). He believed that self-efficacy was one of the principal motivators for changes in behavior and an explanatory factor in the way it can predict behavioral changes through different methods of treatment. Bandura held that the way individuals perceive their selfefficacy can influence their choices and behavior in the activities they choose.

Furthermore, he explained, "efficacy expectations determine how much effort people will 
expend and how long they will persist in the face of obstacles and adverse experiences" (Bandura, 1977a, p.192). Therefore, the more self-efficacy one has, the more actively one approaches activities or tasks assigned in classroom or at the workplace (Reddan, 2016; Tan \& Chou, 2018).

Self-efficacy theory offers one of the principal predictors of performance and confidence in completing a task such as participating in a VP simulation. As discussed previously, students in medical and mental health programs barely experience or are exposed to situations in traditional SB training. Hence, when students encounter these situations in a real-life clinical setting their anxiety and confidence levels are affected. By exposing them and creating these VP environments complemented by traditional lectures followed up by deliberate practice, confidence and motivation can positively influence behaviors. Additionally, these VPs, besides their instructors can serve as models, which Bandura (1977a, 1977b) also described as influential agents to one's selfefficacy. By observing the behavior of these so-called "models," subjects can acquire skills in dealing with a potentially stressful situation.

Research on social learning theory and its applications in medicine and the allied health fields is substantial; however, much of it focuses on communication (Berman, Durning, Fischer, Huwendiek, \& Triola, 2016; Hicks, Coke, \& Li, 2009). For example, topics range from taking a patient's history, inter-professional collaboration/communication, patient interviewing, and disease-specific topics to the treatment of a patient. Research on SB training and the impact on self-efficacy is another subject area that has substantial contributions from researchers in nursing and medical education (Berman, Durning, Fischer, Huwendiek, \& Triola, 2016). In the current study, 
the expectation was to build upon the existing limited amount of literature by focusing on mental health, a largely overlooked area, and on the use of VP simulations by health profession trainees. In addition, there was a focus on measuring their confidence levels and self-efficacy after such an interaction.

\section{Self-Efficacy and Virtual Patient Simulation}

Once more, as this VP technology has continued to develop over the last 15 years, we see it increasingly used to train learners in a variety of disciplines. Learners in nursing, medicine, psychology, pharmacy, and mental health have benefitted from the use of VPs to master clinical and evaluation techniques. Each learner can interact with the VPs, ask questions, and train in a safe environment either individually or in a group setting. Learners can observe behaviors of VPs and model desired outcomes while training for different clinical encounters or patient evaluations. The existing literature has demonstrated the positive impact of high-fidelity simulation (using either standardized patients or high-fidelity mannequins) on performance and self-efficacy. The applications of VP simulation are adaptable to different encounters and learning styles. Whether teaching students how to perform patient examinations to diagnose an illness, the scenarios are adaptable and scalable to needs of instructors.

Jeffries, Woolf, and Linde (2003) explored the use of VP simulation training and self-efficacy using multimedia, CD-ROM based technology on nursing students. The researchers wanted to compare the effectiveness of VP simulation against traditional methods of teaching how to perform an electrocardiogram, a common cardiac examination. Upon their initial evaluation, differences in self-efficacy in learning were not statistically significant when comparing the traditional and simulation group; 
however, pre-post test scores demonstrated a significant difference between the two groups (Jeffries et al., 2003). Both groups performed well using both teaching methods. However, though both groups had no significant outcome differences the findings indicated that considerable cognitive gains and skill acquisition were obtained by both instructional methods (Jeffries et al., 2003).

Recently, and after some advancements in this VP technology, Makransky et al. (2016) evaluated whether simulation training increased students' knowledge, intrinsic motivation, and self-efficacy in generalizing laboratory analyses to clinical practice and decision-making. Essentially, they wanted to increase competencies and bridge the gap between theory and practice in medical education, especially in the area of medical genetics; a difficult and growing field of medicine. Medical genetics is a challenging field as it relates to the understanding the effects of genetic variations in common diseases and disorders. Makransky et al. (2016) wanted to use a case-based approach to medical genetics using VP simulation as a way to potentially enhance students'understanding of concepts while increasing motivation. The desire to enhance students' understanding was a result of previous literature highlighting the use of VP simulation as a method to increase knowledge and clinical reasoning (Cook, Erwin, \& Triola, 2010). Thus, the researchers proposed that the use of this technology would allow students to choose and perform laboratory tests (related to genetic testing) enhancing their knowledge and understanding of available genetic testing methods (Makransky et al., 2016).

Students in that simulation completed a pretest to determine baseline knowledge, intrinsic motivation, and self-efficacy. They, then, participated in a 2-hour medical 
genetics simulation and a posttest immediately after to evaluate the VP simulation as well as their knowledge. The posttest reassessed their knowledge, intrinsic motivation and self-efficacy. The results showed that students average self-efficacy about their skills to perform medical genetics activities increased significantly from the pretest (Makransky et al., 2016) demonstrating the effectiveness of VP simulation increasing self-efficacy with difficult and challenging concepts in medical education.

Similarly, a case report by Albright et al. (2016) discussed the use of VP technology to develop skillful and collaborative conversations to improve physical and mental health. The authors discussed the applications of VP technology as a way to engage patients by training health professionals to better communicate goals, preferences, or even challenges as a way to transform health (Albright et al., 2016). The authors discussed the potential of VP technology for health professionals to learn how to conduct screening, motivational interviewing, and even interventions with at-risk patients, such as mental health or substance abuse disorders. The VP technology the researchers discuss is the Kognito Conversation Platform which uses a combination of game mechanics, data collection, and analytic technologies to simulate emotionally responsive virtual humans that model human behavior (Albright et al., 2016). It also features personalized feedback via a virtual coach after participants choose appropriate responses in a dialogue with the virtual human. For example, one simulation featured resiliency and PTSD for military families managing challenging interactions with their veterans adjusting to postdeployment life. The authors described how simulation training yields an increase in self-efficacy or one's perceived ability to manage conversations in real-life (Albright et 
al., 2016). The exposure leads to an increase in confidence in the ability to perform such tasks thereby enhancing health professionals'skills and reactions to patients.

The application and flexibility of this VP technology can be tailored to different scenarios and disciplines within health professions education. For example, Barnett, Gallimore, Pitterle, and Morrill (2016) evaluated the use of online case simulation against a paper-based case simulation on student confidence and engagement. They looked at the role of the pharmacist and the responsibility for drug therapy decisions and outcomes. Their study used VPs with doctor of pharmacy (PharmD) students to determine if there was an increase in student engagement, knowledge, and perception of confidence in patient management. Essentially, the authors compared the performance and confidence scores of a case involving an osteoarthritis patient and how students assessed medication use, identified medication-related problems, and how they navigated through a medical record thereby providing appropriate drug therapy recommendations (Barnett et al., 2016).

The Barnett et al. (2016) study involved comparing groups, the paper-case group, and the online-simulated patient case group. The paper-case group recieved a 75-minute lecture on the topic of osteoarthritis, completed a pre-experience confidence survey and baseline questions, and then completing the case. The other group, the online-simulated patient case group, completed a pre-experience confidence survey, then an online simulation of the same osteoarthritis case. Both groups received a post-experience confidence survey to determine any differences or changes after the experience. After collecting the data from both groups, an analysis of their confidence levels revealed a significant increase in all questions related to confidence; however, the online simulation 
group had a significantly greater increase in their degree of confidence on some items than did the other group. Overall, the results of the study suggested these pharmacy students found the virtual simulated patients more engaging, enjoyable, and realistic than traditional paper cases (Barnett et al., 2016).

\section{Summary}

This chapter provides a review of the literature relevant to this study. The review of the literature discusses the origins of VP technology and its applications in multiple realms. It also discussed the use of simulation in diagnosing and/or treating patients posing a risk for suicide as well as the use of VPs in health professions settings. Finally, the chapter continued with the theoretical basis for this study which is social learning theory and the theoretical impact of self-efficacy on confidence and performance levels of health profession trainees. The review also highlighted the paucity of literature related to VPs and self-efficacy, as well as to VPs used in mental health scenarios or settings. As such, there is a need to contribute to this growing body of literature and expand on the multiple applications of this technology and how it can contribute to health education. 


\section{CHAPTER III: METHODS}

The purpose of the present quasi-experimental study was to understand and compare three approaches of suicide risk prevention on health profession trainees. The study uses the research and technology used in a study by Foster, Chaudhary et al. (2015) that measured the interaction of students with a bipolar VP who attempts suicide.

However, in addition to interaction, this study includes the measurement of students' selfefficacy after interacting with the VP. The goal was to understand students' perceived self-efficacy in assessing suicide risk after the interaction. Students participating in their study were exposed to either the VP simulation or a video teaching module on interviewing a bipolar patient. The study was undertaken to make a contribution to the growing literature on the use of VP as a potentially effective pedagogical tool and to make a contribution to mental health education, curricula and literature about active learning. The research is part of an effort to improve communication and diagnostic skills of health profession students concerning a highly stigmatized mental health issue.

As the landscape of mental health education continues to change and incorporate more technology, applications and even games into the curricula. Therefore, educators must continue to evolve in how they teach mental health diagnostic skills. The literature documents the use of VP simulation as both a pedagogical and assessment tool in the field of mental health and psychiatry training (Albright et al., 2016; Berman et al., 2016). The utilization of VPs has increased with the enhancement of graphics and the ability to interact in a clinical scenario with a student. As VP technology continues to improve, the use of VPs will continue to increase as a vital teaching tool to enhance diagnosis, communication, and provide feedback to students in training. 
For the current study, the purpose was to measure the impact of using VPs in training health professionals on their self-efficacy and confidence levels (specifically concerning assessing behavioral health concerns). To conduct the measurement, questions on students' feedback, student satisfaction of VPs as used in the work of Foster, Chaudhary et al. (2015), and self-efficacy using Hicks et al. (2009), and Makransky et al. (2016) were included as models in the development of a survey instrument. These works guided the researcher in addressing one of the research questions, which was: To what extent are students interacting with a VP different from those participating in a video simulation and those learning by traditional teaching methods in their self-efficacy in assessing suicidal risk (between pre-and posttest)? Nonetheless, these simple questions had many layers and constructs to consider. For these constructs to be measured, a questionnaire designed to capture this information was necessary.

The construct from that survey that was used in the present study was selfefficacy. Self-efficacy is defined as one's personal beliefs about one's capabilities to learn or to perform actions at desired levels (Bandura, 1977a). The construct is measured in one such questionnaire used by Foster, Robb et al. (2015) in a study evaluating suicide risk assessment and how second-year medical students interact with a VP in real-life clinical scenarios. Self-efficacy was included in my questionnaire as adapted from clinical skills self-efficacy studies discussed later in the current chapter. 


\section{Research Design}

Subjects were assigned to a VP group, a video module group, and a lecture group. The VP group participated in the VP simulation using the Denise VP scenario (Foster et al., 2015), the VP who is bipolar and presents as a possible suicide risk. The VM group participated by watching a video using the same scenario and content covered in the VP simulation. Finally, the lecture group participated in a traditional face-to-face lecture on suicide prevention.

The figure below provides the study flow for the current study along with the total number of participants. Figure 2 includes the academic program for the training groups and the progression of the study (pre and posttest).

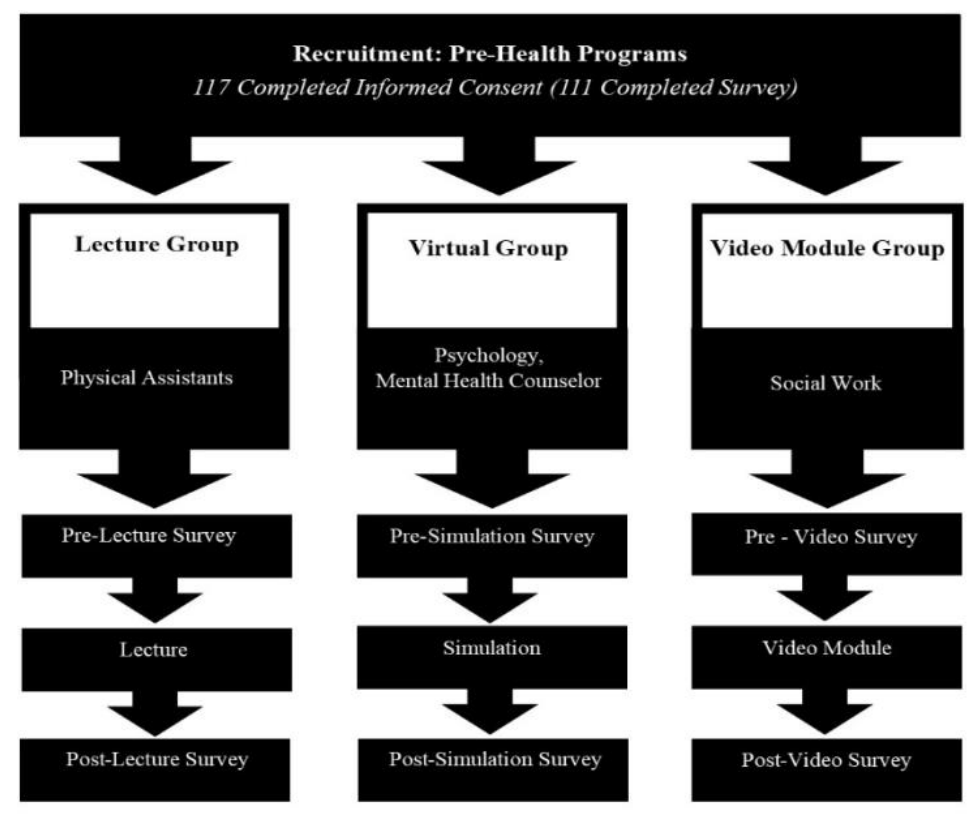

Figure 2. Study flow 
A pretest-posttest quasi-experimental design was used. The pretest-posttest quasiexperimental design is one of the commonly used designs in educational research and is structured like a pretest-posttest randomized experiment, but lacks random assignment (Trochim, 2006). Unfortunately, due to constraints with time and nature of this study, the researcher was not able to randomly assign the students into different groups. All of the participants belonged in different programs and were part of naturally assembled collectives (or classes) meeting at different days and times. In addition, it was impossible to have students in the same room participating in the video and virtual modules simultaneously due to disruption.

Two groups of subjects were randomly assigned to two training groups but was unable to assign the students into the traditional teaching (lecture) group. The lecture group was part of an entire cohort of students in the physician assistant program.

\begin{tabular}{lll}
\hline $\mathrm{O}_{1}$ & $\mathrm{X}_{1}$ & $\mathrm{O}_{2}$ \\
$\mathrm{O}_{1}$ & $\mathrm{X}_{2}$ & $\mathrm{O}_{2}$ \\
$\mathrm{O}_{1}$ & $\mathrm{X}_{3}$ & $\mathrm{O}_{2}$ \\
\hline
\end{tabular}

Note: $\mathrm{O}_{1=\text { Pretest }} \mathrm{O}_{2=\text { Posttest }}, \mathrm{X}_{1=\text { Virtual Patient Simulation Group },} \mathrm{X}_{2=\text { Video Module Group }}, \mathrm{X}_{3=\text { Lecture Group }}$

Figure 3. Quasi-experimental: Pretest-posttest non-equivalent design

The research design was chosen because it was appropriate for testing hypotheses in a way that was feasible, practical, and ethical. According to Campbell and Stanley (1967) when referring to the nonequivalent control group design:

One of the most widespread experimental designs in educational research involves an experimental group and a control group both given a pretest and a posttest, but in which the control group and the experimental group do not have pre-experimental sampling equivalence. Rather, groups constitute naturally assembled collectives such as classrooms, as similar as availability permits but yet 
not so similar that one can dispense with the pretest. The assignment of $X$ to one group or the other is assumed to be random and under the experimenter's control. (p.47)

The "naturally assembled collectives" (Campbell \& Stanley, 1967) in the present study were the health profession trainees in the four aforementioned programs. These trainees are grouped together by a cohort system or similar equivalent depending on their program.

\section{Sampling and Participants}

\section{Target Population}

The target population is the "group of elements for which the survey investigator wants to make inferences by using the sample statistics" (Groves et al., 2009, p. 69). For the current study, the target population are university students involving mental health training, specifically those that include suicide prevention as part of a course or courses in their curriculum. Specifically, these are master's degree level, mental health profession trainees (consisting of PAs, clinical mental health counseling, school counseling, and social work program students) at Florida International University. Again, the study was unique in that it involved PA students from a newly accredited PA program, specifically the Master in Physician Assistant Studies (MPAS) program students at FIU. It also included students from the Master of Social Work, Master in Professional Counseling Psychology, and Master in Counselor Education (Clinical Mental Health Counseling).

\section{Sampling Frame}

According to Groves et al. (2009), the sampling frame is used to identify the elements of the target population thereby focusing on a specific element for the investigation. The particular pre-health professional population or sampling frame, 
which concerns this research are the students enrolled in several master's degree programs at FIU, specifically enrolled in health professional programs. Each of these programs involves some amount of involvement in the mental health field. Moreover, all programs in this study involve curriculums dealing with crisis intervention or suicide prevention when encountering clients/patients in a clinical setting.

\section{Sampling Design}

The sampling design used in the study is convenience sampling. It is a type of nonprobability sampling where available elements of the target population are easily

obtained. Farrokhi and Mahmoudi-Hamidabad (2012) explained that convenience sampling is:

A kind of nonprobability sampling or non-random sampling in which members of the target population are selected for the purpose of the study if they meet certain practical criteria, such as geographical proximity, availability at a certain time, easy accessibility, or the willingness to volunteer. (p.785)

The method allows for including a representation of the sampling frame. It is one of the most commonly used designs and "one of the least expensive, without a need for all of the population elements as well as allows us to formulate results quickly allowing for immediate data collection” (Acharya, Prakash, Saxena, \& Nigam, 2013, p. 332).

As to the drawbacks, convenience sampling can easily present an opportunity for bias that might skew the results of a survey because the sample is not random and it may prevent researchers from generalizing the results from the sample to the population (Acharya et al., 2013). Landers and Behrend (2015) discuss this limitation from the perspective of external validity, which refers to the ability of a researcher to make valid 
conclusions about the population from which a particular sample is randomly drawn" (Landers \& Behrend, 2015, p. 145).

Therefore, specifically in this study, the results of the survey used in the study might not necessarily reflect the same opinions or views of other pre-health professional students at other universities. Second to this drawback is the possibility of incomplete conclusions because there might be misrepresentations in the sample (Kelley, Clark, Brown, \& Sitzia, 2003). However, though lacking a larger sample, the potential information gathered in the present study can be used for the advancement of science, curriculum development, and proficiency in the evaluation of suicide risk. Although this method presents limitations, it provides for a quick way to gather information from the sample is readily available since it comes from the population close at hand and it cost effective.

\section{Sample Size Estimate}

Before starting recruitment or data collection, it is important to determine the sample size through a priori statistical power analysis, or how many participants are needed in order to achieve a sufficient statistical power, or the likelihood of rejecting the null hypothesis when it is false (Hinkle et al., 2003). Besides statistical power, the effect size, which is a measure of the strength of the significant difference, is also needed (Cohen, 1988). For the present study, a power analysis was conducted, testing for effects of between-subjects of more than two groups to determine the adequate sample size for the study using the G*Power 3.1.9.2 software (Faul, Erdfelder, Buchner, \& Lang, 2009; Faul, Erdfelder, Lang, \& Buchner, 2007). A priori power analysis, rather than post hoc 
power analysis, was selected because it determines the necessary sample size before recruiting participants (Faul et al., 2009).

For the current study, the power analysis was set by a priori analysis using a statistical test for ANOVA (fixed effects, omnibus, one-way), with an alpha of 0.05 , power of 0.65 , number of groups set to three, and a medium effect size $(0.25 \sigma$; Cohen, 1988 ; Hinkle et al., 2003). These input parameters resulted in a desired sample size of 114 needed for the study.

\section{Recruitment of Subjects}

As part of the recruitment of subjects, four different master-level health professional programs were identified for the study. These four programs within FIU are the Master in Physician Assistant Studies, Master of Science in Psychology (Professional Counseling), Master of Science in Counselor Education (Clinical Mental Health Counseling), and the Master of Social Work programs. Each program features different curricula and trainings related to mental health (i.e., mood disorders, depression, and suicidal ideation in patients).

Four program directors were contacted before recruiting students from each program to describe the research goals and objectives prior to commencement. A document specifying study aims and expected outcomes was circulated to each director. After initial meetings were conducted, the program directors from each of the programs contacted their faculty in order to initiate subsequent meetings for data collection. The faculty responsible for teaching crisis- related concepts and curriculum helped in recruiting students to participate in the VP simulation. However, it was also explained to 
the faculty that some students will be exposed to a video teaching module of the same material. All faculty obliged and were instrumental in allowing students to participate in the VP simulation.

\section{Possible Errors}

As with any sampling procedures, there is the possibility of errors. Other errors such as random variation from characteristics of the population are also possible. In addition, the possibility of bias may play a role because study participants respond to the survey differently than the target population as a whole. Another possibility is the construction of the survey instrument, where the statements asked are not clear (including the answers to the statements). Each of these possibilities must be evaluated as this research is planned and executed.

\section{Instrument and Measures}

In order to collect data related to the interaction, a survey instrument was constructed using questions adapted from existing and validated survey instruments. First, a set of questions was adapted from Foster, Robb et al. (2015) "Denise: A Virtual Patient" that is related to satisfaction and interaction with the VP patient using a 5-point Likert scale. Questions related to the student interaction with the VP patient used statements "I enjoyed the interaction with...". The Likert scale focuses on degree of agreement and ranges from " 1 " for strongly disagree to " 5 " for strongly agree. These statements used were validated with a sample of second-year medical students (Foster, Robb et al., 2015). In this study, 67 students were recruited as a random sample and the researchers compared to students assigned to the VP group to those of assigned to a video module. According to, Foster, Chaudhary et al. (2015), the survey items dealing with 
communication, rapport, interaction, and satisfaction had Cronbach's alpha at 0.97 and 0.84, respectively. Additionally, questions from that study were also adapted for this survey regarding familiarity with mental illness. Some example items are, "I have a friend who has a mental illness" or "I have an immediate or distant family member with a mental illness." These were nominal questions, which were answered with a "yes" or "no."

To measure participants' self-efficacy, a combination of items related to respondents' confidence after this simulation encounter was adapted from Artino, DeZee et al. (2012) and Hicks et al. (2009). In the Artino, Dong et al. (2012) study, the researchers used a combination of content validity (using medical education experts) and exploratory factor analysis to validate their instrument regarding self-efficacy. The exploratory factor analysis used a principal axis approach with oblique rotation on 19 individual self-efficacy items to obtain reliability evidence (Artino, DeZee, et al., 2012). As a result, three components were extracted, which included self-efficacy, specifically interpersonal skills self-efficacy, and evidence-based medicine self-efficacy, with Cronbach alpha values of 0.92, 0.76, and 0.79, respectively (Artino, Dong et al., 2012). The statements were tailored to a clinical skills scenario involving medical students and designed to measure their confidence in evaluating a patient. Finally, the last set of questions asked basic demographic information as well as their previous work experience in the mental health field. Consequently, the Artino, Dong et al., 2012 survey was adapted for those in the lecture group who had only face-to-face lectures, asking the same questions but the wording was changed for VP and video survey, e.g. wording that was specific to the individual module, such as "video" to "virtual", etc. Combined, these 
elements allowed for the collection of empirical evidence to test the hypotheses through statistical analysis.

The survey instrument used for the study was validated using cognitive interviews over two semesters. Cognitive interviews allowed the researcher to probe how respondents would understand the questions (Groves et al., 2009). The interviews were conducted with a small group of physician assistant and social work students. The information collected from these is important to test the questions before using a survey instrument for clarity and flow.

In addition, the researcher consulted with an expert in the field, Dr. Adriana Foster, to make these questions easier to understand for respondents. The researcher interviewed in the same manner as the students, i.e. reading aloud the questions for clarity and understanding. After these interviews, the researcher modified the order of the questions for flow and consistency. As a result, questions or statements used were shorter in length and written using simple vocabulary.

\section{Data Collection and Procedures}

Data in the study are mainly collected through the use of surveys. The survey or questionnaire is a "systematic method of gathering information from a sample of a population to develop quantitative descriptors (or statistics) of the characteristics of the

population" (Groves et al., 2009, p. 2). According to De Leeuw, the goal when designing a survey is to "optimize data collection procedures and reduce total survey error within the available time and budget" (p.235). Surveys are available in paper or in an electronic format, which can be distributed online. The clear advantage of an online survey is the 
fast and near-instant transfer of the data from the sample, data which are easily exportable to any statistical analysis package.

One consideration was the technical issues that might arise when deploying a survey via the Web. Certainly, there are many considerations when considering online as a way to administer the survey, but a paper version was made available as a backup. However, no students requested a paper version. Participants were asked to complete the survey online during one of the class sessions as part of a class assignment or lecture related to discussing suicide prevention. The online survey used the Qualtrics platform and embedded in the LibGuide for all the groups of the participants. The research process was explained to the participants at the beginning of the survey, including the purpose of the research and benefits/costs of the research. Participants were also asked to sign the informed consent form online.

\section{Nonresponse}

One of the weaknesses of online survey is possible high non-response rate, which could be due to the technical issues associated with Web surveys and lack of motivation from students' part. Technical issues could be issues with the connection, students forgetting to bring their laptops to class or network failure. Groves et al. (2009) mentions technical issues as a possible reason for "lower response rates and may discourage some from completing (or even starting) the survey as compared to paper-and-pencil surveys" (p. 474). Therefore, it is best to be prepared for technical difficulties to happen and be present during the survey administration. There is no evidence that intervieweradministered surveys using technology affects response rates; however, evidence supports that self-administered surveys using paper-based methods tend to have higher 
response rates (Groves et al., 2009). Using online along with paper-and-pencil surveys (as a backup) was one way to address the concerns around technical issues related to an online survey.

Another reason for nonresponse rate is item nonresponse for either inadequate comprehension of the questions asked or lack of motivation to disclose information from students' part. Lack of compression of the question is traced to the construction of the question itself. The wording might be unclear or is not logical to the respondent.

According to Bowling (2005),

It is important to remember when constructing a survey instrument there are cognitive demands on the respondents: comprehension of the question, recall of the requested information from memory, evaluation of the link between the retrieved information and the question, and communication of the response. (p.281)

To address the possible issue of students' lack of motivation in completing the survey, pre-notification in verbal and email format was given to students by the course director and the researcher at the start of the course. Also, students were informed that all responses would be confidential and anonymous.

\section{Procedure}

Since the study called for the participation of human subjects, training from the Collaborative Institutional Training Initiative (CITI) for Institutional Review Board (IRB) course was completed to promote the ethical treatment of participants. Approval was sought from the Florida International University IRB before starting the research, and the research protocol was submitted via the Topaz Electronic Protocol Application System for IRB (Approval\# IRB-18-0171-AM01, Reference\# 106799). As part of this review, consent forms were submitted, which highlighted any benefits or potential harms 
that a subject might experience in the course of the study. In addition, the VP, video module, and lecture group survey instruments, along with recruitment materials, were submitted for final IRB review.

After some discussion with the program directors and permission to proceed was obtained, faculty from each program allowed for a brief introduction to their classes, where the research and informed consent procedures were described. Informed consent was completed online for all the VP, VM, and lecture groups at the beginning of the class and before students complete the survey. After the informed consent was obtained, participants proceeded with either module or lecture. Participants then were directed to a link to one of three Libguides (i.e., the VP, video, or lecture group Libguide). Each Libguide contained a link to the informed consent, a link to the pretest survey, the VP simulation or video module, and a link to the post-survey, all on one page. The links to these Libguides were made private and only accessible to participants who were directed to the specific URL, depending on what group they were assigned to.

Students in the four master's degree programs took the post-simulation survey after the VP simulation, the video module interaction, or the face-to-face lecture. Responses to the surveys were recorded on Qualtrics Survey Software, which is free for all students, faculty, and staff at FIU. Both surveys were embedded in the learning management system Blackboard or Canvas, depending on the program. Using these learning management systems allowed for streamlining and content management, providing a space to host links to the VP simulation or video teaching module. 


\section{Data Analysis}

A post-simulation survey was administered to all groups and their interaction and self-efficacy levels were analyzed using the Statistical Package for the Social Sciences (SPSS) version 25 Gradpack.

The three hypotheses in the study aim to determine if (a) there is a significant difference among the three groups of students' self-efficacy between pre- and posttest, (b)if there is a significant difference between the three groups' self-efficacy after controlling for students' major, and (c) if there is a significant relationship between students' previous healthcare or mental illness experience and their self-efficacy in assessing suicide risk.

Three statistical techniques were used to test these hypotheses. A repeated measures mixed design one-way analysis of variance (ANOVA) was used to test the first hypothesis, an analysis of covariance (ANCOVA) was used to test the second hypothesis and bivariate correlation analysis for the third hypothesis.

ANOVA. The first of these statistical techniques used was a one-way repeated measures mixed design ANOVA, where subjects were measured two or more times and the total variation was partitioned into three components: variation among individuals, variation among test occasions; and, residual variation (Hinkle et al., 2003). This design is a mixed design because it contains both between-subject (e.g., three groups) and within-subjects (time) factors variation (Lamb, 2003). The between-subject variation focuses on the variation between the means of the groups and the mean of the total group (Hinkle et al., 2003). The within-factor concentrates on the variation among all subjects within a group (Hinkle et al., 2003; Lamb, 2003). 
The repeated measures ANOVA allows the researcher to look into the different groups and their performances across different time points. For the present study, the researcher examined the variation between all the groups who participated in each of the training methods as well as the variation of the individuals within these groups between pre- and post-test. Using a repeated measures ANOVA is advantageous in certain cases with fewer participants, and random assignment is not possible (Lamb, 2003).

ANCOVA. Another statistical technique applied in this study was an ANCOVA to analyze the effect of covariates or extraneous variables on the dependent variable. An ANCOVA provides a means to statistically control the effects of an extraneous variable, also known as a covariate (Hinkle et al., 2003), on the dependent variable. The ANCOVA is a combination of regression analysis and analysis of variance or an ANOVA which controls the effects of the extraneous variable, An ANCOVA when you know there is a factor that explains part of the variance. By doing this, a researcher can get more precise results and rule out any influence from factors that affect the results of the study. For the current study, the researcher was concerned with the possible effects of previous clinical/work experience as a covariate. These could potentially influence the results of the study regarding the self-confidence levels of subjects. Therefore, it was best to parcel out these variables for the analysis, therefore, reducing the error variance of the results (Hinkle et al., 2003).

Bivariate correlation analysis. The last statistical analysis used in the study was a bivariate correlation analysis of previous experience and self-efficacy, specifically, the relationship between previous mental health or medical work experience and levels of self-efficacy in the posttest survey. Bivariate correlation analysis is a very common 
statistical technique used in the behavioral social sciences (Hinkle et al., 2003).

Correlation refers to the measure of the relationship between two variables, which is indicated by a correlation coefficient, that is, an index or the $r$ coefficient that describes the extent to which two sets of data are related (Hinkle et al., 2003). This $r$ coefficient or otherwise known as the Pearson coefficient is named after the English statistician Karl Pearson (1857-1936), who developed this index to determine the measure of the relationship between variables and how to interpret this relationship depending on the size of the correlation (Hinkle et al., 2003). When one considers the measure of a relationship between variables, the size of the correlation and its interpretation usually are reported as a number (from 0 to 1 ) that indicate a positive or negative correlation. To demonstrate this, Hinkle et al. (2003) provided a table for interpreting the size of the of a correlation coefficient (p. 109).

\begin{tabular}{ll}
\hline Size of Correlation & Interpretation \\
\hline .90 to $1.00(-.90$ to -1.00$)$ & Very high positive (negative) correlation \\
.70 to $.90(-.70$ to -.90$)$ & High positive (negative) correlation \\
.50 to $.70(-.50$ to -.70$)$ & Moderate positive (negative) correlation \\
.30 to $.50(-.30$ to .50$)$ & Low positive (negative) correlation \\
.00 to $.30(.00$ to -.30$)$ & Little if any correlation \\
\hline
\end{tabular}

Figure 4. Rule of Thumb for Interpreting the Size of a Correlation Coefficient

\section{Summary}

This chapter outlined the methodology used for this quasi-experimental study. The study used master's-level students enrolled in four health profession programs: Physician Assistants, Social Work, Counselor Education, and Psychology. A posttraining survey was administered to determine the impact as well as the interaction of a virtual patient simulation on these students. These students were assigned into either the 
the VP simulation module or the video module training groups or the lecture group which had a face- to- face lecture. The statistical analysis was conducted using SPSS Gradpack version 25 to interpret the results and highlight any significant differences in self-efficacy between these groups. 


\section{CHAPTER IV: RESULTS}

The following chapter includes the results of this quasi-experimental study and post hoc statistical analysis of data collected. The purpose of this study was to examine the impact of three different approaches in suicide risk prevention on self-efficacy on health profession trainees. In this chapter, results of the quantitative analysis conducted includes analysis of (a) demographic information of the three groups that participated, (b) the self-efficacy pre-and post-aggregate scores, (c) the interaction between the three groups, and (d) the results of hypotheses testing are presented. Each research question will be highlighted and followed by an answer to the question, which includes a statistical analysis and summary for each. This information will provide inferential information about the population sampled, in this case, pre-health professions students, based on the data collected (Hinkle et al., 2003).

\section{Demographics of the Sample}

The following demographic information describes each of the groups that participated in the study. As discussed in Chapter 1, the study included health profession trainees in the following master's level programs: Master in Physician Assistant Studies, Master of Social Work, Master in Counselor Education (Clinical Mental Health Counseling Track), and Master in Professional Counseling Psychology students. This section will be further divided into subsections: all participants, VP group, VM group, and the lecture group of students. 
The following describes the demographics of all participants by race, ethnicity, training groups, work experience, academic program, as well as descriptive statistics (with means and standard deviations for all groups pre-and posttest).

Gender, race and ethnicity. The sample consisted of 111 participants; with most of them women $(n=89)$ and the remaining, men $(n=22)$ with seven missing cases. Table 1 displays the frequencies and percentages for race and ethnicity. Approximately $69 \%$ of the participants self-identified as White. The remaining participants across the sample identified as Black (10\%), Asian (6\%), native Hawaiian or Pacific Islander (2\%), and Other or unspecified (24\%). Additionally, in terms of ethnicity, $68 \%$ of participants identified as Hispanic/Latino and the remainder as non-Hispanic Latino (38.7 \%). These demographics are reflective of the population composition and diversity of FIU and the Miami metropolitan area where the school is located.

Table 1

Race, Ethnicity, Frequencies, and Percentages of the Sample

\begin{tabular}{lcc}
\hline Category & Frequency & Percentage \\
\hline White & 69 & 62.2 \\
Black & 10 & 9 \\
Asian & 6 & 5.4 \\
Native Hawaiian or Pacific & 2 & 1.8 \\
Islander & & \\
Other & 24 & 21.6 \\
Total & 111 & 100 \\
\hline & & \\
Hispanic/Latino & 68 & 61.3 \\
Non-Hispanic/ Latino & 38.7 & 38.7 \\
Total & 111 & 100 \\
\hline
\end{tabular}


Training groups. Table 2 displays the frequencies and percentages of the training groups. Approximately $37.8 \%$ of participants were in the lecture group and were students enrolled in the Master in Physician Assistant Studies program. The remaining training groups were the video module group (31.5\%), which was made up of students enrolled in the Master of Social Work program; and the virtual patient group (30.6\%), which was made up of students enrolled in the Master in Counseling Education: Clinical Mental Health Counseling and Master in Professional Counseling programs.

Table 2

Comparison Groups, Frequencies, and Percentages of the Sample

\begin{tabular}{lcc}
\hline Category & Frequency & Percentage \\
\hline Lecture & 42 & 37.8 \\
Video & 35 & 31.5 \\
Virtual & 34 & 30.6 \\
Total & 111 & 100 \\
\hline
\end{tabular}

Age. Table 3 displays the frequencies of the different age groups across the sample. Most of the participants were in the 25-35 years old (59.5\%) category; the remainder were $18-24(33.3 \%), 36-45(4.5 \%)$, and over $45(2.7 \%)$ categories. Over 50\% were in the 25- 35 age range, which is consistent with students nationally who are enrolled in master's level programs. However, this table highlights that a good portion of students (those in the 18-24 range) are younger. 
Table 3

Age, Frequencies, and Percentages of the Sample

\begin{tabular}{lcc}
\hline Age range in years & Frequency & Percentage \\
\hline $18-24$ & 37 & 33.3 \\
$25-35$ & 66 & 59.5 \\
$36-45$ & 5 & 4.5 \\
Over 45 & 3 & 2.7 \\
Total & 111 & 100 \\
\hline
\end{tabular}

Previous experience. Table 4 displays years of previous medical or mental health experience of the participants. Approximately, 50.5\% of participants had 1-3 years of previous experience in the medical or mental health field. The remainder of participants had no experience $(30.3 \%), 4-7$ years $(13.5 \%)$, $7-10$ years $(0.9 \%)$, and over 10 years $(1.8 \%)$. Therefore, more than $50 \%$ of the sample came in with some experience in the medical and mental health field with almost one in three having no experience at all. Previous experience is one of the covariates discussed later in this chapter as having a possible effect on the outcome of levels of self-efficacy at the posttest.

Table 4

Work Experience, Frequencies, and Percentages of the Sample

\begin{tabular}{lcc}
\hline Years of previous experience & Frequency & Percentage \\
\hline None & 37 & 33.3 \\
1-3 Years & 56 & 50.5 \\
4-7 Years & 15 & 13.5 \\
7-10 Years & 1 & 0.9 \\
Over 10 Years & 2 & 1.8 \\
Total & 111 & 100 \\
\hline
\end{tabular}

Academic program. Table 5 displays the frequencies and percentages of participants by academic program. Approximately $37.8 \%$ of participants were enrolled in the Physician Assistant program, the remainder were in the Social Work (32.4\%), 
Counselor Education (17.1\%), and Psychology (12.6\%) programs. The bulk of the sample were from the Physician Assistant (participated in the lecture group) and Social Work (participated in the video module) programs. Later in this chapter, academic program or major will be discussed in terms of any impact they might have on selfefficacy between pre-and posttest.

Table 5

Academic Program, Frequencies, and Percentages of the Sample

\begin{tabular}{lcc}
\hline Academic program & Frequency & Percentages \\
\hline Physician Assistant & 42 & 37.8 \\
Psychology & 14 & 12.6 \\
Social Work & 36 & 32.4 \\
Counselor Education & 19 & 17.1 \\
Total & 111 & 100 \\
\hline
\end{tabular}

Pre-post survey aggregate scores by group. Table 6 below presents a display of the pre-and post-survey aggregate scores with corresponding means and standard deviations for each of the training groups. At the pretest, the virtual group had the highest aggregate self-efficacy score $(M=28.97, S D=4.549)$ compared to the video group $(M=27.54, S D=4.598)$ and the lecture group $(M=26.64, S D=4.908)$. One can see from Table 6 below that the mean pretest score of the virtual group was higher than the other groups, which means the participants in this group had higher levels of self-efficacy than the other two groups before the training.

At the posttest, the participants in the lecture group had the highest post-survey self-efficacy aggregate score $(M=29.24, S D=4.908)$ when compared to those of the VM group ( $M=27.91, S D=5.833)$ and the VP group $(M=26.68, S D=5.209)$. According to the scores, the lecture group's aggregate scores from pretest to the posttest show an increase 
in self-efficacy after participation in the lecture. Similarly, but only slightly, the video group's aggregate self-efficacy scores also increased after their participation in the module. The only decrease from the pre-and post-aggregate score was from the virtual group. The virtual group participants' self-efficacy scores decreased after their VP simulation experience.

Table 6

Descriptive Statistics of Pre and Post Self-Efficacy Aggregate Scores

\begin{tabular}{llllr}
\hline Scores & $\begin{array}{l}\text { Training } \\
\text { Method }\end{array}$ & Mean & $S D$ & $N$ \\
\hline Pre-Survey Score & Lecture & 26.64 & 4.908 & 42 \\
& Video & 27.54 & 4.598 & 35 \\
& Virtual & 28.97 & 4.549 & 34 \\
& Total & 27.64 & 4.759 & 111 \\
\hline Post-Survey Score & Lecture & 29.24 & 4.101 & 42 \\
& Video & 27.91 & 5.833 & 35 \\
& Virtual & 26.68 & 5.209 & 34 \\
& Total & 28.4 & 5.104 & 111 \\
\hline
\end{tabular}

The total aggregate score of all three groups from pre-survey $(M=27.64$, $S D=4.759)$ increased to post-survey $(M=28.4, S D=5.104)$ after participation in the study. More detail and elaboration into the groups and variation of scores will be discussed later as each of the hypotheses are tested and research questions are answered.

\section{Hypotheses Testing}

The following section discusses each of the research questions and corresponding hypotheses presented in different subsections with the respective results. Each research question represents a different subsection and includes an explanation of the findings. For each of these quantitative research questions, analyses were conducted using SPSS Statistics 25 . For this study, there were three research questions (one of which had three 
sub-questions) and three hypotheses, which provided the framework of the following analyses.

\section{Research Question 1}

To answer the first research question, "To what extent are students interacting with a Virtual Patient different from those having a video simulation (of the same content) and those learning by traditional teaching methods in their self-efficacy in assessing suicidal risk between pre-and posttests?, a repeated measures ANOVA was conducted to answer this and its three corresponding sub-questions. Those sub-questions are: (a) to what extent are students' self-efficacy of three groups different across pre-and posttests, (b) to what extent are the students' self-efficacy different before and after they experience three teaching approaches; and, $(c)$ is there a significant interaction between three groups and two time points (i.e., pre-and posttest)? The results presented below provide detail by hypothesis.

Hypothesis 1. The hypothesis for RQ1, "There is a significant difference among three groups of students' self-efficacy between pre-and post-test," attempts to identify any differences between the three groups by analyzing the variance within and between subjects across pre-and posttest. For RQ1 (a) to what extent are students' self-efficacy of three groups different across the pre-and posttests, a repeated measures ANOVA was conducted to compare the effect of the three training methods (lecture, virtual, or video) on self-efficacy. 
RQ1(a). To find out if there are any self-efficacy differences between means of the three groups from pre-to posttest, Table 8 displays the within-subjects effects in the corresponding table.

Table 7

Hypothesis 1, ANOVA Table for Pre and Posttest

\begin{tabular}{|c|c|c|c|c|c|c|}
\hline Source & $S S$ & $d f$ & $\begin{array}{l}\text { Mean } \\
\text { Square }\end{array}$ & $F$ & Sig. & $\eta^{2}$ \\
\hline & & within su & & & & \\
\hline time & 2.765 & 1 & 2.765 & 0.32 & 0.57 & $<.001$ \\
\hline $\begin{array}{l}\text { time } * \\
\text { training }\end{array}$ & 224.61 & 2 & 112.30 & 13.21 & $<.001$ & 0.20 \\
\hline \multirow[t]{2}{*}{ error } & 917.67 & 108 & 8.50 & & & \\
\hline & & $\begin{array}{l}\text { between } \\
\text { subjects }\end{array}$ & & & & \\
\hline training & 1.735 & 2 & 0.867 & 0.02 & 0.978 & $<.001$ \\
\hline error & 4213.428 & 108 & 39.013 & & & \\
\hline
\end{tabular}

Note: $\mathrm{SS}=$ Sum of Squares, $\mathrm{DF}=$ degrees of freedom, Sig. =significance, $\eta_{2}=$ Partial eta squared. *. The mean difference is significant at the .05 level.

A repeated measures ANOVA was conducted (see above) using the factor of time or the two points, in this case from pre to posttest, and the dependent variable of selfefficacy. The results of this ANOVA indicated a non- significant effect, $F(1,108)=$ $0.32, p=0.57$, partial $\eta_{2}=0.00$. Therefore, based on these results, the answer to RQ1 (a) is that is no difference in students' self-efficacy across the three groups from pre- to posttest. Once more, here we are examining observations over time with the participants of 
the study. However, now the analysis will examine the groups by focusing on the between-subjects factors.

RQ1(b). For RQ1 (b), “To what extent are these students' self-efficacy different before and after they experience three teaching approaches, using the same repeatedmeasures ANOVA the researcher compared the effects of the three methods (lecture, video, and virtual) across the three groups. To find out if there were any differences between the group means after experiencing the training; Table 8 also displays the between-subjects effects.

This same repeated-measures ANOVA looked at the differences between group means before and after the training in relation to their self-efficacy. The results of this ANOVA indicated a non-significant effect, $F(2,108)=0.02, p=0.978, \eta_{2}=0.00$ between the groups. Therefore, based on these results, the answer to RQ1(b) is no difference between the groups before and after their experience. However, after these results, it is worth exploring the interaction between the groups and the time-points (pre-post).

RQ1(c). For RQ1 (c), "Is there a significant interaction between self-efficacy of the three groups and two time points (i.e., pre and posttest)?, a repeated measures ANOVA was conducted to answer the question. Table 8 displays the pairwise comparisons of the groups between the two time points as well as the difference between the means from pretest to posttest. Table 9 displays the pairwise comparisons of the two time points (pre and post) and the means differences of the training groups.

As previously discussed, Table 6, provides descriptive statistics of the mean scores from the pre-and posttests. At the pretest, the virtual group had the highest mean score $(M=28.97, S D=0.80)$ before the training followed by the video group $(M=27.54$, 
$S D=0.79)$ and the lecture (control) group $(M=26.64, S D=0.73)$. However, after the training, the mean scores across the groups highlight interesting findings. The group with the highest mean score after the training was the lecture group $(M=29.23, S D=0.77)$ followed by the video group $(M=27.91, S D=0.85)$ and the virtual group with the lowest mean score $(M=26.68, S D=0.86)$. Based on these results, at the posttest, the lecture group's mean score increased slightly, the video group had no increase, and the virtual group's mean score decreased.

Table 8

Hypothesis 1-Pairwise Comparison of Groups Pre to Posttest

\begin{tabular}{|c|c|c|c|c|c|c|}
\hline Training & (I) $(\mathrm{J})$ & $\begin{array}{c}\text { Mean } \\
\text { Difference } \\
(\mathrm{I}-\mathrm{J})\end{array}$ & $\begin{array}{l}\text { Std. } \\
\text { Error }\end{array}$ & Sig. & $\begin{array}{l}\text { Lower } \\
\text { Bound }\end{array}$ & Upper Bound \\
\hline Lecture & 12 & $-2.595 *$ & 0.636 & 0.000 & -3.856 & -1.334 \\
\hline Video & 12 & -0.371 & 0.697 & 0.595 & -1.753 & 1.010 \\
\hline Virtual & 12 & 2.294* & 0.707 & 0.002 & 0.893 & 3.695 \\
\hline
\end{tabular}

Note: I=Pretest, J=Posttest, Sig.=Significance, $\mathrm{CI}=$ Confidence Interval

$*$. The mean difference is significant at the .05 level.

A repeated measures ANOVA mixed design was conducted to see the interaction between the groups and time. The results of the pairwise comparisons are shown in Table 8. Six unique pairwise comparisons were conducted between the means for the lecture, video, and virtual groups. Two of the six pairwise comparisons were significant at the .05 level. The smallest $p$ value for the comparison of the pre-and post of the lecture group, and its $p$ value of $<.001$ is less than $\alpha=.05$ with a positive mean difference score of 2.59 is significant. In addition, the next smallest $p$ value for the comparison of the virtual group from pre-and post and its $p$ value of .002 is less than $\alpha=.05$ with a negative mean difference score of 2.29 was also significant. Based on these results, the lecture (control) 
group shows an increased self-efficacy score after participating in a traditional face-toface lecture. Conversely, the participants in the virtual group show a decrease in their self-efficacy score. The video group's scores were not statistically significant.

Table 9 Hypothesis 1-Pairwise Comparisons of Time*Training Methods

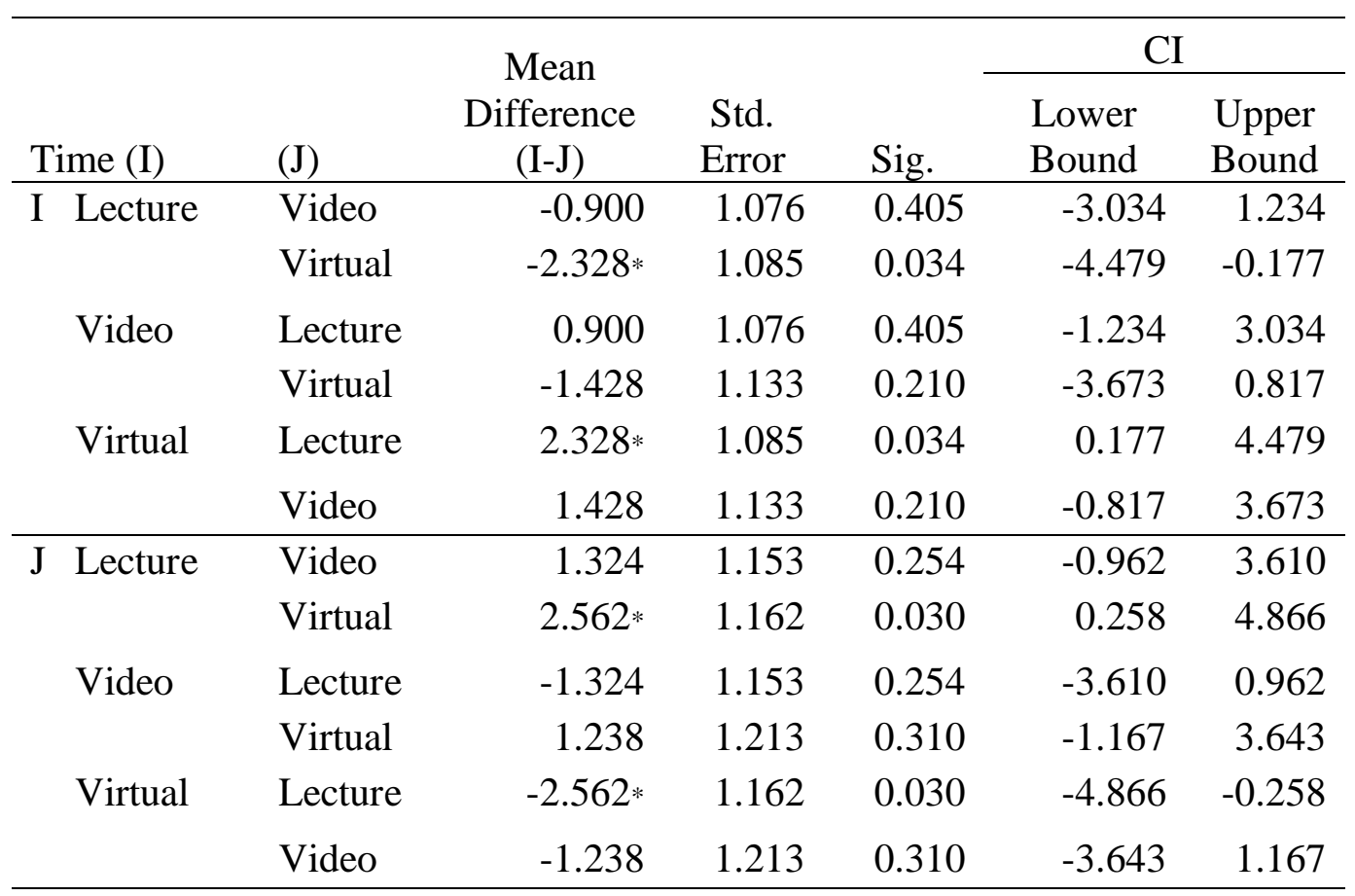

Note:* The mean difference is significant at the .05 level. Time 1 represents pretest and Time 2 represents the posttest.

The results of the pairwise comparisons above display the interaction between time and the training groups are shown in Table 9. Six pairwise comparisons were conducted to see the mean differences between the three groups. Two of the six pairwise comparisons were significant at the .05 level. The smallest $p$ value for the comparison of the lecture group and the virtual group at the posttest and its $p$ value of 0.03 is less than $\alpha=.05$ with the mean difference of 2.56 . The second smallest $p$ value, for the comparison of the lecture group and the virtual group at the pretest and its $p$ value of .034, is less than $\alpha=.05$ with the mean difference of -2.32 . 
Based on the results provided in Tables 8 and 9, there is a significant interaction between the lecture and virtual groups and the two time points, and the differences between their mean scores. The lecture group mean score significantly increased from pre-to posttest than the virtual group's mean score. Alternatively, the virtual group mean score decreased from pre-to posttest after participation in the simulation exercise.

Therefore, to answer $R Q 1$ and its corresponding sub-questions, $R Q 1$ (a) and (b) respectively, students' self-efficacy is not significantly different across pre-and posttest, or are they significantly different after the experience the different training methods (lecture, video, or virtual). However, when answering RQ1 (c), we do see a significance between the interaction and the differences in their mean scores between lecture (control) and the virtual groups, while the video group remained the same. With these results, we can conclude that there is no significant difference among the three groups of students' self-efficacy between pre-and posttest.

\section{Research Question 2 (RQ2)}

To answer the second research question, “After controlling students' academic program or major, to what extent are they different in their self-efficacy between pre-and posttest?", an analysis of covariance or ANCOVA was conducted to control for the effect of an academic program on students' self-efficacy on the results. The results presented below provide detail by hypothesis.

Hypothesis 2. The hypothesis for RQ2, “After controlling for students' academic program or major, there is a significant difference between the mean pre-and posttest self-efficacy of the three groups", attempts to identify any differences between the means 
of the three training methods after an analysis of covariance between and within subjects across pre-and posttests.

RQ2. To find out if there are any differences amongst individuals in the three groups from pre-to posttest, Table 10 displays the ANCOVA table with the betweensubjects effects and within-subjects effects presented below.

Table 10

Hypothesis 2 ANCOVA Table for Academic Program

\begin{tabular}{|c|c|c|c|c|c|c|}
\hline Source & $S S$ & $d f$ & $\begin{array}{l}\text { Mean } \\
\text { Square }\end{array}$ & $F$ & Sig. & $\eta 2$ \\
\hline & & within sl & & & & \\
\hline time & 0.006 & 1 & 0.006 & 0.001 & 0.980 & 0.00 \\
\hline $\begin{array}{l}\text { time } * \\
\text { program }\end{array}$ & 0.0095 & 1 & 0.095 & 0.010 & 0.921 & 0.00 \\
\hline \multirow[t]{2}{*}{ error } & 898.746 & 95 & 9.460 & & & \\
\hline & & $\begin{array}{l}\text { between } \\
\text { subjects }\end{array}$ & & & & \\
\hline $\begin{array}{l}\text { academic } \\
\text { program }\end{array}$ & 73.278 & 1 & 73.278 & 1.808 & 0.18 & 0.02 \\
\hline error & 3821.147 & 95 & 40.538 & & & \\
\hline
\end{tabular}

Note: $\mathrm{SS}=$ Sum of Squares, $d f=$ degrees of freedom, Sig.=Significance, $\eta_{2}=$ partial eta squared.

A repeated-measures, mixed design ANCOVA, we looked at within-subjects effects and the variation amongst the individuals in the groups. Table 10 displays the test of within-subjects effects, which indicated a non-significant effect, $F(1,95)=0.010, p=$ $0.921, \eta_{2}=0.00$ between time and academic program. Using the same analysis, the 
differences between group means before and after the different training methods was examined in relation to their self-efficacy after controlling for the academic program. This was done to see if covarying academic program would influence the results.

Table 10 displays the test of between-subjects effects, which indicated a nonsignificant effect, $F(1,95)=73.28, p=1.808, \eta_{2}=0.02$ between the training method and academic program. Therefore, based on these results, the answer to RQ2 is that there is no difference between the groups before and after their experience even after controlling for the academic program. Based on the results presented in Tables 10, academic program or major does not have a significant effect on the results. Therefore, we can conclude that there is no difference between the self-efficacy of the three groups after controlling for students' major or academic program.

\section{Research Question 3 (RQ3)}

To answer the third research question, "Is there a significant relationship between students' previous healthcare or mental illness experience and their self-efficacy in assessing suicidal risk", the researcher conducted a bivariate correlation analysis. This correlation analysis included one independent and two dependent variables. The independent variable used was previous healthcare or mental illness experience. The dependent variable was students' pre-aggregate and post-aggregate self-efficacy scores. The results presented below provide detail by hypothesis.

Hypothesis 3. After testing the hypothesis for RQ3, "There is a significant relationship between students' previous healthcare or mental illness experience and their self-efficacy in assessing suicidal risk", will determine the measure of the relationship, if 
any, between experience and levels of self-efficacy. It also seeks to identify if a significant relationship exists between previous experience and self-efficacy (at the presurvey and post-survey) in assessing suicidal risk.

RQ3. To determine the measure of the relationship between previous experience and levels of self-efficacy at the pretest and posttest, Table 11 displays the results of the bivariate correlation analysis between three variables. The three variables included the years of previous medical or mental health work experience, the pretest self-efficacy aggregate score, and the posttest self-efficacy aggregate score.

Table 11

Hypothesis 3-Correlations

\begin{tabular}{|c|c|c|c|c|}
\hline & & $\begin{array}{l}\text { Years of } \\
\text { previous } \\
\text { work } \\
\text { experience }\end{array}$ & $\begin{array}{l}\text { Post-Survey } \\
\text { Self- } \\
\text { Efficacy } \\
\text { Score } \\
\end{array}$ & $\begin{array}{c}\text { Pre-Survey Self-Efficacy } \\
\text { Score }\end{array}$ \\
\hline \multirow{3}{*}{$\begin{array}{l}\text { Years of } \\
\text { previous } \\
\text { work } \\
\text { experience }\end{array}$} & $\begin{array}{l}\text { Pearson } \\
\text { Correlation }\end{array}$ & 1 & $.199 *$ & $.219 *$ \\
\hline & $\begin{array}{l}\text { Sig. }(2- \\
\text { tailed })\end{array}$ & & 0.048 & 0.029 \\
\hline & $N$ & 99 & 99 & 99 \\
\hline
\end{tabular}

Note: *Correlation is significant at the 0.05 level (2-tailed).

Based on the results presented in Table 11, there was a significant correlation between years of previous experience and students pre-survey self-efficacy at $r=.219$, $p=0.03$. There was also a significant correlation between years of previous experience and students post-survey self-efficacy at $r=.199, p=0.05$. Therefore, based on these results, we can accept the alternative hypothesis and conclude there is a significant relationship between students' previous work or mental illness experience and their selfefficacy in assessing suicide. 


\section{Time on Task}

One final consideration that was also taken into account was the variable of time spent on task and whether this would influence the results. The participants across the different academic programs varied in terms of the length of time they spent from the pre-training survey to the post-training survey. Time on task in this study, as a variable, is the calculation of the time spent from the start of the pre-survey to the post-survey, not on the individual simulation or training method itself, but rather the total time from start to finish. Certain information was collected in both surveys, where participants had to enter their start and end time for their given training method or module. Additional questions arose, such as What is the relationship between time on task and improvement in scores from pretest to posttest for the virtual and video groups? Is there a correlation between time spent on task and differences in self-efficacy scores for the virtual patient group?; and finally, Is there a correlation between time spent watching the video module and improvement (posttest minus pretest) scores for confidence and self-efficacy?

To answer the first question, Is there a relationship between time on task and improvement in scores from the pretest of the posttest, for the virtual patient simulation group and the video group?, a bivariate correlation analysis was conducted to determine if there was a significant relationship between the variables. The variables for this analysis are the difference in self-efficacy aggregate scores from pre-and posttest, the post survey self-efficacy aggregate score, and the total minutes spent on task. Table 12 provides the results of the bivariate correlation analysis. 
Table 12

Correlations Table-Time on Task and Differences in Scores

\begin{tabular}{|c|c|c|c|c|}
\hline & & Total Minutes & SEDiff & $\begin{array}{l}\text { Post-Survey } \\
\text { Aggregate } \\
\text { Self-Efficacy } \\
\text { Score }\end{array}$ \\
\hline \multirow[t]{3}{*}{ Total Minutes } & $\begin{array}{l}\text { Pearson } \\
\text { Correlation }\end{array}$ & 1 & -.005 & -.126 \\
\hline & Sig. (2-tailed) & & .965 & .302 \\
\hline & $N$ & 69 & 69 & \\
\hline \multirow[t]{2}{*}{ SEDiff } & $\begin{array}{l}\text { Pearson } \\
\text { Correlation }\end{array}$ & -.005 & 1 & .618 \\
\hline & $\begin{array}{l}\text { Sig. (2-tailed) } \\
N\end{array}$ & $\begin{array}{l}.965 \\
34\end{array}$ & 34 & .000 \\
\hline \multirow{2}{*}{$\begin{array}{l}\text { Post-Survey } \\
\text { Aggregate } \\
\text { Self-Efficacy } \\
\text { Score }\end{array}$} & $\begin{array}{l}\text { Pearson } \\
\text { Correlation }\end{array}$ & -.126 & .618 & 1 \\
\hline & $\begin{array}{l}\text { Sig. (2-tailed) } \\
N\end{array}$ & $\begin{array}{l}.302 \\
69\end{array}$ & $\begin{array}{l}.000 \\
69\end{array}$ & 69 \\
\hline
\end{tabular}

Note: SEDiff is the post-score minus pre-score.

Based on the results of the bivariate correlation analysis presented in Table 12, there was no significant correlation, $r=.005, p=.965$, between self-efficacy in pretest and posttest (post-score minus pre-score or SEDiff in the table) for both the virtual simulation and video groups.

For the second question, "Is there a correlation between time on task interacting with the virtual patient group and improvement (posttest minus pretest scores) for selfefficacy?", another bivariate correlation analysis was conducted. The variables for this analysis are the difference between post and pre-survey scores (or SEDiff), and total minutes spent on task. Table 13 provide the results of this bivariate correlation analysis. 
Table 13

Correlations Table-Time on Task \& Difference in Scores for Virtual Patient Group

\begin{tabular}{llcc}
\hline \multirow{2}{*}{ SEDiff } & SEDiff & Total Minutes \\
& $\begin{array}{l}\text { Pearson } \\
\text { Correlation }\end{array}$ & 1 & .073 \\
& $\begin{array}{l}\text { Sig. (2-tailed) } \\
N\end{array}$ & 34 & .682 \\
& & & 34 \\
Total Minutes & $\begin{array}{l}\text { Pearson } \\
\text { Correlation }\end{array}$ & .073 & 1 \\
& Sig. (2-tailed) & .682 & \\
& $N$ & 34 & 34 \\
\hline
\end{tabular}

Note: SEDiff is the posttest-score minus the pretest score.

Based on the results of the correlation analysis provided in Table 13, there is no significant correlation, $r=.073, p=.682$, between the two variables for the virtual patient group.

For the third question, "Is there a correlation between time spent watching the video module and improvement (posttest minus pretest) scores for confidence and selfefficacy?":, a bivariate correlation analysis was conducted to see if there was a relationship between these variables. The variables are the difference between post and pre-survey scores (SEDiff in table provided) and total minutes spent on task for the video module group. Table 14 provides the results of this bivariate correlation analysis. 
Table 14

Correlations Table-Time on Task \& Difference in Scores for Video Patient Group

\begin{tabular}{llcc}
\hline & & SEDiff & $\begin{array}{l}\text { Total } \\
\text { Minutes }\end{array}$ \\
\hline SEDiff & $\begin{array}{l}\text { Pearson } \\
\text { Correlation }\end{array}$ & 1 & $-.439 *$ \\
& Sig. (2-tailed) & & .008 \\
& $N$ & 35 & 35 \\
Total & Pearson & $-.439 *$ & 1 \\
Minutes & Correlation & & \\
& Sig. (2-tailed) & .008 & \\
& $N$ & 35 & 35 \\
\hline Note $*$ Correlation is significant at the 0.05 level (2-tailed)
\end{tabular}

Note: *Correlation is significant at the 0.05 level (2-tailed).

SEDiff is post-survey minus pre-survey scores.

Based on the results of the bivariate correlation analysis, provided in Table 14, there is a significant correlation based on the coefficient, $r=-4.39, p=0.08$, suggesting a negative relationship. This indicates the longer time spent on the module, the less improvement in confidence and self-efficacy for the video module group.

\section{Summary}

This chapter presented the findings of this quasi-experimental study. The demographics of the sample were discussed along with the three initial research questions and their corresponding hypotheses. Also, upon further analysis, the likelihood of time on task (as a variable) for each of the training methods, as a possible influence on the results, was also presented with findings.

The first hypothesis was tested using a mixed design repeated measures ANOVA. The second hypothesis was tested using an ANCOVA controlling for the academic program as the covariate. Finally, the third hypothesis was tested using a bivariate 
correlation analysis to determine the relationship between previous work or mental illness experience and self-efficacy and confidence. Testing for the first and second hypothesis yielded no statistical significance. However, the results of testing the third hypothesis indicated a significant correlation to previous work or mental illness experience and selfefficacy. Finally, given the concern of the possible effect of time on task on self-efficacy, the results indicated a negative correlation between the difference of the post-surveyaggregate self-efficacy score and the pre-survey aggregate self-efficacy score for the VM group. The following chapter will provide a discussion of the results reported as well as suggest implications, limitations, and further recommendations for future research based on these findings. 


\section{CHAPTER V: DISCUSSION}

This chapter summarizes the study, provides a discussion of the findings, discusses implications of the findings related to the existing literature, identifies the study's limitations, and includes recommendations for future research. Lastly, this chapter closes with concluding remarks. The chapter is thus divided into five sections:

(a) the summary of the study, (b) discussion of findings, (c) implications, (d) limitations and (e) recommendations for future research.

\section{Summary}

As mentioned in the introduction of this study, suicide was the 10 th leading cause of death in the United States in 2015, and has steadily increased since 1999 (Centers for Disease Control and Prevention, 2016). Correspondingly, given the likelihood that students in pre-health professional programs, specifically in mental health disciplines, are likely to encounter patients or clients who are suicidal, the need for more training is necessary. Given these results, future therapists and counselors are bound to face this challenge where they practice, especially in community-based mental health services (Osteen et al., 2014). Thus, the need for more training becomes vital and necessary in prevention and intervention (Mirick, Bridger, McCauley, \& Berkowitz, 2016; Mirick, McCauley et al., 2016). Students must be prepared for these encounters and the need for more suicide assessment training embedded within pre-health curriculum should occur more often. Unfortunately, pre-health professional trainees will too often enter the workforce with an already overwhelmed health care system lacking resources in mental health care. 
The purpose of this quantitative study was to investigate and compared three different approaches to suicide risk prevention while measuring the impact to selfefficacy levels of master's degree students in four pre-health professional programs. These pre-health professional trainees were physician assistant students, psychology students (specializing in professional counseling psychology), school counselor students (clinical mental health counseling), and social work students. This study differs in its measurement of self-efficacy because the majority of the literature focuses on clinical, communication or disease specific scenarios. Instead, this study focused on mental health and measured the impact of VP as a supplemental training tool in suicidal risk assessment.

To measure the impact, specifically to self-efficacy, the researcher used a pretestposttest quasi-experimental design for the study. This involved two different training groups and lecture group all given a pretest and posttest survey, but in which the lecture group and the training groups do not have the same sampling equivalence (Campbell \& Stanley, 1967). Then the researcher used a survey instrument to collect data from the research subjects before and after the different training methods. The survey instrument was comprised of questions designed to collect demographic information in relation to age, experience, academic program, as well as self-efficacy scores. The survey was based on previously published surveys (Artino, DeZee et al., 2012; Foster, Robb et al., 2015).

A total of 117 students from the four programs were recruited to be participants for this study and completed an online informed consent form; however, 111 successfully completed pre-and posttest surveys via Qualtrics. Therefore, six potential participants 
either did not complete the survey or did not provide student number to match the preand post-surveys.

The content management system tool, LibGuides, was used to host both the preand post-surveys and a customized URL for each of the training methods. Hence, when the researcher visited the classrooms, each group had a link to their pre-survey, training module (if applicable), and the post survey. This made it easier to collect data and keep information organized when extrapolating information for the data set.

Working closely with program directors, after gaining permission from faculty, the researcher visited participants during their class time. Students were provided with a short synopsis of the study, an explanation of informed consent (including the risks and benefits of the study), as well as goals and objectives of the research. After a short 10minute introduction and completion of the informed consent form, students took a pretraining survey, participated in either a VP module, VM simulation or face to face lecture, then took a post-training survey. In all cases, the researcher remained in the room with the students from the time the students took the pretest survey until they completed the post-survey. Once this was completed, the researcher downloaded and compiled the data for analysis.

After the data were collected and organized, they was analyzed using SPSS Gradpack 25. To test the impact of these training methods on students' self-efficacy and confidence, a combination of a mixed design repeated measures ANOVA, ANCOVA, and bivariate correlation statistical techniques were utilized. The research questions that were answered as a result of this quasi-experimental study are: 
1. To what extent are students interacting with a virtual patient different from those having a video simulation (of the same content) and those learning by traditional teaching in their self-efficacy in assessing suicidal risk between pre-and posttest?

a. To what extent are students' self-efficacy of three groups different across preand posttests?

b. To what extent are these students' self-efficacy different before and after they experience three teaching approaches?

c. Is there a significant interaction between three groups and two time points (i.e., pre-post)?

2. After controlling students' major, to what extent are they different in their selfefficacy between pre-and post?

3. Is there a significant relationship between students' previous healthcare or mental illness experience and their self-efficacy in assessing suicidal risk?

\section{Discussion of Findings}

In this section, the main findings are broken down based on the results of the data analysis provided in Chapter 4. Based on the results of these statistical analyses, one can conclude that there is significant difference between the different training groups between two time points and their interaction. In addition, there is a relationship between students' previous healthcare or mental illness experience and their self-efficacy. The following subsections will summarize the results and provide a brief discussion of each research question. 


\section{Summary and Discussion for Research Question \#1}

To summarize this question, there are three subquestions to summarize in order. Therefore, there will be a summary and discussion for each of the subquestions $a, b$, and $c$.

Discussion for RQ1 (a). The results of the mixed design repeated measures ANOVA indicated no statistically significant difference for group mean self-efficacy scores between the different training groups (VP) or (VM) and the lecture group across pre-and posttests. The researcher found no significant variation within the groups, specifically examining the variation among all subjects within these groups. To do this, the researcher compared the aggregate self-efficacy score (or pre-survey self-efficacy aggregate score) before the training against the aggregate self-efficacy score (or postsurvey self-efficacy aggregate score) after each training.

These results of the ANOVA do not support the first hypothesis, which suggested that there would be a significant difference between the means of the three groups of students concerning their self-efficacy in assessing suicidal risk between pre-and posttest. This finding is inconsistent with Barnett et al.'s (2016) and Makransky et al.'s (2016) findings. In both of these studies, students' self-efficacy increased at posttest after the intervention. However, Barnett et al. dealt with medical genetics and Makransky et al. with drug therapy decision-making. In both cases, self-efficacy increased as well as did knowledge acquisition. 
Discussion for $R Q 1(b)$. The results of the mixed design repeated measures ANOVA indicated no statistically significant group mean difference before and after students experienced three teaching approaches. There was no difference between the groups before and after their experience whether VP, VM, or lecture. The analysis looked at the means between the groups across the two time points and found no significant variation.

The results of this ANOVA do not support the first hypothesis, which suggested that there would be a difference between the groups after experiencing three different teaching approaches. This finding is also inconsistent with similar studies from Barnett et al. (2016) and Makransky et al. (2016) wherein subjects' self-efficacy increased after the intervention. However, it is worth noting that these studies focused on the use of VP in other areas in the health sciences, not on mental health.

Discussion for RQ1(c). Once more, using the same mixed design repeated measure ANOVA, when the researcher considered the interaction of the three groups between the two points, and there was a statistically significant result. Table 8 first indicated this significant interaction between time and training methods in the analysis, which led the researcher to investigate further. Consequently, examining the comparisons of the three groups and their mean scores across two-time points led to interesting results, which then led to additional questions. These results were twofold: first, self-efficacy in assessing suicidal risk increased for the lecture group at the posttest, and second, self-efficacy in assessing suicidal risk decreased for the virtual patient group at posttest. Therefore, in this study, the traditional face to face lecture had a 
positive impact on self-efficacy and confidence; virtual simulation training negatively impacted self-efficacy from pre-to posttest.

\section{Summary and Discussion for Research Question \#2}

The results of the ANCOVA indicated no statistically significant difference between the three group means after controlling for students' academic program or major. The goal here was to analyze if academic program had a confounding effect on the results. However, academic program or major had no influence on the results after the researcher controlled for this variable. Given the differences of each program, as well as differences in training, practicum, internship, or face to face exposure, there was the possibility that this might affect the outcome. This became a consideration given that all subjects in these programs had different amounts of exposure to clients or patients, again depending on what point they were in their in their individual set of courses.

The results of the ANCOVA do not support the second hypothesis, which suggested that there would be a difference between the three group means after controlling for the academic program. This came from the belief that these academic programs would have varying levels of exposure or familiarity with the clinical scenario or subject matter with regards to suicide risk. Moreover, depending on the curriculum, each program or course was taken and how much of this material is covered can vary. Study findings do not support previous research (Bandura, 1977a, 1997; Bandura \& Adams, 1977) concerning observational learning and modeling. Course professors are models of desired behavior, thereby, individuals form ideas of how to respond based on 
what is observed. In this study, there was no way to find out how much of this material is covered in each program's curriculum.

\section{Summary and Discussion for Research Question \#3}

The results of the bivariate correlation analysis indicated a statistically significant correlation between previous healthcare or mental illness experience and self-efficacy assessing suicidal risk. The bivariate correlation analysis included three variables: previous healthcare or mental illness experience, the aggregate pre-survey self-efficacy score, and the aggregate post-survey self-efficacy score. The more healthcare or mental illness experience, the greater the self-efficacy assessing suicidal risk reported by students.

Based on these results, the researcher accepted the third hypothesis, which suggested that there is a significant relationship between students' previous healthcare or mental illness experience and their self-efficacy in assessing suicide. This finding is consistent with much of the literature (Bandura, 1977a, 1997; Reddan, 2016; Tan \& Chou, 2018). The more exposure one has to this scenario the more likely that that individuals will feel competent to perform tasks or attain certain goals within the work environment, especially handling difficult situations (Tan \& Chou, 2018). 
To provide a closer look into the amount of direct experience the participants received in their programs, Table 15 provides a breakdown.

Table 15

Hours (Direct or Indirect) of Training Received

\begin{tabular}{lcc}
\hline Hours & Frequency & Percent \\
\hline None & 17 & 15.3 \\
$1-100$ hours & 37 & 33.3 \\
100-500 hours & 29 & 26.1 \\
500 hours or more & 28 & 25.2 \\
Total & 111 & 100 \\
\hline
\end{tabular}

The majority of the participants received 1-100 hours (33.3\%), then second 100-500 hours $(26.1 \%)$, followed by third 500 hours or more $(25.2 \%)$ of training. Only 17 out of the 111 participants had no training yet. Furthermore, according to Table 5, participants (by percentage) had 1-3 (50.5\%), 4-7 (13.5\%), 7-10 (0.9\%), and over 10 years $(1.8 \%)$ years of previous work or mental illness experience. Clearly, most participants had previous experience in the field.

\section{Summary and Discussion of Time Spent on Task}

Based on the results of the hypothesis testing, additional questions arose regarding time spent on task as possibly influencing the results of the study. These questions were related to the relationship between time on task and improvement in scores from pretest to posttest for the virtual and video groups. Time spent on task means the amount of time spent from the start of the pre-training survey to the completion of the post-training survey. To analyze this, the researcher compared the difference between the group mean posttest self-efficacy score and the group mean pretest self-efficacy score of both the VP and the VM groups. In other words, the researcher wanted to see if there was a 
relationship between time spent from the start of the pre-training survey to the completion of the post-training survey and any changes in self-efficacy from pre-to posttest.

The results of the bivariate correlation analysis conducted indicated no significant relationship between the difference between post and pre-aggregate scores for VP or VM groups. Therefore, one can conclude that the time spent on task is not related to selfefficacy and confidence for these two groups in this study.

\section{Summary and Discussion of Social Learning Theory}

As part of the theoretical framework in this quasi-experimental study, social learning theory was explored. As previously explained, social learning theory looks at observational learning and the acquisition of skills and learning that are based on a student's social environment (Schunk, 2012). Based on their observations, students will acquire skills and learn from their instructors as well as from other students. Learning occurs at home, at work, and in social settings. Bandura (1997) and other researchers examined the social environment where students learned and other personal factors that affect learning. Given the broadness of social learning theory, this study focuses on Bandura's work regarding self-efficacy and confidence. Self-efficacy focuses on one's belief about one's capacity to learn or to perform actions at designated levels (Schunk, 2012).

The literature suggested that social learning theory and Bandura's (Bandura, 1977a, 1977b, 1997; Bandura \& Adams, 1977) work on self-efficacy could offer a predictor of performance in completing a task. Specifically, the task of participating in a VP simulation of a clinical scenario involving mental health. Moreover, the theory posits 
that by exposing students to a VP environment complemented by traditional lectures, followed by deliberate practice, confidence and motivation can positively influence behaviors. However, the results of the study did not indicate an increase in self-efficacy and confidence for the VP group.

\section{Implications}

In this section, implications are extrapolated from the results of the self-reported responses in this quasi-experimental study. The main aim of this study was to determine if VP simulation is a viable training tool to increase self-efficacy assessing suicidal risk and confidence as compared to two other teaching methods dealing with a suicidal risk scenario. Accordingly, the hope is that this study contributes to the paucity of present research on the use of VP simulation in training mental health professionals. Based on the results, this section will address how VP simulation impacts self-efficacy, the impact of traditional teaching methods versus VP simulation, time on task, and the role of experience in one's self-efficacy.

\section{Impact of VP on Self-Efficacy}

The pre-test aggregate self-efficacy score, compared to the VM and lecture group, the VP group had the highest score $(M=28.97, S D=4.549)$. The VP group ended lower at posttest $(M=26.68, S D=5.209)$. The students assigned to this group were in the master's in psychology and in the counselor education programs. The findings of this study while indicating a negative impact on self-efficacy, still inspires questions of how effective VP might be as a training tool. It is worth noting that Foster, Chaudhary et al. (2015) had lower mean scores for their participants in VP compared to the VM group when it came to satisfaction using the tool. 
Virtual patient participants in that study indicated to the researcher they "enjoyed" using the VP as well as finding the transcripts and instructor feedback generated at the end useful. Some indicated also that when presented with the instructor feedback portion of the VP simulation they felt that they were missing some crucial information to elicit from the virtual patient, Denise (Foster, Chaudhary et al., 2015). Participants expressed enjoyment at finding "discoveries" or symptoms (using the DSM IV for criteria) as they progressed with the VP; however, at the end when presented with the feedback they missed one or more the symptoms. This potentially could have had an effect on their self-efficacy score. Unfortunately, the posttest survey in the present study did not include a question or field for open text to provide more detail about students' satisfaction using the VP simulation.

\section{Enjoyment}

Based on the interaction of participants with the researcher in the present study, it is worth exploring the relationship between participation in a VP simulation and enjoyment. Even though, the mean of the group's self-efficacy did not increase after the VP training, maybe task-specific enjoyment did. In addition to Foster, Chaudhary et al., 2015, other studies have examined the role of student enjoyment, interests, as well as self-efficacy in relation to teaching methods (Alenezi, Karim, \& Veloo, 2010; Artino, 2010; Jin, 2011; Lumby, 2011; Mitchell, Chen, \& Macredie, 2005; Putwain, Sander, \& Larkin, 2013; Redmond, 2012; Schukajlow et al., 2012; Svirko \& Mellanby, 2017). This variable is worth exploring in future research. 


\section{Traditional Pedagogical Methods vs. VP Simulation}

In this study, another finding after comparing the post survey self-efficacy aggregate score of the training groups, concerned the mean score of the lecture group. The lecture group consisted of participants who participated in a traditional face to face lecture involving suicide risk and assessment. This group consisted of master's in physician assistant studies students who receive this lecture as part of their curriculum in a course titled "Human Behavior" or by course ID, PAS 6005 (Florida International University-Communications, 2019).

At the pretest, the lecture group $(M=26.64, S D=4.908)$ had the lowest aggregate score compared to the other groups; however, at posttest their aggregate score increased $(M=29.24, S D=4.908)$. In this case, the traditional face to face lecture had a positive impact on self-efficacy. However, the VP group had a negative impact after experiencing the training module. This finding indicates that traditional pedagogical methods provide a strong basis for increase self-efficacy. It also is consistent with Bandura (Bandura, 1977a, 1977b, 1995, 1997) when discussing observational learning and modeling behavior. However, the participants of this 90-minute lecture experienced over an hour of material specific suicide and suicide risk assessment. This length of time inspired questions as to whether time on task is a factor worth considering concerning its impact on self-efficacy of the participants.

Given these results, it is worth exploring combining traditional face to face lectures with either the VP or VM to reinforce materials covered in class. The combination of these pedagogical methods could produce a positive impact on selfefficacy. 


\section{Time Spent on Task}

The amount of total time on task was calculated by adding the minutes spent based on a text field provided, where participants indicated the current time (e.g., $12: 35 \mathrm{pm}$ ) in both the pre-and post-surveys. This means that total time spent on task was measured as the total amount from start of the pre-test survey to the time indicated at the end of the posttest survey. Based on the results, time spent on task has no significant effect on self-efficacy for both the VP and video group, which was reported in Chapter 4. Remarkably, based on the results of a bivariate correlation analysis, comparing the score difference between pre-and post for the video group, the longer time spent on task, the less improvement and self-efficacy. The researcher concluded that time on task did not influence improvement of self-efficacy for the virtual and video groups.

\section{Role of Previous Experience}

Based on the findings of this quasi-experimental study, it can be inferred that previous healthcare or mental illness experience does have an impact on self-efficacy and confidence. Again, referring to observational learning and modeled behaviors, learning occurs on both an individual and group basis (Bandura, 1977a, 1977b, 1997; Bandura \& Adams, 1977). Previous work experience and familiarity with mental illness does provide opportunities to observe modeled behavior. It is likely that the more experience people have, the higher their self-efficacy. The findings of this research along with the previous literature are consistent with this outcome. 


\section{Limitations}

\section{Survey Instrument Validation}

The main goal of this quasi-experimental study was to test the effect of VP simulation on self-efficacy using a common scenario encountered in a mental health setting. One primary limitation is the use of a combination of survey instruments into one study. The researcher was able to validate both the pre- and post-survey questions using cognitive interviews over the course of two semesters (Beatty \& Willis, 2007). While effective, cognitive interviews are qualitative in nature, and though they can indicate if a problem with a question exists, they cannot provide quantitative information on the extent or size on survey estimates (Collins, 2003). More validation and testing of the version of this survey instrument used for this study are necessary.

\section{Generalizability}

A major limitation of this study is that only FIU students participated. The findings of research are only generalizable to FIU students enrolled in these master's level pre-health profession programs. The sample was composed of a limited number of students in mental health counseling, psychology, physician assistant studies, and social work programs that cannot be generalized to other similar programs. Furthermore, the

original survey instruments in the Foster, Chaudhary et al. (2015) study were designed for medical type of interviews. Aside from the physician assistants, the rest of the sampled students for this study did not have medical training. For future research, a 
more robust study would include students from similar programs across the South Florida area to increase generalizability and statistical power.

\section{Convenience Sampling}

As reported in Chapter 3, convenience sampling is a type of nonprobability or nonrandom sampling, where members of the target population are easily accessible and willing to participate (Farrokhi \& Mahmoudi-Hamidabad, 2012). Convenience sampling remains as one of the most affordable and easy way to obtain participants for research; however, it does have some disadvantages. One disadvantage that exists is the possibility of bias and the fact that the sample may not be representative of the population. The participants of this research study may not be representative of pre-health professionals or of other students in similar programs at other institutions. In addition, this is also a matter of convenience due to the nature of the curriculum in these programs, where suicide or suicidal ideation is a topic covered in courses. Participants for this study were recruited through program directors and faculty members at FIU and expanding this research to other universities in South Florida would be a good next step for this research.

\section{Lack of Randomization}

One major limitation of this study is the lack of randomization of subjects, which is one of the disadvantages of a quasi-experimental study design. The participants were part of groups assigned by class in their individual programs and were not selected randomly. In addition, the sample size was small compared to the number of students enrolled in pre-health professional programs at FIU. 


\section{Time Constraints}

Data collection occurred over a period of an academic semester (approximately over three months). The researcher had a limited window of time to visit classrooms and recruit participants during certain times of the week and semester. Faculty members in the four programs all agreed to help the researcher but participants were only allowed by faculty members to provide time on certain weeks when classes would meet. In most cases, students would attend class every other week due to internship or practicum requirements of their program. Therefore, the researcher had to meet on the days that they would report to their course director, usually in courses scheduled during the evenings. At other times, the researcher was granted permission to visit the classrooms during regularly scheduled lectures during the day and conduct the research during class time.

Yet another consideration is the use of self-efficacy to measure proficiency in a patient interview. One question that might arise is self-efficacy good enough to assess proficiency in an interview? Lack of "objective" assessment of efficacy in a real interview could also be a limitation.

\section{Recommendations for Future Research}

A recommendation to build upon this and Foster, Chaudhary et al. (2015) is to conduct a mixed methods study to interview students (i.e. focus groups) following up on the results of the quantitative findings. The study could include following a cohort of students from different pre-health programs through their academic program.

Such information could be used to enhance VP simulation as part of curricula combined with traditional face to face lectures. Students, educators, and other 
stakeholders could benefit from the research using VPs in self-directed learning assignments to other platforms such as virtual reality, which has become more portable and advanced in the last 20 years. It is not out of the realm of possibility that VPs could evolve to avatars viewed on a set of goggles utilizing virtual reality instead of a computer screen for patient encounters.

\section{Follow-up and Mixed Methods Design}

This study was conducted during one academic semester with master's degree level pre-health professional students at a given time. Additional follow-up interviews to determine what participants liked or disliked about the individual simulation exercises or process could have enriched findings and provide a greater level of detail. Therefore, a mixed methods study design is ideal to bring about or expand the findings of this quantitative study. A convergent mixed methods design, is where the researcher begins by collecting quantitative data, interpret the results, then proceeds to follow-up by using qualitative data analysis to be compared or combined with the quantitative data (Creswell \& Plano Clark, 2018). For example, when members of the VP group completed the simulation they expressed enjoyment verbally working with the program but felt they missed out on certain questions or information to ask the VP. This was all based on the instructor feedback portion at the end of the module. While this outcome affected their self-efficacy negatively, they learned about what questions they should ask in the event of a patient presenting as a suicide risk.

The online survey instrument used for this study did not include an open-ended question field. By having some open-ended questions on the survey instrument, the 
possibility of obtaining more information about the experience and how to enhance the VP experience could have provided additional insight. This includes the research to collecting some qualitative data, such as conducting focus groups or interview sessions with participants. In addition, a tutorial can be created to familiarize non-medical trainees on how to interact with VPs.

\section{Conclusion}

First, this quasi-experimental study was conducted to investigate the use of a VP simulation using a mental health scenario to measure self-efficacy of master's degree level mental health profession trainees. This study provides a beginning into understanding the impact of VM simulation on self-efficacy in suicide assessment. In this study, the researcher determined that VM simulation did not have a statistically significant effect on self-efficacy. However, based on verbal feedback from participants, learning was achieved during the research process. As indicated above, this feedback is worth exploring for future research.

Second, was the interaction of the groups from pre-and post, there was a statistically significant difference in the levels of self-efficacy for the VP and lecture groups. The VP group's self-efficacy decreased from pre-to post-test and the control (lecture) group's self-efficacy increased from pre-to posttest. Again, as indicated above, this finding is worth exploring in future research.

Third, this study looked at the possible impact of academic program or major might have on self-efficacy and performance. It was suggested by faculty members in these programs that given the different amount of clinical training received in each of these programs as possibly influencing the results. However, the results of the ANCOVA 
show that there were no statistically significant differences between the groups when controlling for academic major or program.

Fourth, this quasi-experimental study also looked at the relationship between previous work or mental illness experience and levels of self-efficacy. The results of the bivariate correlation analysis showed that there was a statistically significant relationship between previous experience and self-efficacy of the participants. In this study, the more previous healthcare or mental illness experience people have, the higher their selfefficacy in assessing suicide risk.

VP simulation and its use in mental health education could benefit from more studies like this to expand training programs in suicide prevention. VP simulation and training are also beneficial for seasoned mental health professionals. This technology can be used to develop training programs to build resiliency while reducing stress when encountering this scenario. It is the hope of this researcher that this and future related studies can expand on existing training in suicide risk assessment and increase prevention efforts. 


\section{REFERENCES}

Acharya, A. S., Prakash, A., Saxena, P., \& Nigam, A. (2013). Sampling: Why and how of it? Indian Journal of Medical Specialities, 4(2), 330-333.

doi:10.7713/ijms.2013.0032

Albright, G., Adam, C., Serri, D., Bleeker, S., \& Goldman, R. (2016). Harnessing the power of conversations with virtual humans to change health behaviors. mHealth, 2 , 44. doi:10.21037/mhealth.2016.11.02

Alenezi, A. R., Karim, A. M. A., \& Veloo, A. (2010). An empirical investigation into the role of enjoyment, computer anxiety, computer self-efficacy and internet experience in influencing the students' intention to use E-learning: A case study from Saudi Arabian governmental universities. Turkish Online Journal of Educational Technology - TOJET, 9(4), 22-34. Retrieved from http://ezproxy.fiu.edu/login?url=https://search.proquest.com/docview/851231267?ac countid=10901

Allied health. (2015). The American heritage dictionary of medicine ( 2 nd ed.). Boston, MA: Houghton Mifflin. Retrieved from http://ezproxy.fiu.edu/login?url=http://search.credoreference.com.ezproxy.fiu.edu/co ntent/entry/hmmedicaldict/allied_health/0

Amini, H., Shakiba, A., Sharifi, V., Shirazi, M., Sadeghi, M., Abolhasani, F., \& Hajebi, A. (2016). Evaluation of the performance of general practitioners in a collaborative care program by employing simulated patients. Social Psychiatry and Psychiatric Epidemiology, 51(9), 1311-1319. doi:10.1007/s00127-016-1226-3

Artino, A. R., Jr., DeZee, K. J., Waechter, D. M., Cruess, D. F., Durning, S. J., Dong, T., \& Gilliland, W. R. (2012). Medical skills self-efficacy survey. doi:10.1037/t36006000

Artino, A.R., Jr., Dong, T., DeZee, K. J., Gilliland, W. R., Waechter, D. M., Cruess, D. F., \& Durning, S. J. (2012). Development and initial validation of a survey to assess students' self-efficacy in medical school. Military Medicine, 177(9 Suppl), 31-37. doi:10.7205/MILMED-D-12-00240

Artino, A. R., Jr. (2010). Online or face-to-face learning? Exploring the personal factors that predict students' choice of instructional format. The Internet and Higher Education, 13(4), 272-276. doi://dx.doi.org/10.1016/j.iheduc.2010.07.005

Badash, I., Burtt, K., Solorzano, C. A., \& Carey, J. N. (2016). Innovations in surgery simulation: A review of past, current and future techniques. Annals of Translational Medicine, 4(23), 453. 
Bandura, A. (1977a). Self-efficacy: Toward a unifying theory of behavioral change. Psychological Review, 84(2), 191-215.

Bandura, A. (1977b). Social learning theory. Englewood Cliffs, N.J: Prentice Hall.

Bandura, A. (1995). Self-efficacy in changing societies. Cambridge: Cambridge University Press. Retrieved from http://lib.myilibrary.com?ID=589073

Bandura, A. (1997). Self-efficacy: The exercise of control. New York, NY: W.H. Freeman.

Bandura, A., \& Adams, N. E. (1977). Analysis of self-efficacy theory of behavioral change. Cognitive Therapy and Research, 1(4), 287-310.

Barnett, S. G., Gallimore, C. E., Pitterle, M., \& Morrill, J. (2016). Impact of a paper vs virtual simulated patient case on student-perceived confidence and engagement. American Journal of Pharmaceutical Education, 80(1), 16. doi:10.5688/ajpe80116

Bauman, E. B. (2013). Game-based teaching and simulation in nursing and healthcare. New York, NY: Springer.

Beatty, P. C., \& Willis, G. B. (2007). Research synthesis: The practice of cognitive interviewing. Public Opinion Quarterly, 71(2), 287-311. doi:10.1093/poq/nfm006

Bediang, G., Raetzo, M. A., \& Geissbuhler, A. (2012). Virtual patient simulation: A comparison of two approaches for capacity building in Sub-Saharan Africa. Studies in Health Technology and Informatics, 180, 978-82. Retrieved from http://www.ncbi.nlm.nih.gov/pubmed/22874339

Belkin, G. S. (1981). Practical counseling in the schools (2nd ed.). Dubuque, IA: William C. Brown.

Berman, N. B., Durning, S. J., Fischer, M. R., Huwendiek, S., \& Triola, M. M. (2016). The role for virtual patients in the future of medical education. Academic Medicine, 91(9), 1217-1222.

Botezatu, M., Hult, H., \& Fors, U. G. (2010). Virtual patient simulation: What do students make of it? A focus group study. BMC Medical Education, 10, 91. doi:10.1186/1472-6920-10-91

Botezatu, M., Hult, H., Tessma, M. K., \& Fors, U. G. H. (2010a). As time goes by: Stakeholder opinions on the implementation and use of a virtual patient simulation system. Medical Teacher, 32(11), e509-e516. Retrieved from http://kipublications.ki.se/Default.aspx?queryparsed=id:121529230 
Botezatu, M., Hult, H., Tessma, M. K., \& Fors, U. (2010b). Virtual patient simulation: Knowledge gain or knowledge loss? Medical Teacher, 32(7), 562-568. doi:10.3109/01421590903514630

Botezatu, M., Hult, H., Tessma, M. K., \& Fors, U. G. H. (2010c). Virtual patient simulation for learning and assessment: Superior results in comparison with regular course exams. Medical Teacher, 32(10), 845-850. doi:10.3109/01421591003695287

Bowling, A. (2005). Mode of questionnaire administration can have serious effects on data quality. Journal of Public Health, 27(3), 281-291.

Braskamp, L. A., \& Ory, J. C. (1994). Assessing faculty work: Enhancing individual and institutional performance. San Francisco, CA: Jossey-Bass, Inc.

Brown, H. N. (1987). The impact of suicide on therapists in training. Comprehensive Psychiatry, 28(2), 101-112.

Campbell, D. T., \& Stanley, J. C. (1967). Experimental and quasi-experimental designs for research (2nd ed.). Chicago, IL: Rand McNally.

Castelli Dransart, D. A., Heeb, J.-L., Gulfi, A., \& Gutjahr, E. M. (2015). Stress reactions after a patient suicide and their relations to the profile of mental health professionals. BMC Psychiatry, 15, 265.

Centers for Disease Control and Prevention. (2016). Suicide is a leading cause of death in the United States. Retrieved from https://www.nimh.nih.gov/health/statistics/suicide.shtml

Cohen, J. (1988). Statistical power analysis for the behavioral sciences (2nd ed.). Hillsdale, N.J.: L. Erlbaum Associates. Retrieved from http://ezproxy.fiu.edu/login?url=http://search.ebscohost.com/login.aspx?direct=true $\& \mathrm{db}=$ cat06026a $\& \mathrm{AN}=$ fiu. $022385953 \&$ site $=$ eds-live

Collins, D. (2003). Pretesting survey instruments: An overview of cognitive methods. Quality of Life Research, 12(3), 229-238.

Cook, D. A., Erwin, P. J., \& Triola, M. M. (2010). Computerized virtual patients in health professions education: A systematic review and meta-analysis. Academic Medicine, 85(10), 1589-1602.

Creswell, J. W., \& Plano Clark, V. L. (2018). Designing and conducting mixed methods research (3rd ed.). Thousand Oaks, CA: Sage. 
De Leeuw, E. D. (2005). To mix or not to mix data collection modes in surveys. Journal of Official Statistics, 21(5), 233-255. Retrieved from https://www.narcis.nl/publication/RecordID/oai:dspace.library.uu.nl:1874\%2F20257 7

Deladisma, A. M., Cohen, M., Stevens, A., Wagner, P., Lok, B., Bernard, T.,...Lind, S. (2007). Do medical students respond empathetically to a virtual patient? The American Journal of Surgery, 193(6), 756-760. doi:10.1016/j.amjsurg.2007.01.021

Department of Psychology. (2017). Master of science in psychology. Retrieved from http://psychology.fiu.edu/graduate-programs/masters-programs/

Doel, M. (2012). Social work: The basics. New York, NY: Routledge.

Duberstein, P. R., Chapman, B. P., Epstein, R. M., McCollumn, K. R., \& Kravitz, R. L. (2008). Physician personality characteristics and inquiry about mood symptoms in primary care. Journal of General Internal Medicine, 23(11), 1791-1795. doi:10.1007/s11606-008-0780-0

Dubovsky, S., Antonius, D., Ellis, D., Ceusters, W., Sugarman, R., Roberts, R., . . Braen, G. (2017). A preliminary study of a novel emergency department nursing triage simulation for research applications. BMC Research Notes, 10, 1-12.

DxR Development Group. (2017). DxR clinician. Retrieved from https://dxrgroup.com/products/clinician/

Fallucco, E. M., Hanson, M. D., \& Glowinski, A. L. (2010). Teaching pediatric residents to assess adolescent suicide risk with a standardized patient module. Pediatrics, 125(5), 953-959. doi:10.1542/peds.2009-2135

Farberow, N. L. (2005). The mental health professional as suicide survivor. Clinical Neuropsychiatry, 2(1), 13-20.

Farrokhi, F., \& Mahmoudi-Hamidabad, A. (2012). Rethinking convenience sampling: Defining quality criteria. Theory and Practice in Language Studies, 2(4), 784-792. doi:10.4304/tpls.2.4.784-792

Faul, F., Erdfelder, E., Buchner, A., \& Lang, A.-G. (2009). Statistical power analyses using G*Power 3.1: Tests for correlation and regression analyses. Behavior Research Methods, 41(4), 1149-1160. doi:10.3758/BRM.41.4.1149

Faul, F., Erdfelder, E., Lang, A.-G., \& Buchner, A. (2007). G*Power 3: A flexible statistical power analysis program for the social, behavioral, and biomedical sciences. Behavior Research Methods, 39(2), 175-191. doi:10.3758/BF03193146 
Feldman, M. D., Franks, P., Duberstein, P. R., Vannoy, S., Epstein, R., \& Kravitz, R. L. (2007). Let's not talk about it: Suicide inquiry in primary care. Annals of Family Medicine, 5(5), 412-418. doi:10.1370/afm.719

Fleming, M., Olsen, D., Stathes, H., Boteler, L., Grossberg, P., Pfeifer, J.,...Skochelak, S. (2009). Virtual reality skills training for health care professionals in alcohol screening and brief intervention. Journal of the American Board of Family Medicine, 22(4), 387-398. doi:10.3122/jabfm.2009.04.080208

Florida International University-Communications. (2019). Curriculum. Retrieved from https://medicine.fiu.edu/academics/degrees-and-programs/master-in-physicianstudies/curriculum/

Foster, A., Chaudhary, N., Kim, T., Waller, J., Wong, J., Borish, M.,..., Buckley, P. F. (2016). Using virtual patients to teach empathy: A randomized controlled study to enhance medical students' empathic communication. Simulation in Healthcare: The Journal of the Society for Simulation in Healthcare, 11(3), 181-189.

Foster, A., Chaudhary, N., Murphy, J., Lok, B., Waller, J., \& Buckley, P. F. (2015). The use of simulation to teach suicide risk assessment to health profession trainees Rationale, methodology, and a proof of concept demonstration with a virtual patient. Academic Psychiatry, 39(6), 620-629. doi:10.1007/s40596-014-0185-9

Foster, A., Robb, A., Cordar, A., Chaudhary, N., Noseworthy, D., \& Lok, B. (2015). Denise: A virtual patient. MedEdPORTAL Publications, 11, 10145. doi:10.15766/mep_2374-8265.10145

Foster, V. A., \& McAdams, C. R. (1999). The impact of client suicide in counselor training: Implications for counselor education and supervision. Counselor Education and Supervision, 39(1), 22-33.

Gallo, L. L. (2017). Professional issues in school counseling and suicide prevention. Journal of School Counseling, 15(11), 1-27.

Gallo, L. L. (2018). The relationship between high school counselors' self-efficacy and conducting suicide risk assessments. Journal of Child and Adolescent Counseling, 4(3), 209-225.

Giordano, C., Arenson, C., Lyons, K. J., Collins, L., Umland, E., Smith, K., . . Rose, M. (2013). Effect of the health mentors program on student attitudes toward team care. Journal of Allied Health, 42(2), 120-124.

Groves, R. M., Fowler, F. J., Couper, M. P., Lepkowski, J. M., Simnger, E., \& Tourangeau, R. (2009). Survey methodology (2nd ed.). Hoboken, NJ: John Wiley \& Sons. 
Guise, V., Chambers, M., \& Valimaki, M. (2012). What can virtual patient simulation offer mental health nursing education? Journal of Psychiatric and Mental Health Nursing, 19(5), 410-418. doi:10.1111/j.1365-2850.2011.01797.x

Gulfi, A., Castelli Dransart, D. A., Heeb, J.-L., \& Gutjahr, E. (2010). The impact of patient suicide on the professional reactions and practices of mental health caregivers and social workers. Crisis, 31(4), 202-210. doi:10.1027/0027$5910 / \mathrm{a} 000027$

Hanson, M.D., Johnson, S., Niec, A., Pietrantonio, A. M., High, B., MacMillan, H., \& Eva, K. W. (2008). Does mental illness stigma contribute to adolescent standardized patients' discomfort with simulations of mental illness and adverse psychosocial experiences? Academic Psychiatry, 32(2), 98-103. doi:10.1176/appi.ap.32.2.98

Hanson, M. D., Niec, A., Pietrantonio, A. M., Johnson, S., Young, M., High, B.,...Eva, K. W. (2007). Effects associated with adolescent standardized patient simulation of depression and suicidal ideation. Academic Medicine, 82(10), S61-S64. doi:10.1097/ACM.0b013e31813ffedd

Hanson, M., Tiberius, R., Hodges, B., Mackay, S., McNaughton, N., Dickens, S., \& Regehr, G. (2002). Implications of suicide contagion for the selection of adolescent standardized patients. Academic Medicine, 77(10), S100-S102.

Heim, M. (1993). The metaphysics of virtual reality. New York, NY: Oxford University Press.

Hendin, H., Haas, A. P., Maltsberger, J. T., Szanto, K., \& Rabinowicz, H. (2004). Factors contributing to therapists' distress after the suicide of a patient. The American Journal of Psychiatry, 161(8), 1442-1446. Retrieved from http://ezproxy.fiu.edu/login?url=https://search-proquestcom.ezproxy.fiu.edu/docview/220487166?accountid=10901

Henriksen, K., Rodrick, D., Grace, E. N., \& Brady, P. J. (2018). Challenges in health care simulation: Are we learning anything new? Academic Medicine, 93(5), 705-708. doi:10.1097/ACM.0000000000001891

Herbert Wertheim College of Medicine. (2017). Master in physician assistant studies program review. Retrieved from https://medicine.fiu.edu/academics/degrees-andprograms/master-in-physician-studies/index.html

Hershenson, D. B., \& Power, P. W. (1987). Mental health counseling: Theory and practice. Elmsford, NY: Pergamon Press. 
Hicks, F. D., Coke, L., \& Li, S. (2009). Report of findings from the effect of high fidelity simulation on nursing students' knowledge and performance: A pilot study. Chicago, IL: National Council of State Boards of Nursing.

Hinkle, D. E., Wiersma, W. \& Jurs, S. G. (2003). Applied statistics for the behavioral sciences (5th ed.). Boston, MA: Houghton Mifflin.

Hooper, L.M., Epstein, S.A., Weinfurt, K.P., DeCoster, J., Qu, L., \& Hannah, N. J. (2012). Predictors of primary care physicians' self-reported intention to conduct suicide risk assessments. The Journal of Behavioral Health Services \& Research, 39(2), 103-115. doi:10.1007/s11414-011-9268-5

Huang, G., Reynolds, R., \& Candler, C. (2007). Virtual patient simulation at US and Canadian medical schools. Academic Medicine, 82(5), 446-451. doi: 10.1097/ACM.0b013e31803e8a0a

i-Human Patients. (2018). i-Human Patients company overview. Retrieved from http://www.i-human.com/company-overview/

Jeffries, P. R., Woolf, S., \& Linde, B. (2003). Technology-based vs. traditional instruction. A comparison of two methods for teaching the skill of performing a 12lead ECG. Nursing Education Perspectives, 24(2), 70-74.

Jerald, J. (2016). The vr book: Human-centered design for virtual reality. New York, NY: Morgan \& Claypool.

Jin, S. A. A. (2011). Leveraging avatars in 3D virtual environments (second life) for interactive learning: The moderating role of the behavioral activation system vs. behavioral inhibition system and the mediating role of enjoyment. Interactive Learning Environments, 19(5), 467-486. doi://dx.doi.org/10.1080/10494820903484692

Johnson, T. R., Lyons, R., Chuah, J. H., Kopper, R., Lok, B. C., \& Cendan, J. C. (2013). Optimal learning in a virtual patient simulation of cranial nerve palsies: The interaction between social learning context and student aptitude. Medical Teacher, 35(1), e899-e907. doi:10.3109/0142159X.2012.714884

Kelley, K., Clark, B., Brown, V., \& Sitzia, J. (2003). Good practice in the conduct and reporting of survey research. International Journal for Quality in Health Care, 15(3), 261-266. doi:10.1093/intqhe/mzg031

Lamb, G. D. (2003). Understanding "within" versus "between" ANOVA designs: Benefits and requirements of repeated measures. Paper presented at the annual meeting of the Southwest Educational Research Association, San Antonio, TX. Retrieved from 
http://ezproxy.fiu.edu/login?url=http://search.ebscohost.com/login.aspx?direct=true $\& \mathrm{db}=$ eric $\& \mathrm{AN}=\mathrm{ED} 474271 \&$ site $=$ ehost-live $\&$ scope $=$ site

Landers, R. N., \& Behrend, T. S. (2015). An inconvenient truth: Arbitrary distinctions between organizational, mechanical turk, and other convenience samples. Industrial and Organizational Psychology, 8(2), 142-164. doi:10.1017/iop.2015.13

Leigh, G. T. (2008). High-fidelity patient simulation and nursing students' self-efficacy: A review of the literature. International Journal of Nursing Education Scholarship, $5(1), 1-17$.

Levinson, W., \& Pizzo, P. A. (2011). Patient-physican communication: It's about time. JAMA, 305(17), 1802-1803. doi:10.1001/jama.2011.556

Liaw, S. Y., Chan, S. W., Chen, F., Hooi, S. C., \& Siau, C. (2014). Comparison of virtual patient simulation with mannequin-based simulation for improving clinical performances in assessing and managing clinical deterioration: Randomized controlled trial. Journal of Medical Internet Research, 16(9), e214. doi:10.2196/jmir.3322

Lu, C., Lee, H., Hsu, S., \& Shu, I. (2016). Elements of scenario-based learning on suicidal patient care using real-time video. Studies in Health Technology and Informatics, 225, 257-261.

Luebbert, R., \& Popkess, A. (2015). The influence of teaching method on performance of suicide assessment in baccalaureate nursing students. Journal of the American Psychiatric Nurses Association, 21(2), 126-133. doi:10.1177/1078390315580096

Lumby, J. (2011). Enjoyment and learning: Policy and secondary school learners' experience in England. British Educational Research Journal, 37(2), 247-264. Retrieved from http://ezproxy.fiu.edu/login?url=https://search.proquest.com/docview/860366119?ac countid=10901

Makransky, G., Bonde, M. T., Wulff, J. S., Wandall, J., Hood, M., Creed, P. A., . . . Norremolle, A. (2016). Simulation based virtual learning environment in medical genetics counseling: An example of bridging the gap between theory and practice in medical education. BMC Medical Education, 16, 1-9. doi:10.1186/s12909-0160620-6

McConnell, H., \& Pardy, A. (2008). Virtual patient simulation for prevention of medical error: Beyond just technical upskilling. World Hospitals and Health Services: The Official Journal of the International Hospital Federation, 44(3), 36-39. 
McCoy, L., Lewis, J. H., \& Dalton, D. (2016). Gamification and multimedia for medical education: A landscape review. The Journal of the American Osteopathic Association, 116(1), 22-34. Retrieved from http://www.ncbi.nlm.nih.gov/pubmed/26745561

McNiel, D. E., Hung, E. K., Cramer, R. J., Hall, S. E., \& Binder, R. L. (2011). An approach to evaluating competence in assessing and managing violence risk. Psychiatric Services, 62(1), 90-92. doi:10.1176/ps.62.1.pss6201_0090

Mirick, R. G., Bridger, J., McCauley, J., \& Berkowitz, L. (2016). Continuing education on suicide assessment and crisis intervention for social workers and other mental health professionals: A follow-up study. Journal of Teaching in Social Work, 36(4), 363-379.

Mirick, R., McCauley, J., Bridger, J., \& Berkowitz, L. (2016). Continuing education on suicide assessment and crisis intervention: What can we learn about the needs of mental health professionals in community practice? Community Mental Health Journal, 52(5), 501-510.

Mitchell, T. J. F., Chen, S. Y., \& Macredie, R. D. (2005). The relationship between web enjoyment and student perceptions and learning using a web-based tutorial. Learning, Media and Technology, 30(1), 27-40. Retrieved from http://ezproxy.fiu.edu/login?url=https://search.proquest.com/docview/62143572?acc ountid=10901

Osteen, P. J., Jacobson, J. M., \& Sharpe, T. L. (2014). Suicide prevention in social work education: How prepared are social work students? Journal of Social Work Education, 50(2), 349-364.

Putwain, D., Sander, P., \& Larkin, D. (2013). Academic self-efficacy in study-related skills and behaviours: Relations with learning-related emotions and academic success. British Journal of Educational Psychology, 83(4), 633-650. doi:10.1111/j.2044-8279.2012.02084.x

Reddan, G. (2016). The role of work-integrated learning in developing students' perceived work self-efficacy. Asia-Pacific Journal of Cooperative Education, 17(4), 423-436. Retrieved from http://ezproxy.fiu.edu/login?url=http://search.ebscohost.com/login.aspx?direct=true $\& \mathrm{db}=$ eric $\& \mathrm{AN}=\mathrm{EJ} 1131584 \&$ site $=$ ehost-live $\&$ scope $=$ site

Redmond, T. A. (2012). The pedagogy of critical enjoyment: Teaching and reaching the hearts and minds of adolescent learners through media literacy education. Journal of Media Literacy Education, 4(2), 106-120. Retrieved from http://ezproxy.fiu.edu/login?url=https://search.proquest.com/docview/1312419915?a ccountid=10901 
Rittle, M. (2017). Mental health on the forefront of issues for certified physician assistants. Retrieved from https://www.nccpa.net/news/mentalhealth

Robert Stempel College of Public Health and Social Work. (2017). Masters of social work. Retrieved from http://stempel.fiu.edu/academics/social-work/areas-ofstudy/ms-of-social-work/degree-requirements/index.html

Rossen, B., Cendan, J., \& Lok, B. (2010). Using virtual humans to bootstrap the creation of other virtual humans. In Intelligent Virtual Agents. Paper presented at the International Conference on Intelligent Virtual Agents (pp. 392-398). Berlin, DE: Springer.

Rossen, B., Lind, S., \& Lok, B. (2009). Human-centered distributed conversational modeling: Efficient modeling of robust virtual human conversations. In Intelligent Virtual Agents. Paper presented at the International Workshop on Intelligent Virtual Agents (pp. 474-481). Berlin, DE: Springer.

School of Education. (2017). Masters of counseling education. Retrieved from http://education.fiu.edu/counselor_ed/mentalhealth.html

Schukajlow, S., Leiss, D., Pekrun, R., Blum, W., Muller, M., \& Messner, R. (2012). Teaching methods for modelling problems and students' task-specific enjoyment, value, interest and self-efficacy expectations. Educational Studies in Mathematics, 79(2), 215-237. doi:10.1007/s10649-011-9341-2

Schunk, D. H. (2012). Learning theories: An educational perspective (6th ed.). Boston, MA: Pearson.

Shadow Health, Inc. (2017). Mission and vision. Retrieved from https://shadowhealth.com/mission-and-vision.html

Shoemaker, M. J., de Voest, M., Booth, A., Meny, L., \& Victor, J. (2015). A virtual patient educational activity to improve interprofessional competencies: A randomized trial. Journal of Interprofessional Care, 29(4), 395-397. doi:10.3109/13561820.2014.984286

Shoemaker, M. J., Platko, C. M., Cleghorn, S. M., \& Booth, A. (2014). Virtual patient care: An interprofessional education approach for physician assistant, physical therapy and occupational therapy students. Journal of Interprofessional Care, 28(4), 365-367. doi:10.3109/13561820.2014.891978

Smith, M. A., Siemianowski, L. A., \& Benedict, N. (2016). Virtual patient case sharing across two schools of pharmacy. American Journal of Pharmaceutical Education, $80(9), 1-5$. 
Smith, M. J., Bouch, J., Bradstreet, S., Lakey, T., Nightingale, A., \& O'Connor, R. C. (2015). Health services, suicide, and self-harm: Patient distress and system anxiety. The Lancet Psychiatry, 2(3), 275-280.

Snow, J., \& Mann, M. (2013). Qualtrics survey software: Handbook for research professionals. Retrieved from https://www.qualtrics.com/

Springshare. (2018). LibGuides - content management and curation platform for libraries. Retrieved from https://springshare.com/libguides/

Stedman, T. L., STAT!Ref (Online service), \& Teton, D. S. (2006). Stedman's medical dictionary (28th ed.). Philadelphia, PA: Lippincott Williams \& Wilkins. Retrieved from http://www.loc.gov/catdir/enhancements/fy0712/2005021544-d.html http://ezproxy.fiu.edu/login?url=http://online.statref.com/dictionaryhelp.aspx?type= dictionary\&grpalias $=$ FIU

Stevens, A., Hernandez, J., Johnsen, K., Dickerson, R., Raij, A., Harrison, C., . . Lind, D. S. (2006). The use of virtual patients to teach medical students history taking and communication skills. The American Journal of Surgery, 191(6), 806-811. doi:10.1016/j.amjsurg.2006.03.002

Sunnqvist, C., Karlsson, K., Lindell, L., \& Fors, U. (2016). Virtual patient simulation in psychiatric care: A pilot study of digital support for collaborate learning. Nurse Education in Practice, 17, 30-35. Retrieved from http://hdl.handle.net/2043/21035

Svirko, E., \& Mellanby, J. (2017). Teaching neuroanatomy using computer-aided learning: What makes for successful outcomes? Anatomical Sciences Education, 10(6), 560-569. doi:10.1002/ase.1694

Tan, S. Y., \& Chou, C. C. (2018). Supervision effects on self-efficacy, competency, and job involvement of school counsellors. Journal of Psychologists and Counsellors in Schools, 28(1), 18-32. Retrieved from http://ezproxy.fiu.edu/login?url=http://search.ebscohost.com/login.aspx?direct=true $\& \mathrm{db}=$ eric $\& \mathrm{AN}=\mathrm{EJ} 1179208 \&$ site $=$ ehost-live $\&$ scope $=$ site http://dx.doi.org/10.1017/jgc.2017.19

Trochim, W. M. K. (2006). The nonequivalent groups design. Retrieved from https://socialresearchmethods.net/kb/quasnegd.php

Vannoy, S. D., Fancher, T., Meltvedt, C., Unutzer, J., Duberstein, P., \& Kravitz, R. L. (2010). Suicide inquiry in primary care: Creating context, inquiring, and following up. Annals of Family Medicine, 8(1), 33-39. doi:10.1370/afm.1036

Virtual Experiences Research Group. (2012). Virtual people factory. Retrieved from http://verg.cise.ufl.edu/wordpress/project/virtual-people-factory/ 
Washburn, M., Bordnick, P., \& Rizzo, A. (2016). A pilot feasibility study of virtual patient simulation to enhance social work students' brief mental health assessment skills. Social Work in Health Care, 55(9), 675-693.

doi:10.1080/00981389.2016.1210715

Wolters Kluwer Health. (2017). vSim for nursing. Retrieved from http://thepoint.lww.com/vsim 
APPENDICES 
APPENDIX A

CONSENT TO PARTICIPATE IN A RESEARCH STUDY 


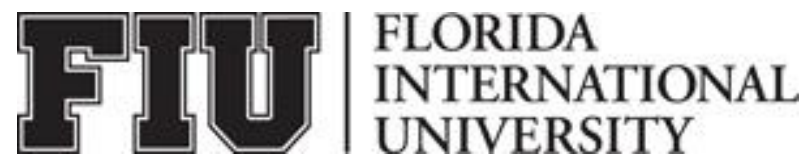

\section{ADULT ONLINE CONSENT TO PARTICIPATE IN A RESEARCH STUDY}

Virtual Patient Simulation: Training Pre-Health Professionals in Suicide Risk Prevention

\section{PURPOSE OF THE STUDY}

You are being asked to be in a research study. The purpose of this study is to study the effects of virtual patient simulation on patient interaction and self-efficacy.

\section{NUMBER OF STUDY PARTICIPANTS}

If you decide to be in this study, you will be one of a possible 115 people in this research study.

\section{DURATION OF THE STUDY}

Your participation will require 20-30 minutes of your time to go through a pre-survey, a simulation (or not depending on the group assigned) and answer a short 23 to 27 item post-survey.

\section{PROCEDURES}

If you agree to be in the study, we will ask you to do the following things:

1. Provide your Panther ID (for matching purposes only) for each survey; they will be eliminated for the statistical analysis.

2. If you participate in a virtual patient simulation of to assess if the patient presents a possible suicide risk and harm to herself. As you progress in the simulation, you will find "discoveries" or symptoms to help with your assessment. Interact with the virtual patient by asking it questions and you will receive feedback or responses. Your questions, as well as your responses, will be recorded in a transcript found within the program.

3. Then you answer an online questionnaire regarding your experience i.e. interaction, confidence after the experience, as well as some demographic information.

4. If you are randomly selected for the video module, you will be asked to view a series of short videos and answer some short quiz questions. Once you complete the video module, you will answer an online questionnaire regarding your experience, confidence, as well as some demopgraphic experience.

\section{RISKS AND/OR DISCOMFORTS}

The following risks may be associated with your participation in this study: First, due to the subject matter, there is the potential for some discomfort due to the subject matter 
although minimal. Second, there is no risk of physical harm; all interaction is online with a virtual patient or viewing a video module.

\section{BENEFITS}

The following benefits may be associated with your participation in this study: development of future virtual training for health professions trainees in mental health, specifically in suicide prevention. Ultimately, this research could be used to prevent suicide and enhance existing curriculum by providing additional training in suicide prevention at Florida International University.

\section{ALTERNATIVES}

There are no known alternatives available to you other than not taking part in this study. However, any significant new findings developed during the course of the research, which may relate to your willingness to continue participation will be provided to you.

\section{CONFIDENTIALITY}

The records of this study will be kept private and will be protected to the fullest extent provided by law. In any sort of report, we might publish, we will not include any information that will make it possible to identify a subject. Research records will be stored securely and only the researcher team, Francisco J. Fajardo will have access to the records. However, your records may be reviewed for audit purposes by authorized University or other agents who will be bound by the same provisions of confidentiality.

All information collected will anonymous and data related to your responses and will be kept in a secured location.

\section{COMPENSATION \& COSTS}

You will not receive a payment for your participation.

\section{RIGHT TO DECLINE OR WITHDRAW}

Your participation in this study is voluntary. You are free to participate in the study or withdraw your consent at any time during the study. Your withdrawal or lack of participation will not affect any benefits to which you are otherwise entitled. The investigator reserves the right to remove you without your consent at such time that they feel it is in the best interest.

\section{RESEARCHER CONTACT INFORMATION}

If you have any questions about the purpose, procedures, or any other issues relating to this research study you may contact Francisco J. Fajardo at Florida International University,(305) 348-1464, ffaja001@ fiu.edu.

\section{IRB CONTACT INFORMATION}


If you would like to talk with someone about your rights of being a subject in this research study or about ethical issues with this research study, you may contact the FIU Office of Research Integrity by phone at 305-348-2494 or by email at ori@fiu.edu.

\section{PARTICIPANT AGREEMENT}

I have read the information in this consent form and agree to participate in this study. I have had a chance to ask any questions I have about this study, and they have been answered for me. By clicking on the "consent to participate" button below I am providing my informed consent.

\section{I consent, begin the study}

I do not consent, I do not wish to participate 
APPENDIX B

PARTICIPANT SURVEYS 


\section{Pre-Simulation Survey}

Panther ID \# (This is only for matching purposes only).

The following items rate your self-efficacy and confidence. For each item, select a response that best reflects your level of confidence ( 1 being "not confident" to a 5 for "confident").

Q1 I am confident I can apply my knowledge of mental health to evaluate patients.
1
2
3
4
5 
Q2 I am confident I can gather essential information to evaluate patients.
1
2
3
4
5

Q3 I am confident I can perform a mental status exam.

1

2

3

4

5

Q4 I am confident I can ask the right questions to evaluate patients.

1

2

3

4

5 
Q4 I am confident I can effectively communicate with patients.
1
2
3
4
5

Q5 I am confident I can evaluate patients.
1
2
3
4
5 
Q12 I am confident I can make patients comfortable so that they are willing to communicate with me.
1
2
3
4
5

The following items are used to determine your familiarity with mental illness.

Q13 At your place of employment, have you worked with any peers with a mental illness?

Yes

No

Q14 Do you have a friend who has a mental illness?
Yes
No 
Q15 Have you been involved in services/treatment for persons with a mental illness?

Yes

No

Q16 I have an immediate or extended family member who has a mental illness.

Yes

No

Q17 I live with a person who has a mental illness.

Yes

No

Q18 Demographics (the following questions are related to demographic information-all information is anonymous and confidential).

Q19 Gender

Male

Female 
Q20 Age

$18-24$

25-35

$36-45$

Over 45

Q21 Years of previous medical or mental health work experience:

None

1-3 Years

4-6 Years

7-10 Years

Over 10 Years

Q22 Have you had any previous experience (personal or professionally) with someone who was suicidal?
No
Yes 
Q23 How many hours (direct or indirect) of training have you received (i.e. practicum, internship, etc.)?

None

1-100 hours

100-500 hours

500 hours or more

Q24 Race

White (non-Hispanic or Latino)

Black or African American

American Indian or Alaska Native

Asian

Native Hawaiian or Pacific Islander

Other (please specify)

\section{Q25 Ethnicity}

Hispanic/Latino

Non-Hispanic/Latino 
Q26 Please select your academic program.

Masters in Physician Assistant Studies

Masters in Professional Counseling Psychology

Masters in Social Work

Masters in Counselor Education (Clinical Mental Health Counseling)

Q27 Please indicate the current time (e.g. 12:35pm) 


\section{Virtual Patient Survey}

Q1 Panther ID \# (This is only for matching purposes only).

Please answer the following questions with the best response regarding your interaction with the Virtual Patient Simulation program (VP). Select the best response that reflects your agreement or disagreement with the statement.

Q2 I enjoyed the interaction with the VP.

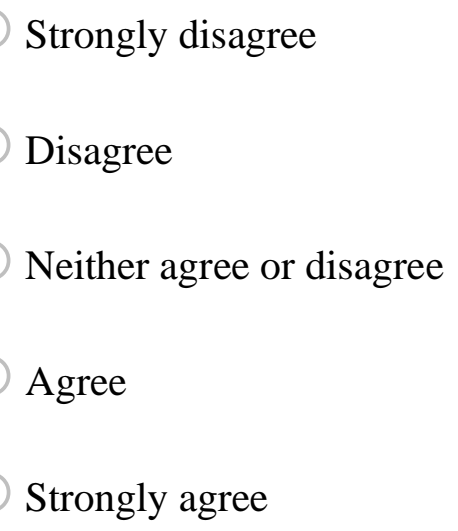


Q3 I prefer the VP over traditional teaching methods (i.e. face-to-face lectures, interacting with your professor).

Strongly disagree

Disagree

Neither agree or disagree

Agree

Strongly agree

Q4 The VP interaction helped me formulate questions about mood and symptoms.

Strongly disagree

Disagree

Neither agree nor disagree

Agree

Strongly agree 
Q5 The VP's answers were appropriate for this scenario.

Strongly disagree

Disagree

Neither agree nor disagree

Agree

Strongly agree

Q6 The interaction with the VP simulated real-life situations.

Strongly disagree

Disagree

Neither agree nor disagree

Agree

Strongly agree 
Q7 The VP interaction is a valuable tool for interviewing with my future patients.

Strongly disagree

Disagree

Neither agree nor disagree

Agree

Strongly agree

\section{Q8 The VP program is easy to use.}

Strongly disagree

Disagree

Neither agree nor disagree

Agree

Strongly agree 
Q9 The discoveries in the interaction with the VP were useful. (Discoveries are symptoms or elements of the patient's history).

Strongly disagree

Disagree

Neither agree nor disagree

Agree

Strongly agree

Q10 Reading the transcript of the interaction with the VP was useful.

Strongly disagree

Disagree

Neither agree nor disagree

Agree

Strongly agree

The following items rate your self-efficacy and confidence in relation to your knowledge and skills after completing this the video module. For each item, select a response that best reflects your level of confidence ( 1 being "not confident" to a 5 for "confident". 
Q11 I am confident I can apply my knowledge of mental health to evaluate patients.

1

2

3

4

5

Q12 I am confident I can gather essential information to evaluate patients.

1

2

3

4

5

Q13 I am confident I can perform a mental status exam.

1

2

3

4

5 
Q14 I am confident I can ask the right questions to evaluate patients.

1
2
3
4
5

Q15 I am confident I can effectively communicate with patients.

1

2

3

4

5

Q16 I am confident I can evaluate patients.

1

2

3

4

5 
Q17 I am confident I can make patients comfortable so that they are willing to communicate with me.
1
2
3
4
5

Q18 Please indicate the current time (e.g. 12:35pm) 


\section{Video Module Survey}

Panther ID \# (This is only for matching purposes only).

Please answer the following questions with the best response regarding your interaction with the video module (VM). Select the best response that reflects your agreement or disagreement with the statement.

Q1 I enjoyed working through the VM.

Strongly disagree

Disagree

Neither agree nor disagree

Agree

Strongly agree

Q2 I prefer the VM over traditional teaching methods (i.e. face-to-face lectures, interacting with your professor).

Strongly disagree

Disagree

Neither agree nor disagree

Agree

Strongly agree 
Q3 The VM helped me formulate questions about mood and symptoms.

Strongly disagree

Disagree

Neither agree nor disagree

Agree

Strongly agree

Q4 The VM content was appropriate for this scenario.

Strongly disagree

Disagree

Neither agree nor disagree

Agree

Strongly agree

Q5 The VM content simulated real-life situations.

Strongly disagree

Disagree

Neither agree nor disagree

Agree

Strongly agree 
Q6 The VM is a valuable tool for learning how to interview my future patients.

Strongly disagree

Disagree

Neither agree nor disagree

Agree

Strongly agree

Q7 The VM was easy to use.

Strongly disagree

Disagree

Neither agree nor disagree

Agree

Strongly agree

The following items rate your self-efficacy and confidence in relation to your knowledge and skills after completing this the video module. For each item, select a 
response that best reflects your level of confidence ( 1 being "not confident" to a 5 for "confident".

Q8 I am confident I can apply my knowledge of mental health to evaluate patients.
1
2
3
4
5

Q9 I am confident I can perform a mental status exam.
1
2
3
4
5

Q10 I am confident I can gather essential information to evaluate patients.
1
2
3 
4

5

Q11 I am confident I can ask the right questions to evaluate patients.
- 1
○ 2
3
4
5

Q12 I am confident I can effectively communicate with patients.
1
2
3
4
5

Q13 I am confident I can evaluate patients.
1
2 
3

4

5

Q14 I am confident I can make patients comfortable so that they are willing to communicate with me.

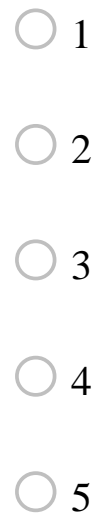

Q15 Please indicate the current time (e.g. 12:35pm) 


\section{Post- Lecture Survey}

Panther ID \# (This is only for matching purposes only).

The following items rate your self-efficacy and confidence. For each item, select a response that best reflects your level of confidence ( 1 being "not confident" to a 5 for "confident".

Q1 I am confident I can apply my knowledge of mental health to evaluate patients.
1
2
3
4
5

Q2 I am confident I can gather essential information to evaluate patients.
1
2
3
4
5 
Q3 I am confident I can perform a mental status exam.
1
2
3
4
5

Q4 I am confident I can ask the right questions to evaluate patients.
1
2
3
4
5

Q5 I am confident I can effectively communicate with patients.

1

2

3

4

5 
Q6 I am confident I can evaluate patients.
1
2
3
4
5

Q7 I am confident I can make patients comfortable so that they are willing to communicate with me.
1
2
3
4
5

Q8 Please indicate the current time (e.g. 12:30pm). 
APPENDIX C

PARTICIPANT RECRUITMENT EMAIL 


\section{Recruitment Email}

Dear Participant,

Thank you for volunteering and your participation in this pilot study. The goal of this study is to determine the effects of virtual patient simulation (VP) on confidence and performance using a suicide risk scenario. Furthermore, the study seeks to test a short survey on the interaction and confidence levels after your experience with a VP. Once you have completed a short VP session, you will take the survey where your responses will be captured via Qualtrics (online survey). All responses are anonymous and confidential.

We hope to use the information collected to train future health professions students and help them become proficient in evaluating patients who present as a possible suicide risk. Consequently, this training could help in the prevention of patients harming themselves and others. This is often a difficult and stressful encounter in a clinical setting, which we hope to improve by creating a safe environment to train students. If you have any questions or concerns, please feel free to contact Francisco J. Fajardo at (305) 348-Xxxx.

Thanks again,

Francisco Fajardo 


\section{APPENDIX D}

INSTITUTIONAL REVIEW BOARD APPROVAL 


\section{MEMORANDUM}

To: $\quad$ Dr. Mandayam Thirunarayanan

CC: $\quad$ Francisco Fajardo

From: Maria Melendez-Vargas, MIBA, IRB Coordinator

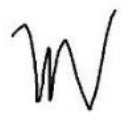

Date: $\quad$ May 14, 2018

Protocol Title: "Virtual Patient Simulation: Training Pre-Health Professionals in Suicide Risk Prevention"

The Florida International University Office of Research Integrity has reviewed your research study for the use of human subjects and deemed it Exempt via the Exempt Review process.

IRB Protocol Exemption \#: IRB-18-0171 IRB Exemption Date: $\quad$ 05/08/18 TOPAZ Reference \#: 106799

As a requirement of IRB Exemption you are required to:

1) Submit an Event Form and provide immediate notification of:

- Any additions or changes in the procedures involving human subjects.

- Every serious or unusual or unanticipated adverse event as well as problems with the rights or welfare of the human subjects.

2) Submit a Project Completion Report Form when the study is finished or discontinued.

Special Conditions: N/A

For further information, you may visit the IRB website at http://research.fiu.edu/irb.

MMV/em 
APPENDIX F AMENDMENT TO INSTITUTIONAL REVIEW BOARD APPROVAL 


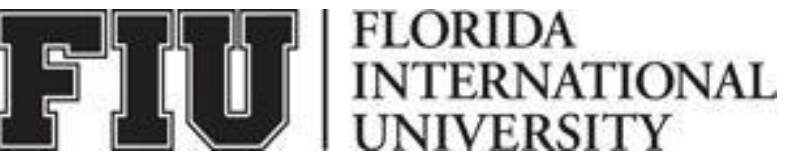

Office of Research Integrity

Research Compliance, MARC 414

\section{MEMORANDUM}

To:

Dr. Mandayam Thirunarayanan

CC:

Francisco Fajardo

From:

Maria Melendez-Vargas, MIBA, Coordinator

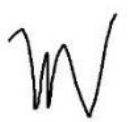

Date:

June 26, 2018

Proposal Title: "Virtual Patient Simulation: Training Pre-Health Professionals in Suicide Risk"

Approval \# IRB-18-0171-AM01

Reference \# 106799

The Florida International University Office of Research Integrity has approved the following modification(s):

Addition of a Panther ID to match participants with the pre-and post surveys.

\section{Special Conditions: N/A}

For further information, you may visit the FIU IRB website at http://research.fiu.edu/irb.

MMV/em 
VITA 
VITA

\section{FRANCISCO JAVIER FAJARDO}

Born, Miami, Florida

1996-2000

B.A., Political Science

Florida International University

Miami, Florida, USA

2001-2002

M.A., Political Science

Florida International University

Miami, Florida, USA

2003-2005

M.P.A., Public Administration

Florida Atlantic University

Boca Raton, Florida, USA

2009-2011

M.L.I.S., Library and Information Science

Florida State University

Tallahassee, Florida, USA

2012-Present

Librarian

Florida International University

Miami, Florida, USA

$2014-2019$

Doctoral Candidate, Curriculum and Instruction

Florida International University

Miami, Florida, USA

\section{PUBLICATIONS AND PRESENTATIONS}

Fajardo, F., \& Perez, J. (2017). Supporting student comprehension through technology: Scaffolding techniques in a virtual environment In C. Smallwood, \& L. Sanborn (Eds.), Teaching technology in libraries: Creative ideas for training staff, patrons and students (pp. 6-11). Jefferson: McFarland \& Company.

Perez-Gilbe, H., Fajardo, F. J., \& Perez, J.E. (2017, May). Health Education for South Florida Transgender Women: The FIU HWCOM Medical Library Outreach Project. Presented at 2017 Annual Meeting of the Medical Library Association: Dream, Dare, Do; Seattle, WA. 
Fajardo, Francisco J., Stevens, Gregg (2016, May). Building Connections: Outreach during the First Year as a Liaison Librarian. Poster session presented at the 2016 Annual Meeting of the Medical Library Association: Mosaic: Be Part of the Big Picture; Toronto, ON.

Knuth M, Prentice K, Jones S, Fajardo F, Stevens G, Rana G. The Cross-Cultural Mosaic Café: When It Comes to Making Intercultural Connections: Sharing your Successes and Failures. Presented at the 2016 Annual Meeting of the Medical Library Association: Mosaic: Be Part of the Big Picture, Toronto, ON.

Fajardo, Francisco J.; Perez-Gilbe, Hector, and Perez, Jorge E (2016, October). Reaching Out to the " $T$ ": A Medical Library's Experience Providing Outreach and Consumer Health Resources to the Transgender Community. Poster session presented at the Annual Meeting of the Southern Chapter of the Medical Library Association: Rethink IT: The Evolving Landscape of Libraries; Greenville, SC.

Lupi, Carla, Ward-Peterson, Melissa, Lozano, Juan, Varella, Marcia, Milanez, Marcos, Fajardo, Francisco, et.al (2016, November). Progress Toward Assessment of a Longitudinal Curriculum for EPA 7. Presented at the AAMC Annual Meeting: Learn, Serve, Lead; Seattle, WA.

Stevens, GA \& Fajardo, FJ. (2015, October) Meeting Your Patrons: Engaging and Marketing Your Services as a First-Year Liaison Librarian. Poster presentation, Southern Chapter/Medical Library Association Annual Meeting, San Juan, PR.

Fajardo, F. J., \& Petersen, D. (2013). New Horizons: A Partnership Between a New Medical Library and a Specialized Hospital Library. Journal of Hospital Librarianship, 13(4), 344-352.

Fajardo, Francisco J. \& Kim, Bohyun (2013, July). TechSpace: Kindles with Medical EBooks. Poster session presented at the meeting of the 2013 SEFLIN (Southeast Florida Library Information Network) Regional Conference: Evolving Library Technologies, Miami, Florida.

Melssen, M. C., \& Fajardo, F. J. (2011). On Our Own: Starting an Interlibrary Loan Service from Scratch. Journal of Interlibrary Loan,Document Delivery \& Electronic Reserve 21(4), 185-192. 